\title{
The Light Responses of Proteorhodopsin-bearing, Antarctic Sea-ice Bacteria
}

\author{
David Joll Burr
}

\author{
A thesis \\ submitted to Victoria University of Wellington \\ in partial fulfilment of the requirement \\ for the degree of \\ Master of Science in Marine Biology
}

VICTORIA UNIVERSITY OF WELLINGTON

Te Whare Wānanga o te Ūpoko o te Ika a Māui 



\section{Abstract}

Although homogenous in appearance, Antarctic sea ice forms a complex habitat that is characterised by steep vertical gradients of temperature, irradiance and salinity. Despite these harsh and variable environmental conditions, numerous microbial organisms prosper within Antarctic sea ice. In 2010, bacteria bearing the proteorhodopsin (PR) gene were found within Antarctic sea ice. PR is a photoactive membrane protein that functions as a light-driven proton pump. The hydrogen ion membrane gradient that PR establishes has the potential to drive ATP synthesis, thus allowing PR-bearing bacteria to obtain energy from solar radiation. Although this gene is present in up to $80 \%$ of marine bacteria, the active contribution of PR in vivo is debatable. Light induced growth or enhanced survival is generally observed only when PR-bearing bacteria are grown under sub-optimum conditions, such as limited nutrients or carbon, or variations in salinity. This has lead to the general hypothesis that PR has multiple functions, becoming most influential under conditions of stress. In this way, Antarctic sea-ice bacteria may utilise PR to promote survival and enhance energy inputs, when exposed to the harsh conditions of this environment.

To explore this hypothesis, potential PR-bearing isolates were cultured from samples of Antarctic sea-ice bacteria. Using 16S rRNA gene sequencing as well as a comparison of phenotypic and environmental characteristics, the isolates were identified as; Psychrobacter nivimaris, Polaribacter dokdonensis, Paracoccus marcusii and Micrococcus sp. These species, along with Psychroflexus torquis (an Antarctic sea-ice bacterium known to possess PR) were examined for the presence of the PR gene. This gene was identified in P. torquis, Ps. nivimaris and Po. dokdonensis. To my knowledge, this is the first time PR has been found in Ps. nivimaris.

To assess the influence of irradiance on these species, a series of culture based experiments were undertaken. In 2012, a preliminary field experiment was conducted in which a mixed culture of PR-bearing and non PR-bearing bacteria; Ps. nivimaris, Po. dokdonensis, Pa. marcusii and Micrococcus sp., was incubated in situ in the annual sea ice surrounding Ross Island, Antarctica. The method developed for these experiments is unique, in that cultures of sea-ice bacteria have not before been incubated within their natural environment. No major differences in growth patterns were observed when bacteria were incubated under different wavelengths and light intensities, however, valuable insight into methodological improvement was obtained. Using these refinements, a second in situ incubation experiment was conducted at 
the same field site, in 2013. Over this 2 week incubation, monocultures of $P$. torquis grown in full strength media grew most readily under $50 \%$ - and blue-light treatments, with red- and green-light yielding lower biomasses, and no growth occurring in the dark. Ambient sea-ice irradiance resulted in highly variable growth, attributed to high irradiance growth-inhibition. These results indicate that $P$. torquis utilises low levels of light in order to increase its growth in Antarctic sea ice.

The influence of light on the growth of P. torquis, Ps. nivimaris and Po. dokdonensis was examined in a laboratory-based experiment, in which media strength and temperature were varied. When cultured at $12^{\circ} \mathrm{C}, P s$. nivimaris grown under constant irradiance reached a higher biomass than in darkness. This trend was most pronounced when this species was cultured in a $10 \%$ media concentration. A trend of decreased exponential-growth was observed in light-incubated cultures of Ps. nivimaris, grown at $4^{\circ} \mathrm{C}$ or $-1^{\circ} \mathrm{C}$. Elevated maximum growth of Po. dokdonensis was observed under irradiated conditions in the $10 \%$ media treatment. This species however, only grew at $12^{\circ} \mathrm{C}$; an unexpected result for an Antarctic microbe. P. torquis was not affected by irradiance under any culture conditions and did not grow at $-1^{\circ} \mathrm{C}$. This last result contrasts the results of the in situ incubations and may have been affected by factors such as culture age.

This research demonstrates multiple examples of light-enhanced growth occurring in PR-bearing Antarctic sea-ice bacteria, with the most prominent trends occurring in reduced concentration media. Therefore, this work agrees with the overarching hypothesis that PR is most influential under conditions of stress. The varying effect of temperature on the influence of PR suggests that some species are able to use this protein at low temperatures, whilst others cannot. Therefore, PR likely provides a selective advantage to some species, depending on a variety of physicochemical factors, including nutrient and carbon availability, salinity and temperature. 


\section{Acknowledgments}

Happiness and bacteria have one thing in common; they multiply by dividing.

- Rutvik Oza

I would like to express my gratitude to my supervisors, Ken Ryan and Els Maas. Without the encouragement, patience and guidance of you, the completion of this project would not have been possible. Ken, introducing me to the staggering beauty of Antarctica is the greatest adventure I could ever be gifted; a once in a lifetime opportunity that I was lucky enough to experience twice. Els, the skills I have gained from you, both microbiological and life skills, are invaluable. Although not as charismatic as Antarctica, bacteria, in their own way, can be equally as beautiful.

A special thanks must be extended to Andrew Martin. Your help in the field, along with your mentoring and friendship means a great deal to me. The other members of K043; Marius, Chris, Sonja, Katerina, Christine and Andrew McMinn, I'm glad my Antarctic experiences were shared with you. Thank you for each and every ice core that you drilled.

To Katie, Mark, Lisa, Fernanda, Francisca and the other Ryan lab group members, your feedback and your friendship have helped me immensely. Debbie, Tim and Anne, thank you for all your help in the NIWA labs. For providing me with the resources to complete this project, thank you to Eileen and Bex, as well as Kevin Feng of UTas. To my office mates Ben, Harry and Matt, my flatmates, and all the other friends I've made at VUW, thanks for keeping my life balanced.

Most importantly, my family; Mum and Dad, Nana and Grandpa, Annaliese, thank you for encouraging me to chase my passion and always being proud of me. That means far more to me than I let on. Hannah, thank you for standing by me during both my successes and failures. I don't know where I'd be without you. Finally, I would like to dedicate this thesis to my late Great Grandmother, Frances Raudio. Your wisdom and planning has allowed not only me, but all of your great grandchildren to enjoy this time in our lives, while avoiding a great deal of anxiety. 


\section{Table of Contents}

Abstract

Acknowledgments iii

Table of Contents iii

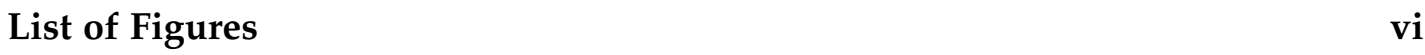

List of Tables vii

List of Abbreviations viii

1 Introduction 1

1.1 The Antarctic Ecosystem . . . . . . . . . . . . . . . . . . . 1

1.1.1 Sea-ice microbial community . . . . . . . . . . . . 2

1.2 Microbial Rhodopsins . . . . . . . . . . . . . . . . . . 6

1.2.1 Proteorhodopsin . . . . . . . . . . . . . . . . 6

1.3 Thesis Structure . . . . . . . . . . . . . . . . . . . . . . . . . 14

2 Identification and Investigation of Cultured Antarctic Sea-ice Bacteria 15

2.1 Introduction . . . . . . . . . . . . . . . . . . 15

2.2 Materials and Methods . . . . . . . . . . . . . . . . . . . . 17

2.2.1 Growth conditions . . . . . . . . . . . . . . . . . . 18

2.2 .2 Biochemical tests . . . . . . . . . . . . . . . . . 18

2.2.3 DNA extraction . . . . . . . . . . . . . . . . . . . . . . 19

2.2.4 16S rRNA gene amplification and sequencing . . . . . . . 20

2.2 .5 PR gene amplification . . . . . . . . . . . . . . . 22

2.2.6 Restriction fragment length polymorphism profiling . . . . . 23

2.2 .7 Growth curves . . . . . . . . . . . . . . . . . . . . 24

2.2 .8 Statistical Analysis . . . . . . . . . . . . . . . . . 24

2.2.9 Storage of bacterial isolates . . . . . . . . . . . . . 25

2.3 Results . . . . . . . . . . . . . . . . . 26

2.3.1 Bacterial growth and colony morphology . . . . . . . . 26

2.3.2 Biochemical tests and cellular morphology . . . . . . . . . 28

2.3.3 16S rRNA gene amplification and phylogenetic analysis . . . . 29

2.3.4 Restriction fragment length polymorphism analysis . . . . . . . 30

2.3 .5 PR gene amplification . . . . . . . . . . . . . 37

2.3 .6 Growth curves . . . . . . . . . . . . . . . . . . . . . 38

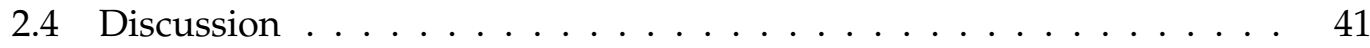


3 Light Enhanced Growth of PR-bearing, Antarctic Sea-ice Bacteria $\quad 47$

3.1 Introduction . . . . . . . . . . . . . . . . . 47

3.2 Materials and Methods . . . . . . . . . . . . . . . . . . 49

3.2.1 In situ incubations . . . . . . . . . . . . . . . . . . . 49

3.2.2 Laboratory-based incubations . . . . . . . . . . . . . 52

3.2 .3 Statistical analysis . . . . . . . . . . . . . . 52

3.3 Results ....................... 53

3.3.1 2012 in situ incubation . . . . . . . . . . . . . . . . 53

3.3.2 2013 in situ incubation . . . . . . . . . . . . . . . . . . . 53

3.3.3 Laboratory-based incubations . . . . . . . . . . . . . . . 57

3.4 Discussion . . . . . . . . . . . . . . . . . . . 61

4 Overview and Conclusion $\quad 65$

4.1 Outline of Research Findings . . . . . . . . . . . . . . . 65

4.1.1 What cultivable bacteria are present in sea-ice bacteria samples? 65

4.1.2 Do these isolated taxa contain the PR gene? . . . . . . . . . . 65

4.1.3 Does light affect the growth of these PR-bearing bacteria? . . . 66

4.2 The Overall Picture . . . . . . . . . . . . . . . . . . . . 67

4.3 Future Research Directions ．. . . . . . . . . . . . . . . . 70

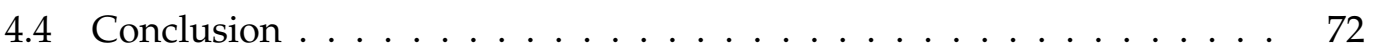

$\begin{array}{ll}\text { Bibliography } & 73\end{array}$

$\begin{array}{ll}\text { Appendices } & 87\end{array}$

Appendix A: Media Recipes . . . . . . . . . . . . . . . . . . . . . . . . . . . . . . . . 87

Appendix B: Supplementary Data . . . . . . . . . . . . . . . . . . . 89 


\section{List of Figures}

$\begin{array}{lr}\text { Chapter } 1 & 1\end{array}$

1.1 Physical gradients established through an ice column . . . . . . . . 2

1.2 Simplified microbial loop diagram . . . . . . . . . . . . . . . 4

1.3 Simplified view of transmembrane proton fluxes in PR-bearing bacteria 9

$\begin{array}{lr}\text { Chapter } 2 & \mathbf{1 5}\end{array}$

2.1 Bacterial colonies grown on MA plates . . . . . . . . . . . 27

2.2 Electrophoresis gel showing 16S rRNA gene amplification bands . . . 30

2.3 Dendrograms of estimated 16S rRNA gene sequences relationships . . 33

2.4 Electrophoresis gel showing PR gene amplification bands . . . . . . . 37

2.5 qPCR PR gene amplification and melt curve profiles . . . . . . . . 38

2.6 Growth curves of Antarctic sea-ice bacteria isolates . . . . . . . . . . . 39

$\begin{array}{lr}\text { Chapter } 3 & 47\end{array}$

3.1 In situ incubation study site . . . . . . . . . . . . . . . . . . 50

3.22013 in situ incubation method. . . . . . . . . . . . . . . . . . . . . . 51

3.3 Mean growth curves obtained from 2012 in situ incubations . . . . . . 54

3.4 Mean growth curves of P. torquis, from 2013 in situ incubations . . . . 56

3.5 Mean Ps. nivimaris growth curves from laboratory-based incubations . 58

3.6 Mean Po. dokdonensis growth curves from laboratory-based incubations 59

3.7 Mean P. torquis growth curves from laboratory-based incubations . . . 59

$\begin{array}{lr}\text { Appendices } & 87\end{array}$

S.1 Annealing temperature qPCR PR gene amplification results . . . . . . 90

S.2 Unique RFLP profiles . . . . . . . . . . . . . . . . . . . . . . . 91

S.3 Treatment of ice cores used in the 2012 in situ incubation . . . . . . . . 92

S.4 Mean absorbance measurements of incubations lacking growth . . . . 94 


\section{List of Tables}

$\begin{array}{lr}\text { Chapter } 1 & 1\end{array}$

1.1 A summarised timeline of the key findings in PR research . . . . . . 11

$\begin{array}{lr}\text { Chapter } 2 & \mathbf{1 5}\end{array}$

2.1 Primers used for $16 \mathrm{~S}$ rRNA gene amplification . . . . . . . . . . . 21

2.2 Primers used for PR gene amplification . . . . . . . . . . . . . 23

2.3 Growth of bacterial samples under different media conditions . . . . . 26

2.4 Colony morphology of bacterial isolates . . . . . . . . . . . . 28

2.5 Cellular morphology of bacterial isolates . . . . . . . . . . . . . . 29

$2.6 \%$ similarity and \% divergence between 16S rRNA gene sequences . . 31

2.7 Variables derived from growth curve experiments . . . . . . . . . . 40

$\begin{array}{ll}\text { Chapter } 3 & 47\end{array}$

3.1 Statistical information derived from 2012 in situ incubations . . . . . 55

3.2 Statistical information derived from 2013 in situ incubations . . . . . . 55

3.3 Variables derived from laboratory-based incubations . . . . . . . . 60

$\begin{array}{lr}\text { Appendices } & 87\end{array}$

S.1 Colony morphology of bacterial samples . . . . . . . . . . . . . 89

S.2 Cellular morphology of bacterial samples . . . . . . . . . . . . . . 89

S.3 Phenol-chloroform DNA extraction concentrations . . . . . . . . . . . . 89

S.4 Annealing temperature qPCR PR gene amplification results . . . . . 90

S.5 qPCR PR gene amplification product melt curve data . . . . . . . . . 91

S.6 Statistical interactions from bacterial growth curves . . . . . . . . . . 91

S.7 Daily weather measurements made at Cape Evans . . . . . . . . . . . 92

S.8 Runs test results of incubation experiment negative controls . . . . . 93

S.9 One-way, factorial ANOVA results of laboratory-based incubation . . 95 


\section{List of Abbreviations}

\begin{abstract}
ANOVA Analysis of variance
ATP Adenosine triphosphate

B-PR Blue-light proteorhodopsin

$\mathbf{d d H}_{2} \mathbf{O}$ Double distilled water

DOC Dissolved organic carbon

DOM Dissolved organic matter

G-PR Green-light proteorhodopsin

gDNA Genomic DNA

GPCR G-protein coupled receptor
\end{abstract}

MA Difco ${ }^{\mathrm{TM}}$ Marine Agar 2216

MB Difco ${ }^{\mathrm{TM}}$ Marine Broth 2216

MGT Mean generation time

PCR Polymerase chain reaction

POM Particulate organic matter

PR Proteorhodopsin
PUFA Polyunsaturated fatty acid

qPCR Quantitative PCR

R2A Reasoner's 2A broth

RFLP Restriction fragment length polymorphism

RFU Relative fluorescence units

rRNA Ribosomal RNA

SDS Sodium dodecyl sulfate

SIMCO Sea-ice microbial community

SWC Seawater complete broth

TBE Tris-borate ethylenediaminetetraacetic acid

TE Tris-ethylenediaminetetraacetic acid

VUW Victoria University of Wellington 


\section{CHAPTER 1}

\section{Introduction}

\subsection{The Antarctic Ecosystem}

Antarctic sea ice provides a vast yet seasonally variable ecosystem, spanning up to 20 million $\mathrm{km}^{2}$ during the austral winter, receding to less than 4 million $\mathrm{km}^{2}$ in the summer (Horner, 1985). Despite its homogenous appearance, sea ice forms a complex three dimensional habitat. Cool air temperatures cause unidirectional heat extraction from surface waters, which results in the formation of vertically elongated ice crystals. These crystals coalesce into a well structured ice matrix known as columnar ice (Garrison et al., 1983; Ackley and Sullivan, 1994). During the freezing process, salts are excluded from the ice and concentrated into brine pockets. Dense brine may drain through columnar ice, developing into a labyrinth of brine channels varying in size from micro- to millimeters (Ackley and Sullivan, 1994).

Steep vertical gradients are characteristic of columnar ice, the most prominent of which is temperature. Air temperatures during summer in McMurdo Sound, Antarctica typically range from $0^{\circ} \mathrm{C}$ to $-20^{\circ} \mathrm{C}$, and can drop below $-50^{\circ} \mathrm{C}$ during the winter (Garrison, 1991; Thomas and Dieckmann, 2009). In contrast, temperature at the ice-water interface remains constant $\left(-1.87 \pm 0.09^{\circ} \mathrm{C}\right)$ causing a rapidly decreasing temperature gradient when moving upwards through the ice matrix (Fig. 1.1; Littlepage, 1965; Thomas and Dieckmann, 2009). These variations in temperature directly influence the osmotic environment of the ice matrix. The colder surface temperatures cause more water to freeze whilst salts continue to be excluded. This causes a reduction in brine volume and an increase in salt concentration towards the surface (Fig. 1.1). Kottmeier and Sullivan (1988) reported surface ice brine channels of approximately $-10^{\circ} \mathrm{C}$, reaching salinities of up to $150 \%$, while the constant temperatures at the ice-water interface lead to stable salinities of $\sim 35 \%$ (Fig. 1.1). Furthermore, solar radiation is attenuated through the sea ice, resulting in light regimes decreasing with depth at a variable rate depending on ice thickness, biological prevalence and the depth of snow cover (Fig. 1.1; Buckley and Trodahl, 1987; Garrison, 1991). Due to a graduated attenuation of different wavelengths, blue-light predominates throughout sea ice, with $\sim 1.5 \mathrm{~m}$ bottom-ice irradiance typically being $<5 \mu \mathrm{mol}$ photons $\mathrm{m}^{-2} \mathrm{~s}^{-1}$ (Buckley and Trodahl, 1987; Ryan et al., 2009). 


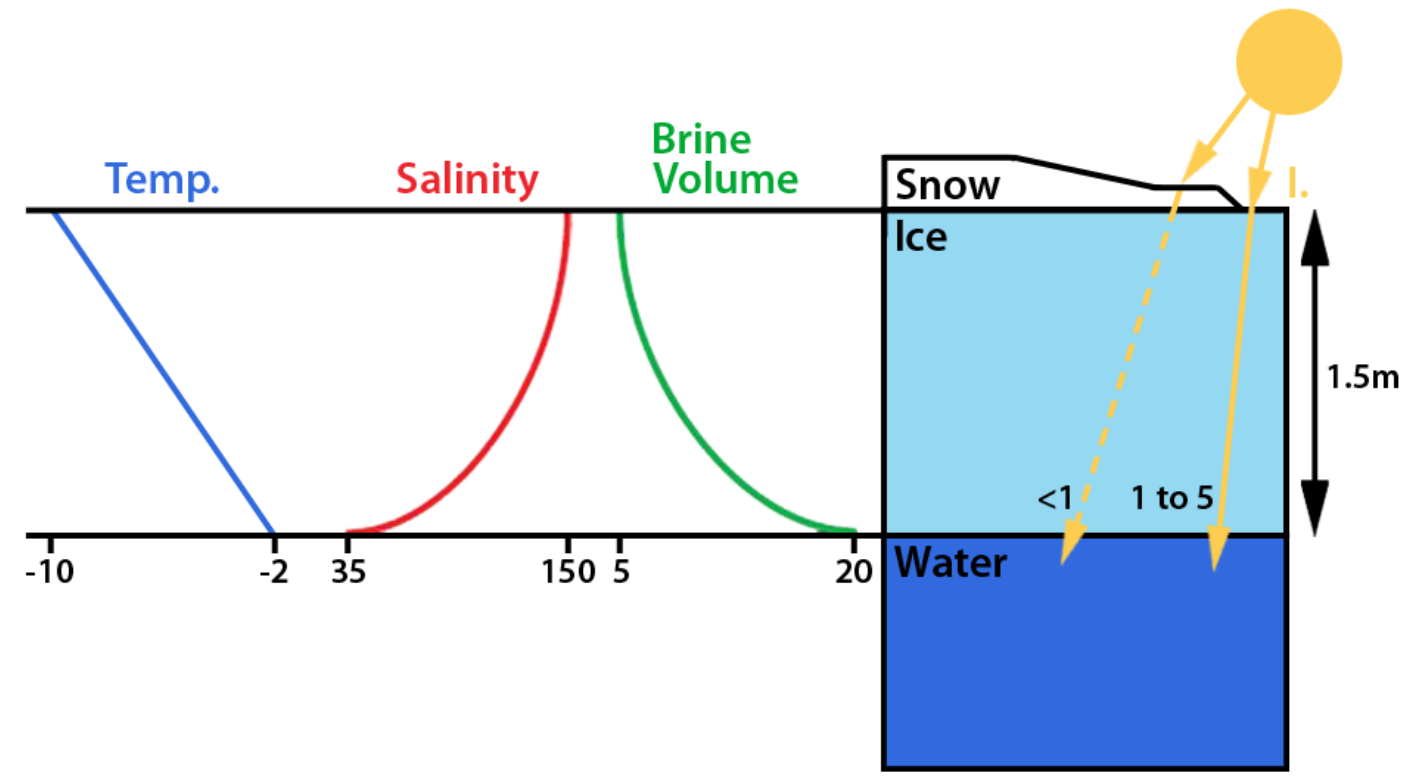

Figure 1.1: Gradients of temperature $\left({ }^{\circ} \mathrm{C}\right)$, salinity (ppt), brine volume (\% of ice matrix) and solar irradiance ( $\mu \mathrm{mol}$ photons $\mathrm{m}^{-2} \mathrm{~s}^{-1}$ ) established through a $1.5 \mathrm{~m}$ ice column cross section. Adapted and redrawn from Thomas and Dieckmann (2002).

\subsubsection{Sea-ice microbial community}

Despite the dynamic and harsh conditions of Antarctic sea ice, brine channels throughout the entire ice matrix support microbial growth, with over 200 sympagic (living within the sea ice) taxa identified prior to the majority of Antarctic genetic diversity studies (Garrison, 1991). The sea-ice microbial community (SIMCO) includes phytoplankton, Bacteria, Archaea, protists, viruses and meroplankton, and can reach biomasses up to two orders of magnitude higher than that of the underlying water column (Sullivan and Palmisano, 1981; Garrison, 1991). The vertical distribution of SIMCO members is dictated by both physicochemical and biological pressures. As the bottom of an ice column has relatively stable conditions and increased exchange with nutrient-rich underlying sea water, SIMCO abundance in the Ross Sea is correlated with ice depth, with the bottom $\sim 20 \mathrm{~cm}$ of ice typically being coloured brown by dense blooms of microalgae (Sullivan and Palmisano, 1981; Andreoli et al., 2000).

The Antarctic SIMCO comprises $25-30 \%$ of annual pack ice primary production (Legendre et al., 1992), with potentially even higher levels in fast or perennial ice (McMinn et al., 2010). Production levels can be so high that oxygen bubbles have been observed forming at the ice-water interface (McMinn et al., 2010). Due to this high level of productivity, the SIMCO is a critical Southern Ocean food source, being 
grazed by zooplankton and higher organisms such as the Antarctic krill Euphasia superba (Daly, 1990; Lizotte, 2001). The continuous availability and widespread nature of sympagic microorganisms allows the SIMCO to be utilised as the primary food source during the winter, when light reduction limits pelagic (living in the open ocean) phytoplankton (Stewart and Fritsen, 2004). Furthermore, the SIMCO may act as an inoculum for the annual phytoplankton spring bloom (Garrison et al., 1987). However, evidence supporting this hypothesis is circumstantial, in that there are similarities between the microalgal species composition in SIMCO and successive spring blooms (Lizotte, 2001). Furthermore, this hypothesis does not account for the abundance or physiological condition of the seed population (Lizotte, 2001), nor does it consider the influence of other sea-ice microbes, such as bacteria and viruses.

Sympagic bacteria growth rates have been estimated at $\sim 10 \%$ day $^{-1}$ (Grossi et al., 1984), resulting in bacterial abundances of $1.02 \times 10^{12}$ cell $\mathrm{m}^{-3}$ in annual Antarctic sea ice (Sullivan and Palmisano, 1984), greatly exceeding pelagic Southern Ocean bacterioplankton estimates (Hanson et al., 1983). Additionally, bacteria have high metabolic activities in Antarctic systems (Martin et al., 2008; Koh et al., 2010), approximately three times that of most temperate systems (Longnecker et al., 2005). The high abundance and increased metabolic activity of sea-ice bacteria suggest that they play a particularly important role in the microbial loop dynamics of the Antarctic ecosystem.

Azam et al. (1983) proposed the microbial loop, a conceptual model in which dissolved organic matter (DOM) is returned to the food web via a bacteria $\rightarrow$ flagellate $\rightarrow$ microzooplankton feeding interaction (Fig. 1.2). The large surface area to volume ratio of bacteria (compared to phytoplankton) allows the uptake of nutrients and DOM at very low concentrations (Azam et al., 1983), from sources such as exopolymeric substances, released photosynthate and ruptured cells (Thomas et al., 2001; Stewart and Fritsen, 2004; Azam and Malfatti, 2007). Bacteria respond to microenvironmental DOM fluxes, forming spatial relationships with algae (Sullivan and Palmisano, 1984) and marine snow (Kiorboe and Jackson, 2001; Azam and Malfatti, 2007).

Antarctic microbial loop processes are fundamentally different than the mechanisms employed in tropical or temperate oligotrophic (nutrient limited) waters. The water column underlying Antarctic sea ice is generally high in nutrients, therefore primary production is typically regulated by energy requirements, rather than nu- 


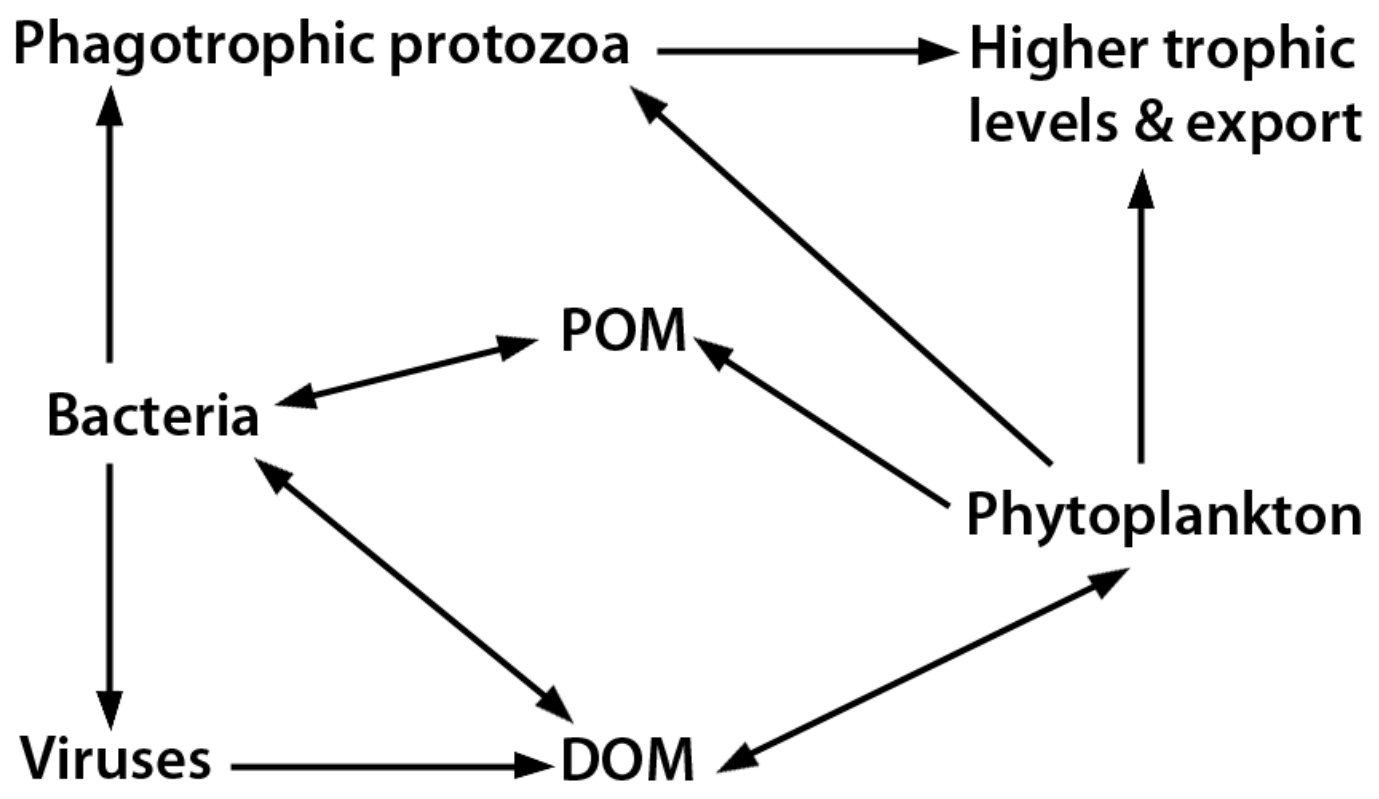

Figure 1.2: Simplified microbial loop diagram, showing movements of energy. DOM = dissolved organic matter, POM = particulate organic matter. Adapted and redrawn from Azam et al. (1983).

trient limitation (Azam et al., 1991). Bacterial DOM uptake in the Southern Ocean allows $\sim 30 \%$ of energy from primary production to be recycled to higher trophic levels (Staley and Gosink, 1999) and the production rate of Antarctic sea-ice bacteria is surprisingly high, equating to $10-15 \%$ of sea-ice primary production (Kottmeier and Sullivan, 1987; Martin et al., 2011). Sea-ice bacteria become even more critical during the winter, when typical bacteria-algae spatial relationships become uncoupled due to the absence of photosynthetic production (Stewart and Fritsen, 2004). Therefore secondary production becomes the base of the Antarctic food web (Azam et al., 1991), exemplified by stronger bacterial-DOM correlations in the winter (Azam and Malfatti, 2007).

The main groups of sea-ice bacteria are the Alpha- and Gamma-proteobacteria, and the Bacteroidetes, however other taxa including the Betaproteobacteria and Grampositive bacteria are found throughout sea ice (Bowman et al., 1997; Staley and Gosink, 1999; Brown and Bowman, 2001; Brinkmeyer et al., 2003; Murray and Grzymski, 2007; Cowie, 2011). Species distribution throughout the ice column is dictated by habitat filtering (Pontarp et al., 2012), with the initial freezing process rapidly reducing the cosmopolitan mixture of species found in Antarctic sea water (Martin et al., 2011). Although some bacteria species are found throughout the entire ice col- 
umn, UV-B radiation and salinity-induced stress further control sea-ice assemblages (Nichols et al., 1999b; Martin et al., 2009), resulting in higher bacterial concentrations closer to the ice-water interface.

The geographic isolation and extreme environmental conditions of Antarctic sea ice has given rise to a unique set of evolutionary pressures. These conditions are detrimental to the majority of pelagic microbes, however those that are sufficiently adapted may have a greater propensity for growth given the lack of competition (Ackley and Sullivan, 1994). Low temperatures cause decreased membrane fluidity, slowed enzymatic activity and cell rupture due to ice crystal formation (Morita, 1975; Rothschild and Mancinelli, 2001; Trevors et al., 2012). Psychrophilic (cold adapted) bacteria over come these challenges using high proportions of cellular membrane polyunsaturated fatty acids (PUFA; Nichols et al., 1999a), stress resistant cell cycles (Staley and Gosink, 1999) or antifreeze proteins (Gilbert et al., 2004). Some psychrophilic bacteria have adapted to endure a wider range of $\mathrm{pH}$ and salinity values (Nichols et al., 1999b) through production or association with exopolymeric substances, which may buffer osmotic shock and physical damage by ice crystals (Krembs et al., 2002). Furthermore, bacterial pigments such as carotenoids act as a 'microbial sunscreen' (Bowman et al., 1998; Fong et al., 2001), similar to the algal use of mycosporine-like amino acids (Ryan et al., 2002). The broad range of microbial adaption has been demonstrated, in that entire ice-column communities have the potential to withstand complete inversion of vertical sea-ice profiles (Martin et al., 2011). This concept is summarised well by Collins (2012): "Microbes rarely fail to adapt when subjected to harsh environments."

One diverse bacterial adaptation is phototrophism. Cyanobacteria are a large global photosynthetic contributor, however the discovery of several alternative lightbased metabolic strategies has challenged the assumption that chl- $a$ is the only ecologically significant light-harvesting pigment in prokaryotes. This is of particular importance in the Southern Ocean where cyanobacteria are rare and the harvesting of light energy may aid in the survival of heterotrophic bacteria (Koh et al., 2012). For example, bacteriochlorophyll is utilised by many prokaryotic species, such as aerobic anoxygenic phototrophic bacteria (Kolber et al., 2001), a prevalent bacterial group in the Antarctic ecosystem (Koh et al., 2011). Additionally, many heterotrophic bacteria possess microbial rhodopsins, proteins with the potential to exploit light without the fixation of carbon or oxygen. 


\subsection{Microbial Rhodopsins}

Rhodopsins are light-absorbing pigments that are formed through the binding of retinal (vitamin A aldehyde) with integral membrane proteins known as opsins (Béjà et al., 2000). These proteins are found across all three domains of extant life, however they fall into two distinct families; photosensory and microbial rhodopsins. In Eukarya, rhodopsins belong to the G-protein coupled receptor family (GPCR) and discriminate different wavelengths of light (de la Torre et al., 2003; Gómez-Consarnau et al., 2007). For example, rhodopsins are responsible for colour-differentiation in human retina (Baldwin et al., 1997). Prokaryotes can contain both photosensory rhodopsins as well as microbial rhodopsins, photoactive seven-helical membrane proteins that function as a light-driven proton (bacteriorhodopsin) or chloride ion (halorhodopsin) pumps (Béjà et al., 2000). Microbial rhodopsins are not bound to a G-protein and contain covalently bound 13-trans retinal, rather than the 11-cis form found in GPCR rhodopsins (Dioumaev et al., 2002; de la Torre et al., 2003). Similar to microbial rhodopsins, chlorophyll based phototrophy (be it in plants, algae or bacteria) also produces a proton gradient. However, the mechanism of establishing this gradient (the electron transfer chain) is dramatically different.

Microbial rhodopsins were discovered in extreme halophiles belonging to the Archaea (Oesterhelt and Stoeckenius, 1971), suggesting the use of phototrophy may be particularly useful in extreme environments, potentially allowing more energy to be directed towards the maintenance of physical processes. Microbial rhodopsins were thought to have been unique to the halophilic Archaea for almost three decades following their discovery, however a cloned marine Gammaproteobacteria genome fragment was found to contain proteorhodopsin (PR), a bacterial homolog of microbial rhodopsin (Béjà et al., 2000). PR has a similar photochemical cycle to archaeal microbial rhodopsins (Dioumaev et al., 2002) despite these two protein families have low sequence similarities (35-40\%) and likely evolving independently (Béjà et al., 2000). Further bacterial rhodopsin subsets have subsequently been found including xanthorhodopsin, a highly efficient microbial rhodopsin variant (Balashov et al., 2005), and actinorhodopsin, a set of microbial rhopdopsins associated with fresh water Actinobacteria (Sharma et al., 2008).

\subsubsection{Proteorhodopsin}

Since the discovery made by Béjà et al. (2000), PR-encoding genes have been found in a variety of bacterial taxa (Béjà et al., 2001; de la Torre et al., 2003) includ- 
ing Pelagibacter ubique (SAR11), the most abundant marine bacterium on the planet (Giovannoni et al., 2005), as well as being present across a diverse range of marine habitats. For example, the recent Global Ocean Survey found PR in almost 4000 species and to occur across 41 different environments (Rusch et al., 2007). Abundance estimates of PR-bearing bacteria range from 13\% in the Mediterranean and Red Seas (Sabehi et al., 2005) to 70-80\% in environments including the Sargasso Sea and Japanese waters (Venter et al., 2004; Yoshizawa et al., 2012), with a recent global survey estimating genomic presence in $48 \%$ of bacteria (Finkel et al., 2013).

PR genes, although present across a diverse array of bacteria, fall mainly into three phyla: Alphaproteobacteria, Gammaproteobacteria and Bacteroidetes (Béjà et al., 2001; Yoshizawa et al., 2012). Bacteroidetes is a complex phylum consisting of anaerobic, gut-associated bacteria as well as a large number of genera that live freely, often aggregating with organic matter (Zhao et al., 2009). The Flavobacteria, Polaribacter sp. (MED152) was one of the first Bacteroides to be sequenced (Kirchman, 2008) and phototrophy in this clade is due to PR activity (Gómez-Consarnau et al., 2007). It is commonly accepted that PR is spread across many bacterial species due to lateral gene transfer (Giovannoni et al., 2005). Concurrently, horizontal gene transfer of PR from Bacteria to Archaea (Frigaard et al., 2006), eukaryotes (Slamovits et al., 2011) and viruses (Yutin and Koonin, 2012) has also occurred.

A vast number of PR-containing bacteria cannot be cultured, making traditional culture-based assessment of these organisms difficult. However, recent use of highthroughput screening methods has helped identify and quantify PR genes in new habitats, including those that do not conform to traditional marine conditions. Examples include the amplification of PR genes from DNA extracts found in German and Canadian freshwater lakes, as well as brackish peat lakes in the Netherlands (Atamna-Ismaeel et al., 2008). PR-bearing bacteria also inhabit the psychrophilic waters of both the Arctic and Antarctic oceans (Cottrell and Kirchman, 2009) and have recently been found within the brine channels of annual Antarctic sea ice (Koh et al., 2010). The latter study found known PR sequences clustering within the both Proteobacteria and the Bacteroidetes, as well as a new PR analogue belonging to another member of the Bacteroidetes. Koh et al. (2010) also found geographical region and depth within the ice sheet were major factors in determining grouping of PR-bearing bacteria. In addition, Zhao et al. (2009) found the effect of temperature on photocycle kinetics is particularly important in determining the geographic distributions of PR-bearing bacteria. 
PR-bearing bacteria fall into two broad categories that are adapted to either green or blue light (Béjà et al., 2001). The differences between these two PR variants arises from the substitution of a single amino acid at position 105 in the PR protein (Man et al., 2003). Position 105 in green-light adapted PR (G-PR) is occupied by a leucine, whereas blue-light adapted PR (B-PR) have glutamine in this position. This results in a G-PR to B-PR absorption maximum shift from $530 \mathrm{~nm}$ to $490 \mathrm{~nm}$ (Man et al., 2003), with B-PR having a 10-fold slower photocycle rate (Wang et al., 2003). Furthermore, a varient PR family (RS29) found in the Red Sea has an absorption maximum of 515 $\mathrm{nm}$, due to a single blue- and two red-shifted peaks (Man-Aharonovich et al., 2004). This is accounted for by amino acid substitutions at positions 65 and 70, and results in the photocycle of this PR-bearing bacteria being $~ 100$ times slower than a typical G-PR (Man-Aharonovich et al., 2004).

PR variants are not divided monophyletically, as both G-PR- and B-PR-bearing bacteria are spread across multiple clades. Rather, spectral tuning is the result of Darwinian selection due to depth stratification (Bielawski et al., 2004). Relatively high energy blue light penetrates deeper waters than other wavelengths and consequently a higher proportion of B-PR are found at depth. Conversely, G-PR are more typical of turbulent, algae-rich, surface and coastal waters (Béjà et al., 2001; Man et al., 2003). When surveying the PR-bearing bacteria of Antarctic annual sea ice, Koh et al. (2010) found the highest concentration of G-PR at the ice-water interface, whereas B-PR was primarily in the mid-section of the ice column. This is due to blue light being dominant throughout an ice sheet (Buckley and Trodahl, 1987), with a high biomass of sympagic microalgae present in the bottom $\sim 20 \mathrm{~cm}$ reflecting large amounts of green light. Therefore, despite the inverse depth-distribution trends observed in Antarctic sea ice and the open ocean, both observations support the light-based Darwinian selection explanation. In contrast, little or no G-BP have been found in the Caribbean and Sargasso Seas (Rusch et al., 2007; Sabehi et al., 2007), suggesting the spectral tuning of PR is complicated by other environmental parameters. Wang et al. (2003) and Fuhrman et al. (2008) suggest that the slower photocycle rate of B-PR may make it more suitable under oligotrophic conditions.

Regardless of spectral tuning, PR-bearing bacteria can possess up to 25,000 PR proteins per $\mu \mathrm{m}^{2}$ of cell surface (Giovannoni et al., 2005; Yoshizawa et al., 2012), resulting in PR occupying $\sim 20 \%$ of the membrane surface of a PR-bearing bacteria (Giovannoni et al., 2005). Upon light absorption, the retinal molecule of each PR absorbs a photon, causing a conformational shift to a 13-cis isomer. This change 


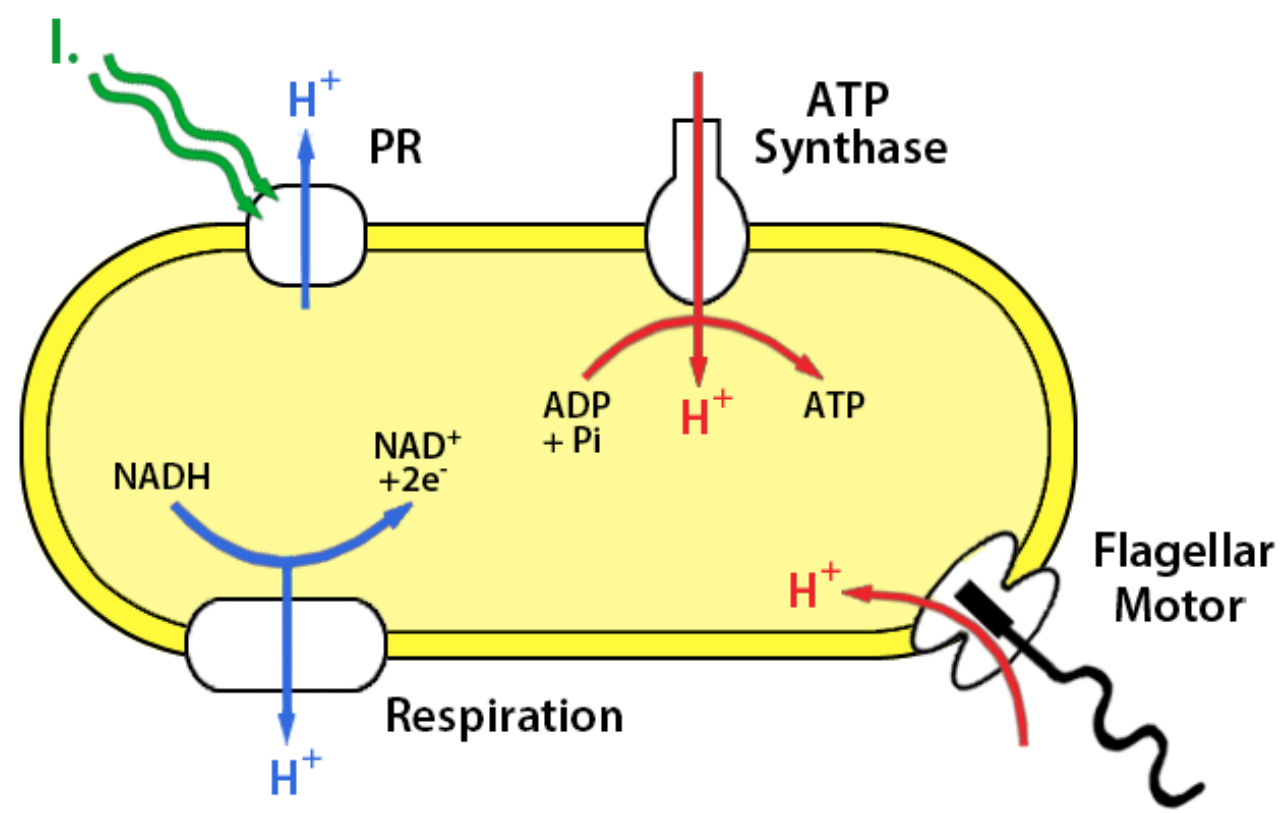

Figure 1.3: Simplified view of transmembrane proton fluxes in a PR-bearing bacterium. Sources of proton efflux (blue) include respiration and PR, and sources of proton inflow (red) include the flagellar motor and ATP synthesis. I. = solar irradiance. Adapted and redrawn from Walter et al. (2007) and Martinez et al. (2007).

in protein conformation causes the translocation of a proton from the cytoplasm, across the cell membrane (Béjà et al., 2000, 2001; Friedrich et al., 2002; Váró et al., 2003). This 'pumping' of protons generates an electrochemical membrane potential, which has the potential to drive adenosine triphosphate (ATP) synthesis as protons re-enter the cell through the ATP synthase complex, $\mathrm{H}^{+}$-ATPase (Fig. 1.3; Béjà et al., 2000, 2001; Fuhrman et al., 2008). Each photocycle of PR is fairly rapid ( $20 \mathrm{~ms}$ ), despite transitioning through several intermediate products (Dioumaev et al., 2002; Váró et al., 2003).

Dioumaev et al. (2002) reported that PR photocycling only occurs under alkaline $\mathrm{pH}$. The alkaline pumping of PR was supported by Friedrich et al. (2002), who found a proton was pumped out of the cell for every two photons absorbed. However, when placed under acidic conditions, protonation of the acceptor molecule results in a reversal of the pumping mechanism, with protons being transported into the cell. Inward pumping can potentially still result in ATP production and in fact only requires one photon to complete a pump cycle (Friedrich et al., 2002). The ability to invert pumping direction broadens the range of PR bacteria and may prove to be a 
valuable feature given predicted changes in ocean chemistry.

The influence of PR has been explored through in vitro expression in Escherichia coli, resulting in light-induced generation of energy for cellular growth, resistance to environmental respiratory challenges, photophosphorylation and increases in cellular activities such as flagellar motion (Fig 1.3 Martinez et al., 2007; Walter et al., 2007; González et al., 2008). However, few researchers have demonstrated an active contribution from PR in vivo. For example, cultures of the PR-bearing bacteria P. ubique (SAR11 and SAR92) as well as Dokdonia donghaensis (PRO95) express no measurable response to light (Giovannoni et al., 2005; Gómez-Consarnau et al., 2007; González et al., 2008; Riedel et al., 2010, 2013). This has caused a significant divide in opinion. Some authors are doubtful of PR making any significant contribution to solar energy capture (Wang et al., 2003), whereas others state PR phototrophy has the potential to meet all cellular energy requirements in the presence of light (Walter et al., 2007).

The widespread and multi-species distribution of PR provides indirect evidence for the benefits of this photo-protein (Sharma et al., 2008; Yoshizawa et al., 2012). The first instance of a naturally PR-possessing bacterium demonstrating light-induced growth occurred when the Bacteroides, D. donghaensis (MED134) was cultured under conditions of limited DOM (Gómez-Consarnau et al., 2007). Increases in abundance and cellular size were observed when this species was exposed to light (180 $\mu \mathrm{mol}$ photons $\mathrm{m}^{-2} \mathrm{~s}^{-1}$ ). Furthermore, light-induced growth of D. donghaensis (MED134) was primarily stimulated by green light with a recorded absorption maximum of $532 \mathrm{~nm}$, correlating well with the green-shifted nature of this PR (Gómez-Consarnau et al., 2007).

In the Antarctic Flavobacterium, Psychroflexus torquis, cellular abundance of PR was stimulated by both salinity and illumination. Light stimulated growth under conditions of salinity stress (at both sub- and supra-optimal concentrations), but not under carbon limitation (Feng et al., 2013). Direct proton pumping (a decline in $\mathrm{pH}$ ) in light-exposed conditions has been observed in P. torquis (Feng et al., 2013), along with eight other Flavobacteria members (Yoshizawa et al., 2012). In light intensities greater than $27.7 \mu \mathrm{mol}$ photos $\mathrm{m}^{-2} \mathrm{~s}^{-1}$, P. torquis had no growth yield differences, suggesting a photo-inhibitory effect at high levels of irradiation (Feng et al., 2013).

Upregulation of PR gene expression and transcription has been observed in $P$. ubique (SAR11) and D. donghaensis (MED134) cultured in the light (Lami et al., 2009; 
Table 1.1: A summarised timeline of the key findings in PR research.

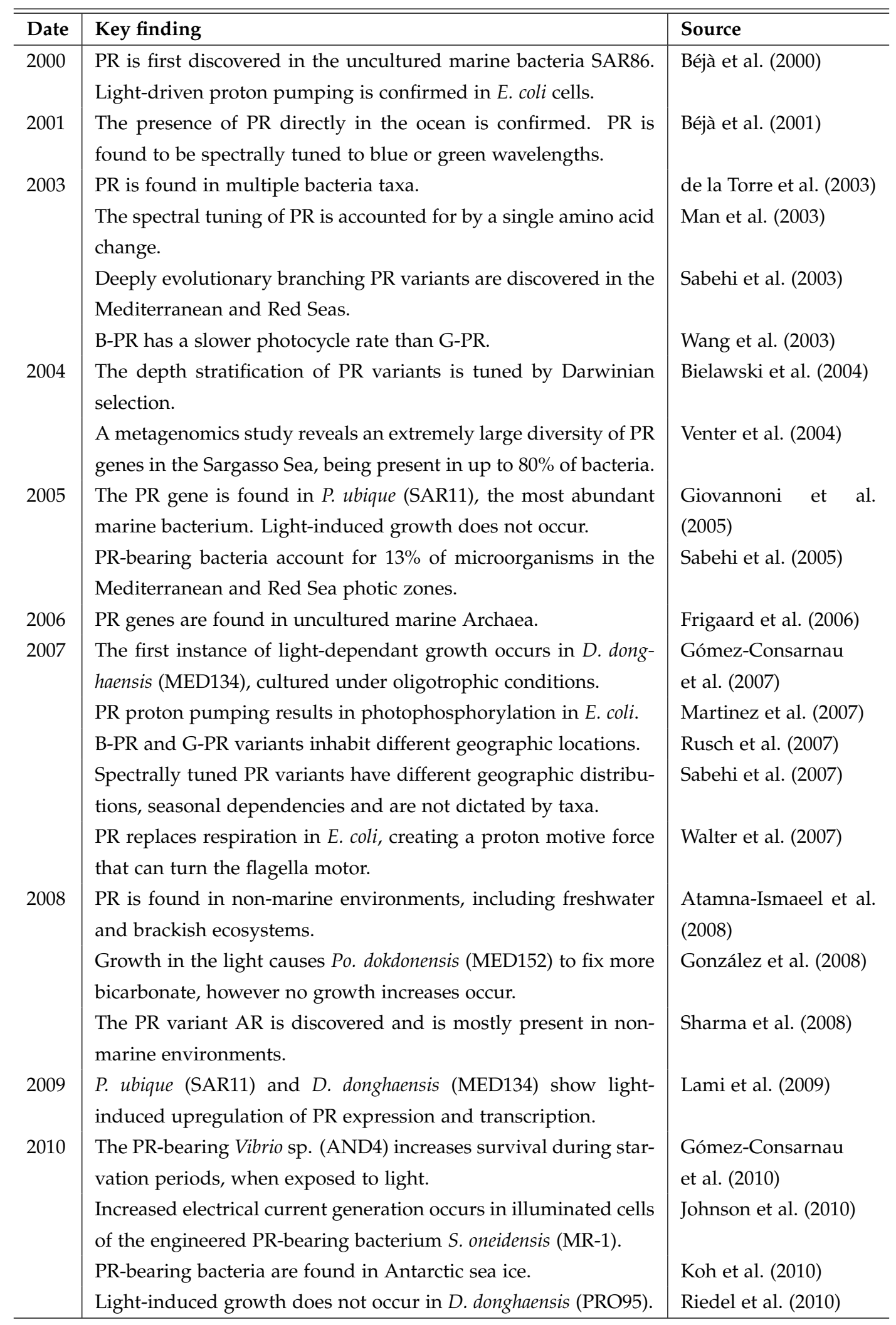




\begin{tabular}{|c|c|c|}
\hline Date & Key finding & Source \\
\hline \multirow[t]{3}{*}{2011} & $\begin{array}{l}\text { PR enzymes and other light-associated proteins are upregulated in } \\
\text { D. donghaensis (MED134) grown in the light. }\end{array}$ & Kimura et al. (2011) \\
\hline & $\begin{array}{l}\text { Eukrayotes are found to have acquired PR through horizontal gene } \\
\text { transfer. }\end{array}$ & $\begin{array}{l}\text { Slamovits et al. } \\
(2011)\end{array}$ \\
\hline & $\begin{array}{l}\text { PR supports the metabolic processes of P. ubique (SAR11) during } \\
\text { periods of carbon starvation. }\end{array}$ & $\begin{array}{l}\text { Steindler et al. } \\
(2011)\end{array}$ \\
\hline \multirow[t]{3}{*}{2012} & PR communities cluster by geographic location rather than depth. & Wei (2012) \\
\hline & $\begin{array}{l}\text { Light-driven proton pumping occurs in multiple PR-bearing } \\
\text { Flavobacteria. }\end{array}$ & $\begin{array}{l}\text { Yoshizawa et al. } \\
\text { (2012) }\end{array}$ \\
\hline & $\begin{array}{l}\text { Viruses are found to have acquired PR through horizontal gene } \\
\text { transfer. }\end{array}$ & $\begin{array}{l}\text { Yutin and Koonin } \\
\text { (2012) }\end{array}$ \\
\hline \multirow[t]{5}{*}{2013} & $\begin{array}{l}\text { PR phototrophy promotes the survival of Vibrio sp. (AND4) in } \\
\text { stationary-phase but did not influence active growth. Differential } \\
\text { PR expression is dictated by nutrient limitation, not light exposure. }\end{array}$ & Akram et al. (2013) \\
\hline & $\begin{array}{l}\text { Light-induced growth occurs in the PR-bearing bacteria P. torquis, } \\
\text { under conditions of salinity stress, not nutrient limitation. }\end{array}$ & Feng et al. (2013) \\
\hline & $\begin{array}{l}\text { The global genomic abundance of microbial rhodopsins is esti- } \\
\text { mated at } 48 \% \text { of microbes. }\end{array}$ & Finkel et al. (2013) \\
\hline & $\begin{array}{l}\text { The first sodium-pumping rhodopsin is discovered in the marine } \\
\text { bacteria Krokinobacter eikastus. }\end{array}$ & Inoue et al. (2013) \\
\hline & $\begin{array}{l}\text { D. donghaensis (PRO95) contains and transcribes both PR and XR } \\
\text { proteins. Light does not enhance growth. }\end{array}$ & Riedel et al. (2013) \\
\hline 2014 & $\begin{array}{l}\text { The first chloride ion pumping bacterial rhodopsin (similar to ar- } \\
\text { chaeal halorhodopsins) is discovered in a marine bacteria, Non- } \\
\text { labens marinus. }\end{array}$ & $\begin{array}{l}\text { Yoshizawa et al. } \\
\text { (2014) }\end{array}$ \\
\hline
\end{tabular}

Kimura et al., 2011). During periods of starvation, light exposed Vibro sp. (AND4) increased in survival during the stationary-phase (Gómez-Consarnau et al., 2010) whilst active growth of this species remained unaffected (Akram et al., 2013). When illuminated, both P. ubique (SAR11) and Polaribacter dokdonensis (MED152) demonstrated increases in metabolic processes (including respiration rate, ATP content, bicarbonate fixation and cellular size) during periods of carbon starvation, with no light-induced differences in biomasses occurring (González et al., 2008; Steindler et al., 2011). Johnson et al. (2010) observed increased electrical current generation in illuminated cells of the engineered PR-bearing bacteria Shewanella oneidensis (MR1), suggesting a potential application of PR in the manufacturing of biofuels. A summarised timeline of the key findings in PR research is presented in Table 1.1. 
Based on this evidence, it is generally accepted that ATP derived from PRmediated proton gradients allows carbon to be diverted from oxidation to biosynthesis (Kirchman, 2008). Béjà et al. (2001) hypothesised that PR may be particularly beneficial under oligotrophic conditions, however the inconsistency of both culture and field based reports does not generally support this model. For instance, Yoshizawa et al. (2012) demonstrated that protein expression of PR occurred regardless of organic matter concentrations. The role of PR may be subtle, becoming more prevalent under conditions of cellular stress, promoting survival and enhancing energy inputs (Giovannoni et al., 2005; Campbell et al., 2008; González et al., 2011). Fuhrman et al. (2008) proposed that PR may have multiple functions, including novel physiological uses, such as a survival mechanism used to assist PR-bearing bacteria exposed to harsh conditions.

The widespread nature and vast biomass of PR-bearing bacteria suggests this protein may be having a large influence on the energy acquisition and carbon cycling of heterotrophic microbes. Although previous research has yielded a mixture of results, a trend is beginning to develop, wherein $\mathrm{PR}$ is perceived to have the greatest influence under stress inducing conditions. Given the recent discovery of PR with Antarctic sea ice (Koh et al., 2010), the bacteria that possess this gene may be utilising light to enhance their growth and survival under these harsh conditions. Therefore, the aim of this thesis is to establish the influence of light on the growth of Antarctic PR-bearing bacteria, when exposed to environmental stressors.

Using previously collected samples of Antarctic sea-ice bacteria (Cowie, 2011), along with the Antarctic PR-bearing bacteria P. torquis, this thesis addressed three main research questions:

1. What cultivable bacteria are present in the previously collected samples of Antarctic sea-ice bacteria?

2. Do these isolated taxa contain the PR gene?

3. How is the growth of these PR-bearing bacteria affected by light under varying conditions of environmental stress? 


\subsection{Thesis Structure}

Chapter 2 details the methods involved in the culture and isolation of the Antarctic sea-ice bacteria. Using $16 \mathrm{~S}$ rRNA gene sequencing and a comparison of phenotypic properties, several isolates were identified. Growth curves were constructed and each species was examined for the presence of the PR gene.

The light-responses of PR-bearing, Antarctic bacteria were explored in Chapter 3. Novel methods were employed, in which cultures of Antarctic sea-ice bacteria were incubated in situ. This incubation experiment exposed these cultures to several of the natural environmental stressors of Antarctic sea ice, while controlling the culture medium and available wavelength. This experiment was paralleled by a laboratorybased incubation, using the PR-containing species identified in Chapter 2. The light responses of these species were explored under a variety of conditions similar to those of Antarctica sea ice. The results of this chapter are currently under preparation for submission to an internationally peer-reviewed journal.

Finally, Chapter 4 provides an summary and evaluation of the preceding chapters and an outline for future research directions. Literature cited in the course of this study has been documented in the bibliography. 


\section{CHAPTER 2}

\section{Identification and Investigation of Cultured Antarctic Sea-ice Bacteria}

\subsection{Introduction}

Approximately 14,000 prokaryotic species have been formally described (http: //bacterio.net/-number.html), typically from studies of pure bacterial isolates. Phenotypic features can be utilised along with genetic information in order to accurately classify an organism. Using the ribosomal RNA (rRNA) small subunit, the phylogenetic diversity of all organisms can be compared (Woese et al., 1990). The $16 \mathrm{~S}$ rRNA gene is comprised of eight conserved and nine variable regions, which evolve at different rates (Olsen et al., 1986). Comparison of the sequence similarity of this gene is the most common approach to classifying prokaryotes. Depending on the organisms and the target gene, the degree of sequence dissimilarity used to classify genus or species remains the subject of debate. Typically, 3\% sequence divergence is used as a conservative measure of species differentiation (Stackebrandt and Goebel, 1994), although this can differ depending on the organism (Nakamura, 1984; Fox et al., 1992).

Restriction fragment length polymorphism (RFLP) can also be applied to $16 \mathrm{~S}$ rDNA, as a means of genetic differentiation. This technique uses a restriction digestion enzyme to 'cut' the DNA at a specific binding site. The number and position of these binding sites varies between taxa, resulting in combinations of DNA fragments that can be visualised using gel electrophoresis (Laguerre et al., 1994). Although RFLP is a useful tool for the rapid differentiation of genotypes, it often needs to be supported by other techniques, such as 16S rRNA gene sequencing or DNA-DNA hybridisation, to accurately distinguish taxa to a species level (Laguerre et al., 1994).

The diversity of Antarctic sea-ice communities has traditionally been investigated using culture-based methods (Delille, 1992; Staley and Gosink, 1999; Bowman et al., 1997). However, nucleic acids can be extracted directly from environmental samples, with the amplification process of a polymerase chain reaction (PCR) resulting in small amounts of DNA being amplified. The first sequencing of 16S rRNA genes 
obtained from Antarctic sea-ice was conducted by Brown and Bowman (2001). Further studies have utilised a combination of culture-based and molecular techniques (Brinkmeyer et al., 2003), with the first 454 pyrosequencing study of sea-ice microbes being conducted in 2010 (Cowie, 2011). Sea-ice bacteria are predominantly Gramnegative, often pigmented, rods (Delille, 1992; Bowman et al., 1997; Brinkmeyer et al., 2003), of which the majority are halotolerant and psychrophilic or psychrotolerant (Brown and Bowman, 2001; Junge et al., 2002). Although a general trend of increasing diversity with sophistication of sampling technique is observed (i.e. diversity using 454 pyrosequencing > culture-based sequencing), the dominant taxa; the $\mathrm{Al}$ pha- and Gamma-proteobacteria, and the Bacteroidetes remained consistently abundant regardless of sampling technique (Brown and Bowman, 2001; Brinkmeyer et al., 2003; Cowie, 2011). These taxa are the major groups in both Antarctic and Arctic sea ice, implying similar environmental pressures are the most influential drivers in shaping the sea-ice bacteria community (Brinkmeyer et al., 2003).

To prosper under such harsh environmental conditions, sea-ice bacterial utilise several adaptations. High proportions of PUFAs in the lipid bilayer allow membrane fluidity to be maintained at low temperatures (Nichols et al., 1999a), and increased osmotic tolerances promote survival in both high salinity brine channels and at low salinities, such as those following the spring melt period (Nichols et al., 1999b). Furthermore, bacteria bearing the PR gene were recently discovered within Antarctic sea-ice (Koh et al., 2010). This protein is most influential under conditions of stress (Gómez-Consarnau et al., 2007, 2010; Steindler et al., 2011; Feng et al., 2013), therefore PR may be a significant energetic contributor in the harsh conditions of the Antarctic sea-ice ecosystem.

Colonies of the PR-bearing, Antarctic sea-ice bacteria, P. torquis are viscous and pigmented, composed of Gram-negative, rod bacteria (Bowman et al., 1998). Six isolates from Antarctic sea ice were sequenced and tentatively identified as $P$. torquis by Cowie (2011). The isolates were cyropreserved at $-80^{\circ} \mathrm{C}$; labelled as $\mathrm{C} 1, \mathrm{C} 1^{*}, \mathrm{C} 4$, $\mathrm{C}^{*}$, C34, and C73, all of which had identical RFLP profiles and showed $98.6-100 \%$ $16 \mathrm{~S}$ rRNA sequence similarity to one another. However, some features such as cellular shape, oxidase and catalase production, and glucose utilisation were subtly different among these isolates. Cowie (2011) suggested that these phenotypic differences may mean the isolates differ at the strain level, or in fact may be separate species. This study originally aimed to investigate these isolates further using DNA-

*differentiates duplicate samples 
DNA hybridisation and amplification of alternative genes. However, after recovery from cryopreservation, preliminary plate-culturing revealed these samples contained mixed colonies ranging from off-white to bright orange in colour.

In order for subsequent chapters to explore how these Antarctic sea-ice bacteria are influenced by light (under varying physicochemical conditions), this chapter addressed three research goals:

1. Isolate, describe and genetically identify the cultivable taxa of Antarctic sea-ice bacteria from samples originally reported as $P$. torquis.

2. Identify whether the PR gene is present in any of these Antarctic sea-ice bacteria.

3. Quantify the differences in the growth patterns of each Antarctic sea-ice bacteria.

As Antarctic bacteria are generally slow growing psychrophiles, incubation conditions will run at relatively cold temperatures, over long time periods. ZoBell's Marine Medium is widely used for bacterial cultures (Bowman et al., 1997; Brinkmeyer et al., 2003), however this medium has approximately 170 times more dissolved organic carbon (DOC) than seawater. To maximise observable diversity, a variety of media were utilised for initial growth conditions. Isolates were genetically identified based on the sequencing of the 16S rRNA gene, and the construction of an RFLP fingerprint library. As, the PR gene typically amplifies at a low annealing temperature $\left(<50^{\circ} \mathrm{C}\right.$; Atamna-Ismaeel et al., 2008; Koh et al., 2010; Cowie, 2011), non-specific annealing and amplification presented a potential a challenge in this amplification (Baumforth et al., 1999). Due to the high sensitivity, real time visualisation and ease in which reaction conditions (such as the annealing temperature) can be manipulated, quantitative PCR (qPCR) was used to amplify the PR gene.

\subsection{Materials and Methods}

In 2008 and 2009, Antarctic sea-ice bacteria samples from Cape Evans, Granite Harbour, Cape Roberts, Terra Nova Bay and McMurdo Station were collected and cryopreserved. For full sampling and culture methods see Cowie (2011). Of these collections, samples $\mathrm{C} 1, \mathrm{C}^{*}, \mathrm{C} 4, \mathrm{C} 4{ }^{*}, \mathrm{C} 34, \mathrm{C} 73$ were used in this study. All samples were handled using aseptic technique throughout this study. Unless stated otherwise, all reagents were purchased from Sigma-Aldrich (USA). 


\subsubsection{Growth conditions}

Using a sterile inoculation loop, cryopreserved bacteria were inoculated in duplicate, into $10 \mathrm{~mL}$ of sterile nutrient broth. Four different media treatments were prepared: Difco ${ }^{\mathrm{TM}}$ Marine Broth $2216(\mathrm{MB})$ at full strength and 10\%, Reasoner's 2A broth (R2A) and Seawater Complete broth (SWC). For full culture media methods see Appendix A. Bacterial cultures were then incubated for 6 days, at $12^{\circ} \mathrm{C}$, under constant illumination $\left(5-20 \mu \mathrm{mol}\right.$ photons $\mathrm{m}^{-2} \mathrm{~s}^{-1}$, provided by $30 \mathrm{~W}$ fluorescent lamps), rotating at $70 \mathrm{rpm}$. Duplicate $10 \mathrm{~mL}$ volumes of un-inoculated nutrient broth were incubated under the same conditions, acting as a negative control.

All cultures (regardless of whether visible growth was present) were streak plated onto sterile Difco $^{\mathrm{TM}}$ Marine Agar 2216 plates (MA) and incubated under the previously described conditions. MA was chosen as the most suitable solid media due to the highest visible community growth being present in MB cultures (as described in Section 2.3.1). After a minimum of 9 days incubation, bacterial colonies were observed using microscopic examination. Individual colonies were aseptically removed from the medium and streak plated onto fresh MA. The process of incubation and re-streaking was repeated until each plate contained a bacterial monoculture. A colony was deemed pure after visual examination under a stereomicroscope (Nikon, Japan) using the colony description criteria outlined by Harley and Prescott (1993), and through the presence of only a singular cell type after Gram staining.

\subsubsection{Biochemical tests}

All biochemical tests were performed in duplicate, on isolated bacterial colonies grown on $\mathrm{MA}$, incubated at $12^{\circ} \mathrm{C}$, under constant illumination $(5-20 \mu \mathrm{mol}$ photons $\left.\mathrm{m}^{-2} \mathrm{~s}^{-1}\right)$.

\section{Gram stain}

A sterile inoculation loop was used to remove a single colony of bacteria from its agar plate. The colony was diluted with a small drop of sterile double distilled water $\left(\mathrm{ddH}_{2} \mathrm{O}\right)$, and heat-fixed onto a glass microscope slide. Slides were then flooded with crystal violet solution for 1 min before rinsing with a minimal volume of $\mathrm{ddH}_{2} \mathrm{O}$. The slides were again flooded for $1 \mathrm{~min}$, using Gram's iodine solution, and rinsed with $\mathrm{ddH}_{2} \mathrm{O}$. Slides were destained with $95 \%$ ethanol for $30 \mathrm{~s}$ and rinsed with $\mathrm{ddH}_{2} \mathrm{O}$ once again. Finally, safranin solution was used as a counter-stain, flooding the slides for $30 \mathrm{~s}$ before a final $\mathrm{ddH}_{2} \mathrm{O}$ rinse. Slides were gently blotted and left to dry. For 
full protocol see Holt et al. (1994).

Slides were examined under a Labophot-2 compound light microscope (Nikon, Japan), using x1000 total magnification (oil immersion). Gram-positive bacteria were characterised by a dark purple colourisation, where as Gram-negative bacteria were light pink in colour (Holt et al., 1994). Bacterial morphologies were described using the criteria outlined by Harley and Prescott (1993).

\section{Oxidase reaction}

A single colony of bacteria was removed from its medium and smeared onto an Oxidase Strip (Oxoid, UK). A positive reaction was characterised by the appearance of a dark purple colour within $10 \mathrm{~s}$ (Cowan and Steel, 1965).

\section{Catalase reaction}

A single colony of bacteria was removed from its medium and covered with a drop of 3\% hydrogen peroxide solution. A positive reaction was characterised by the rapid formation of bubbles (Cowan and Steel, 1965).

\subsubsection{DNA extraction}

Genomic DNA (gDNA) templates to be used in 16S rRNA amplification, were prepared by removing 2-3 isolated colonies from their media and resuspended them in $100 \mu \mathrm{L}$ of UltraPure ${ }^{\mathrm{TM}}$ DNase/RNase free $\mathrm{H}_{2} \mathrm{O}$ (Life Technologies, USA). The bacterial cells were lysed by heating the solution to $99^{\circ} \mathrm{C}$ for $15 \mathrm{~min}$. The cellular suspension was then centrifuged at $5000 \mathrm{xg}$ for $1 \mathrm{~min}$, and $5 \mu \mathrm{L}$ of gDNA template was collected from as close as possible to the cellular pellet, without disturbing it. If amplification was not achieved, fresh samples were re-lysed, with the addition of $6 \mu \mathrm{L}$ of $1 \%$ proteinase $\mathrm{K}$ and $<1 \mathrm{mg}$ lysosome (Roche, USA) to the reaction vessel. Following a $37^{\circ} \mathrm{C}, 30 \mathrm{~min}$ incubation, $10 \mu \mathrm{L}$ of $10 \%$ sodium dodecyl sulphate (SDS) was added to the solution. The solution was again incubated for $30 \mathrm{~min}$ at $37^{\circ} \mathrm{C}$, before pelleting and extracting the gDNA template.

gDNA templates used in qPCR analyses were extracted and quantified using the following phenol-chloroform extraction method (Wilson, 1987): 2-3 isolated colonies were removed from their media and were suspended in $500 \mu \mathrm{L}$ of tris EDTA (TE) buffer ( $\mathrm{pH} 8$ ), $6 \mu \mathrm{L}$ of $1 \%$ proteinase $\mathrm{K}$ and $<1 \mathrm{mg}$ of lysosome. The mixture was then incubated at $56^{\circ} \mathrm{C}$ for 2 hours. $15 \mu \mathrm{L}$ of $20 \%$ SDS was added, followed by a 1 hour incubation at $37^{\circ} \mathrm{C}$. Following the addition of $100 \mu \mathrm{L}$ of $5 \mathrm{M} \mathrm{NaCl}$ and $80 \mu \mathrm{L}$ of 
preheated $10 \%$ cetyltrimethylammonium bromide/ $0.7 \mathrm{M} \mathrm{NaCl}$ solution, the mixture was incubated for $10 \mathrm{~min}$ at $65^{\circ} \mathrm{C}$. $800 \mu \mathrm{L}$ of $24: 1$ chloroform:isoamyl alcohol was added (in a fume hood) and the mixture was rotated for $30 \mathrm{~min}$, after which it was centrifuged at $4^{\circ} \mathrm{C}$ at $13,000 \mathrm{xg}$ for $5 \mathrm{~min}$. The supernatant was pipetted into a new Eppendorf tube and $800 \mu \mathrm{L}$ of 25:24:1 phenol:chloroform:isoamyl alcohol was added. The mixture was again rotated for $30 \mathrm{~min}$ and centrifuged at $4{ }^{\circ} \mathrm{C}$ at 13,000 $\mathrm{xg}$ for $5 \mathrm{~min}$. The supernatant was transferred into a new Eppendorf tube and 800 $\mu \mathrm{L}$ of 24:1 chloroform:isoamyl alcohol was added. Following a final $30 \mathrm{~min}$ rotation the supernatant was pipetted into a new Eppendorf tube where $480 \mu \mathrm{L}$ of ice-cold isopropanol was gently mixed through the solution. The mixture was centrifuged at $4^{\circ} \mathrm{C}$ at $13,000 \mathrm{xg}$ for $20 \mathrm{~min}$ before the supernatant was removed using a speed vacuum system, leaving behind the DNA pellet. $300 \mu \mathrm{L}$ of ice-cold ethanol was added and the mixture was centrifuged at $4^{\circ} \mathrm{C}$ at 13,000 $\mathrm{xg}$ for $15 \mathrm{~min}$. The speed vacuum system was used to remove the ethanol and the pellet was allowed to air dry. Finally, DNA pellets were dissolved in $20 \mu \mathrm{L}$ of UltraPure ${ }^{\mathrm{TM}} \mathrm{H}_{2} \mathrm{O}$.

A Quanti-iT ${ }^{\mathrm{TM}}$ PicoGreen ${ }^{\circledR}$ dsDNA Assay Kit (Invitrogen, USA) was used to determine DNA concentrations obtained. Reagents were prepared according to the manufacturer's instructions and were used immediately, to prevent photodegradation. Assays were performed in triplicate, in a flat top 96-well microplate (Axygen Scientific, USA). Each reaction contained $2 \mu \mathrm{L}$ of DNA extract, $98 \mu \mathrm{L}$ of TE working buffer and $100 \mu \mathrm{L}$ of PicoGreen working reagent (SYBR-based fluorescence). The fluorescence of each DNA extract was compared against DNA standards, ranging from 0-100 ng of DNA. Fluorescence was measured using a FLUOstar OPTIMA microplate reader (BMG Labtech, Germany; $\lambda_{\max }=480 \mathrm{~nm}$ ). Following quantification, DNA extracts were diluted (using UltraPure ${ }^{\mathrm{TM}} \mathrm{H}_{2} \mathrm{O}$ ) to $10 \mathrm{ng} / \mu \mathrm{L}$. All DNA extractions were stored at $-20^{\circ} \mathrm{C}$.

\subsubsection{S rRNA gene amplification and sequencing}

PCR amplification was conducted using an Applied Biosystems ${ }^{\circledR} 2720$ Thermal Cycler (Life Technologies, USA). All PCRs were performed in $25 \mu \mathrm{L}$ volumes containing $5 \mu \mathrm{L}$ of gDNA template, $5 \mu \mathrm{L}$ of $x 5$ HOT FIREPol ${ }^{\circledR}$ Blend Master Mix (Solis BioDyne, Estonia), $500 \mathrm{~nL}$ of each primer (Table 2.1: $16 \mathrm{~S} 27^{\mathrm{F}}, 16 \mathrm{~S} 1492^{\mathrm{R}}$ ), and $14 \mu \mathrm{L}$ UltraPure ${ }^{\mathrm{TM}} \mathrm{H}_{2} \mathrm{O}$. Negative controls (substitution of gDNA template with UltraPure $^{\mathrm{TM}} \mathrm{H}_{2} \mathrm{O}$ ) were included for every reaction. All PCRs were performed under the following conditions: an initial denaturation step at $95^{\circ} \mathrm{C}$ for $15 \mathrm{~min} ; 30$ cycles of 
Table 2.1: Primers used for $16 \mathrm{~S}$ rRNA gene amplification.

\begin{tabular}{ccc}
\hline \hline Primers & Sequence $\left(\mathbf{5}^{\prime} \rightarrow \mathbf{3}^{\prime}\right)$ & Source \\
\hline $16 \mathrm{~S} 27^{\mathrm{F}}$ & AGAGTTTGATCMTGGCTCAG & \\
$16 \mathrm{~S} 1492^{\mathrm{R}}$ & TACGGYTACCTTGTTACGACTT & Lane, 1991 \\
$16 \mathrm{~S} 1391^{\mathrm{R}}$ & CAACAGGGTTTCGAAAATAAGG & \\
\hline F: forward & & \\
R: reverse & &
\end{tabular}

denaturation, annealing and extension at $95^{\circ} \mathrm{C}$ for $30 \mathrm{~s}, 50^{\circ} \mathrm{C}$ for $30 \mathrm{~s}$ and $72^{\circ} \mathrm{C}$ for $1 \mathrm{~min} 30 \mathrm{~s}$, respectively; a final extension step for $7 \mathrm{~min}$ at $72^{\circ} \mathrm{C}$ before holding at $15^{\circ} \mathrm{C}$.

$3 \mu \mathrm{L}$ of each PCR product was run on a $1.0 \%(\mathrm{w} / \mathrm{v})$ DNA grade agarose electrophoresis gel (Lonza, Switzerland) containing $10 \mu \mathrm{L} / \mathrm{mL}$ ethidium bromide for DNA staining. $3 \mu \mathrm{L}$ of Invitrogen ${ }^{\mathrm{TM}} 1 \mathrm{~kb}$ Plus DNA Ladder (Life Technologies, USA) was run in conjunction to the samples. Using a PowerPac ${ }^{\mathrm{TM}}$ Basic Power Supply (Bio-Rad, USA), electrophoresis was run at $90 \mathrm{~V}$ in $x 1$ tris-borate ethylenediaminetetraacetic acid (TBE) buffer at room temperature for $45 \mathrm{~min}$. The gel was then visualised and photographed using a MultiDoc-It ${ }^{\mathrm{TM}} \mathrm{UV}$ trans-illuminator (UVP BioImaging Systems, USA). Successful amplification produced bands in the $\sim 1450$ bp region (Lane, 1991). Unsuccessful amplifications were reattempted, using the $16 \mathrm{~S} 1391^{R}$ primer (Table 2.1).

Following successful amplification, $10 \mu \mathrm{L}$ of sample was sequenced by Macrogen Inc. (Korea). Corresponding forward and reverse sequences were end trimmed and assembled using DNA Baser (version 3.5.1). Sequence mismatches were manually corrected through comparison of chromatograms. Assembled sequences were imported into the ARB software package (version November, 2012; Ludwig et al., 2004) and were automatically aligned according to the SILVA reference alignment (SSURef NR 99; Pruesse et al., 2007). Alignments were manually refined, taking into account the alignment of neighbouring species as well as the secondary structure information of the rRNA gene (Peplies et al., 2008).

DNA distance matrixes were constructed (PHYLIP, version 3.695), comparing isolates of this study against members of similar species (with varying genetic similarity), previously identified isolates (Cowie, 2011) and a member of an outgroup 
species. Using these comparisons phylogenetic tree reconstruction was performed using both the neighbour joining and maximum likelihood methods (PHYLIP, version 3.695), rooted using the outgroup species. 1000 bootstrap replicates were calculated using the majority rule, majority rule extended and strict methods (PHYLIP, version 3.695). Use of multiple tree building methods allows the stability of resulting topologies to be compared (Peplies et al., 2008). Dendrograms and DNA distance matrixes presented were divided into four respective genetic clades; Gammaproteobacteria, Alphaproteobacteria, Bacteroidetes and Actinobacteria. The DNA distance matrixes presented only show data of similar species.

\subsubsection{PR gene amplification}

A preliminary PCR was run in order to test the suitability of a variety of PRspecific primer combinations (Table 2.2$)$ and gDNA extracts $(10 \mathrm{ng} / \mu \mathrm{L})$ of samples know to express PR, including HTCC 1062 (U. Stingl, pers. comm., 2009); 31A8 (Béjà et al., 2000); LK (O. Béjà, pers. comm., 2009); $\mathrm{PR}^{+\mathrm{ctrl}}$, a combined sample of 31A8 and LK gDNA (Y. Koh, pers. comm., 2013); and cultures of P. torquis (ATCC 700755). Cultures of $P$. torquis (generously supplied by Assoc/Prof. John Bowman, University of Tasmania) were grown on MA, incubated under constant illumination (5-20 $\mu \mathrm{mol}$ photons $\left.\mathrm{m}^{-2} \mathrm{~s}^{-1}\right)$, at $4^{\circ} \mathrm{C}$ (J. Bowman, pers. comm., 2013).

PCRs were performed in $25 \mu \mathrm{L}$ volumes containing $1 \mu \mathrm{L}$ of gDNA template (10 $\mathrm{ng} / \mu \mathrm{L}), 12.5 \mu \mathrm{L}$ of $\mathrm{x} 2$ iProof $^{\mathrm{TM}}$ HF Master Mix (Bio-Rad, USA), $500 \mathrm{~nL}$ of each primer (Table 2.2), and $10.5 \mu \mathrm{L}$ UltraPure ${ }^{\mathrm{TM}} \mathrm{H}_{2} \mathrm{O}$. Negative controls (substitution of gDNA template with UltraPure ${ }^{\mathrm{TM}} \mathrm{H}_{2} \mathrm{O}$ ) were included for every PCR. PCRs were run for 40 cycles under the reaction conditions outlined earlier (Section 2.2.4). PCR products were visualised using gel electrophoresis (loading gels with $5 \mu \mathrm{L}$ of 3:5 x3 bromophenol blue 50\% glycerol loading dye:PCR product mixture) and UV trans-illumination, as described previously (Section 2.2.4). Successful amplification produced bands 300-500 bp in length (Béjà et al., 2001).

In order to optimise PR gene amplification, an annealing-temperature gradient qPCR was run using the successful PR gene amplification primer sets and gDNA extracts. qPCRs were run in an CFX96 ${ }^{\mathrm{TM}}$ Real-Time System $\mathrm{C} 1000^{\mathrm{TM}}$ Thermal Cycler (Bio-Rad, USA). Reactions were performed in $20 \mu \mathrm{L}$ volumes, containing $500 \mathrm{~nL}$ of gDNA template $(10 \mathrm{ng} / \mu \mathrm{L}), 10 \mu \mathrm{L}$ of SsoFast ${ }^{\mathrm{TM}}$ EvaGreen $^{\circledR}$ Supermix (Bio-Rad, USA), $500 \mathrm{~nL}$ of each primer (Table 2.2: ${ }^{*} \mathrm{RYIDW}^{\mathrm{F}},{ }^{*} \mathrm{GWSIYP}^{\mathrm{R}}$ ), and $8.5 \mu \mathrm{L}$ UltraPure $^{\mathrm{TM}}$ $\mathrm{H}_{2} \mathrm{O}$. Negative controls (substitution of gDNA template with UltraPure ${ }^{\mathrm{TM}} \mathrm{H}_{2} \mathrm{O}$ ) were 
Table 2.2: Primers used for PR gene amplification.

\begin{tabular}{|c|c|c|c|}
\hline Primer Set & Primer & Sequence $\left(5^{\prime} \rightarrow 3^{\prime}\right)$ & Source \\
\hline \multirow{2}{*}{$\mathrm{PR}_{1}$} & RYIDW $^{\mathrm{F}}$ & MGNTAYATHGAYTGG & \multirow{2}{*}{ Atamna-Ismaeel et al., 2008} \\
\hline & GWSIYPR $^{R}$ & GGNTGGWSNATHTAYCCN & \\
\hline \multirow{2}{*}{$\mathrm{PR}_{M o d}$} & ${ }^{*} \mathrm{RYIDW}^{\mathrm{F}}$ & *MGNTAYATHGAYTGG & \multirow{2}{*}{ Y. Koh, pers. comm., 2013} \\
\hline & ${ }^{*}$ GWSIYP ${ }^{\mathrm{R}}$ & *GGNTGGWSNATHTAYCCN & \\
\hline \multirow{2}{*}{$\mathrm{PR}_{\text {Sav }}$} & $\mathrm{RYVDW}^{\mathrm{F}}$ & MGNTAYGCNGAYTGG & \multirow{2}{*}{ R. Cowie, pers. comm., 2013} \\
\hline & GWVIYPR & GGNTGGGTNATHTAYCCN & \\
\hline
\end{tabular}

* indicates the addition of an EcoR1 restriction enzyme sequence.

F: forward

R: reverse

included for every qPCR.

qPCR consisted of an initial enzyme activation step at $98^{\circ} \mathrm{C}$ for $3 \mathrm{~min}$, followed by 40 cycles of denaturation, annealing and extension. Denaturation was run at $98^{\circ} \mathrm{C}$ for $10 \mathrm{~s}$. The annealing step occurred at one of 8 different temperatures $\left(45.0^{\circ} \mathrm{C}\right.$, $\left.45.5^{\circ} \mathrm{C}, 46.6^{\circ} \mathrm{C}, 48.1^{\circ} \mathrm{C}, 50.1^{\circ} \mathrm{C}, 51.7^{\circ} \mathrm{C}, 52.6^{\circ} \mathrm{C}, 53.0^{\circ} \mathrm{C}\right)$ and was held for $30 \mathrm{~s} . \mathrm{A} 1$ min extension ran at $72^{\circ} \mathrm{C}$, followed by a fluorescence read $\left(\lambda_{\max }=520 \mathrm{~nm}\right)$. qPCR results were plotted using the CFX Manager ${ }^{\mathrm{TM}}$ Software (version 3.1; Bio-Rad, USA), with the SYBR autofluorescence threshold limit set to 200 relative fluorescence units (RFU).

The taxa identified from samples of Antarctic sea-ice bacteria were examined for the presence of the PR gene. PR-qPCR were run in triplicate using P. torquis and 31A8 as positive controls (see Section 2.3.5). Reactions were prepared following the method outlined above, and cycling conditions are the same as for gradient qPCR, using only the optimum annealing temperature $\left(48.1^{\circ} \mathrm{C}\right)$. Melt curve profiles were constructed, comparing the $\mathrm{qPCR}$ amplification products of each isolate against the positive controls, with the SYBR autofluorescence threshold limit set to a change of 100 RFU.

\subsubsection{Restriction fragment length polymorphism profiling}

$5 \mu \mathrm{L}$ of $16 \mathrm{~S}$ rRNA amplification product was added to a solution of $1 \mu \mathrm{L}$ Fermentas TaqI $\left(10 \mathrm{U} / \mu \mathrm{L}, 3000 \mathrm{U}\right.$, recognition site: $\left.\mathrm{T}^{\wedge} \mathrm{CGA}\right)$ restriction enzyme (Thermo Scientific, USA), $1 \mu \mathrm{L}$ Fermentas TaqI buffer (Thermo Scientific, USA) and $3 \mu \mathrm{L}$ UltraPure $^{\mathrm{TM}} \mathrm{H}_{2} \mathrm{O}$. RFLP reactions were incubated at $65^{\circ} \mathrm{C}$ for a minimum of 3 hours. 
$10 \mu \mathrm{L}$ of each RFLP product, along with $3 \mu \mathrm{L}$ of $1 \mathrm{~kb}$ Plus DNA Ladder was loaded onto a $2.0 \%(\mathrm{w} / \mathrm{v})$ MetaPhor $^{\mathrm{TM}}$ agarose electrophoresis gel (Lonza, Switzerland). Electrophoresis was run at $90 \mathrm{~V}$ in TBE buffer at room temperature for 2 hours. The gel was stained for $15 \mathrm{~min}$ in a $0.01 \%$ ethidium bromide solution, before destaining in TBE for $5 \mathrm{~min}$. The gel was then visualised and photographed, under the same conditions as 16S rRNA amplification product electrophoresis gels.

\subsubsection{Growth curves}

The growth patterns of each identified species was investigated. $20 \mathrm{~mL}$ stock cultures were grown to log-phase at $12^{\circ} \mathrm{C}$, rotating at $70 \mathrm{rpm}$, under 5-20 $\mu \mathrm{mol}$ photons $\mathrm{m}^{-2} \mathrm{~s}^{-1} .100 \mu \mathrm{L}$ of stock culture was used to inoculate $10 \mathrm{~mL}$ of sterile MB or $10 \% \mathrm{MB}$, in $15 \mathrm{~mL}$ Corning $^{\mathrm{TM}}$ Pyrex $^{\mathrm{TM}}$ glass screw cap culture tubes (Fisher Scientific, USA). All cultures were grown under the previously described incubation conditions, in triplicate, for 150 hours, along with duplicate negative controls (uninoculated media samples). As bacterial abundance in suspension typically forms a linearly proportional relationship with absorbance (Koch, 1968), the absorbance of each sample was measured as a proxy for biomass. Absorbance measurements were made at $590 \mathrm{~nm}$, using a Jenway Genova Life Science Analyser (Bibby Scientific, UK) spectrophotometer, and an un-inoculated sample of each media was used for calibration. Following incubation, all samples were streak-plated and incubated on MA in order to confirm that samples remained free of contamination.

\subsubsection{Statistical Analysis}

The statistical methods used by Zwietering et al. (1990), Wang and Bushman (2006) and Chase and Harwood (2011) were adapted to quantify the bacterial growth patterns observed. This examined the duration of the lag-phase, the rate of bacterial growth (the gradient of the exponential phase) and the maximum biomass (the height of the log-phase). Initial analyses and graph construction was performed using GraphPad Prism ${ }^{\circledR}$ (version 5.01, 2007), and factorial analysis of variance (ANOVA) tests were conducted in $\operatorname{IBM}^{\circledR}$ SPSS $^{\circledR}$ Statistics (version 20, 2011).

In order to ensure that the negative controls remained free of growth, linear regressions were plotted against each negative control data series and a runs test was performed to determine whether the slope of this line deviated from zero. A repeated measures (mixed model) two-way ANOVA, with a Bonferroni post-hoc test was used to determine if and when a treatment deviated from its respective negative 
control. The lag-phase ended when the growth curve consistently deviated from the negative control, to at least a $99 \%$ confidence level.

The growth of each culture was plotted against a logistic model based on the following equation:

$$
y=\frac{y_{m} \times y_{0}}{\left(y_{m}-y_{0}\right) e^{b x}+y_{0}}
$$

where $y_{m}=$ maximum cellular growth $(\mathrm{abs} \mathrm{cm}-1), y_{0}=$ minimum cellular growth and $b=$ the exponential line slope (the rate of cellular growth). If necessary, lag- or $\log$-phases were either trimmed or extended in order to gain the most accurate fit $\left(\mathrm{R}^{2}\right)$.

Two-way factorial ANOVA tests were used to assess the effect of species and media (plus any interaction effect) on the $y_{m}$ and $b$ values. Scheffe post-hoc tests were used (due to differences in group size) to determine differences between samples. Finally, all $b$ values were transformed into mean generation times (MGT) using the following equation (Powell, 1956):

$$
\begin{array}{ll}
y=a e^{b x} & \mu=k \times 0.693 \\
k=\frac{b}{0.301} & \text { MGT }=\frac{0.693}{\mu}
\end{array}
$$

\subsubsection{Storage of bacterial isolates}

For use in future culture-based studies, all isolates were cryopreserved. $1.5 \mathrm{~mL}$ of log-phase broth culture was centrifuged at 13,000 xg for $15 \mathrm{~min}$ and the supernatant was discarded. The pellet was resuspended in $1.5 \mathrm{~mL}$ of $\mathrm{MB}$ glycerol mix (Appendix A) and stored at $-80^{\circ} \mathrm{C}$. 


\subsection{Results}

\subsubsection{Bacterial growth and colony morphology}

Full strength MB was the most suitable liquid medium, yielding visible colloidal suspensions from all samples, with the exception of sample $\mathrm{C} 4.10 \% \mathrm{MB}$ sustained growth of samples $\mathrm{C} 34, \mathrm{C}^{*}$ and $\mathrm{C} 73$, though growth was minimal for the later two. In both R2A and SWC media, a minimal amount of growth was visible only in sample C34 (Table 2.3). Negative controls remained free of visible growth. Sample $\mathrm{C}^{*}$ formed bright orange colonies, following 15 days of incubation on MA. When samples $\mathrm{C} 1, \mathrm{C} 1^{*}$ and $\mathrm{C} 73$ were grown on MA, these all formed circular, off-white colonies, with a pearlescent shine, after 22 days of incubation. As with the liquid media samples, C4 did not grow on MA plates. See Supplementary Table 1 for full colony morphology descriptions.

Sample C34 was the fastest growing sample, producing colonies after 9 days of incubation on MA. Initial colonies were circular, off-white in colour with a pearlescent shine. However, after another 5 days of incubation, colonies of various shades of orange were also evident (Fig. 2.1A). In total, 6 isolates were recovered (in duplicate) from sample C34. After 7 days of growth on MA plates, isolate 1 formed many large ( $\sim 1 \mathrm{~mm}$ ), off-white colonies with a pearlescent shine. Isolates $2-5$ all showed similar growth patterns, producing a relatively high number of small $(\sim 0.5-1 \mathrm{~mm})$ colonies, however 2 different colours were identified. Isolates 2 and 5 formed bright

Table 2.3: Growth of bacterial samples under different media conditions.

\begin{tabular}{c|ccccc}
\hline \hline Sample & MB & $\mathbf{1 0} \% \mathbf{M B}$ & R2A & SWC & MA \\
\hline $\mathrm{C} 1$ & + & - & - & - & + \\
$\mathrm{C} 1{ }^{*}$ & + & - & - & - & + \\
$\mathrm{C} 4$ & - & - & - & - & - \\
$\mathrm{C} 4$ & ++ & + & - & - & ++ \\
$\mathrm{C} 34$ & ++ & ++ & + & + & ++ \\
$\mathrm{C} 73$ & + & + & - & - & + \\
\hline \\
$-=$ \\
$+=$ no growth \\
$++=$ strong growth
\end{tabular}




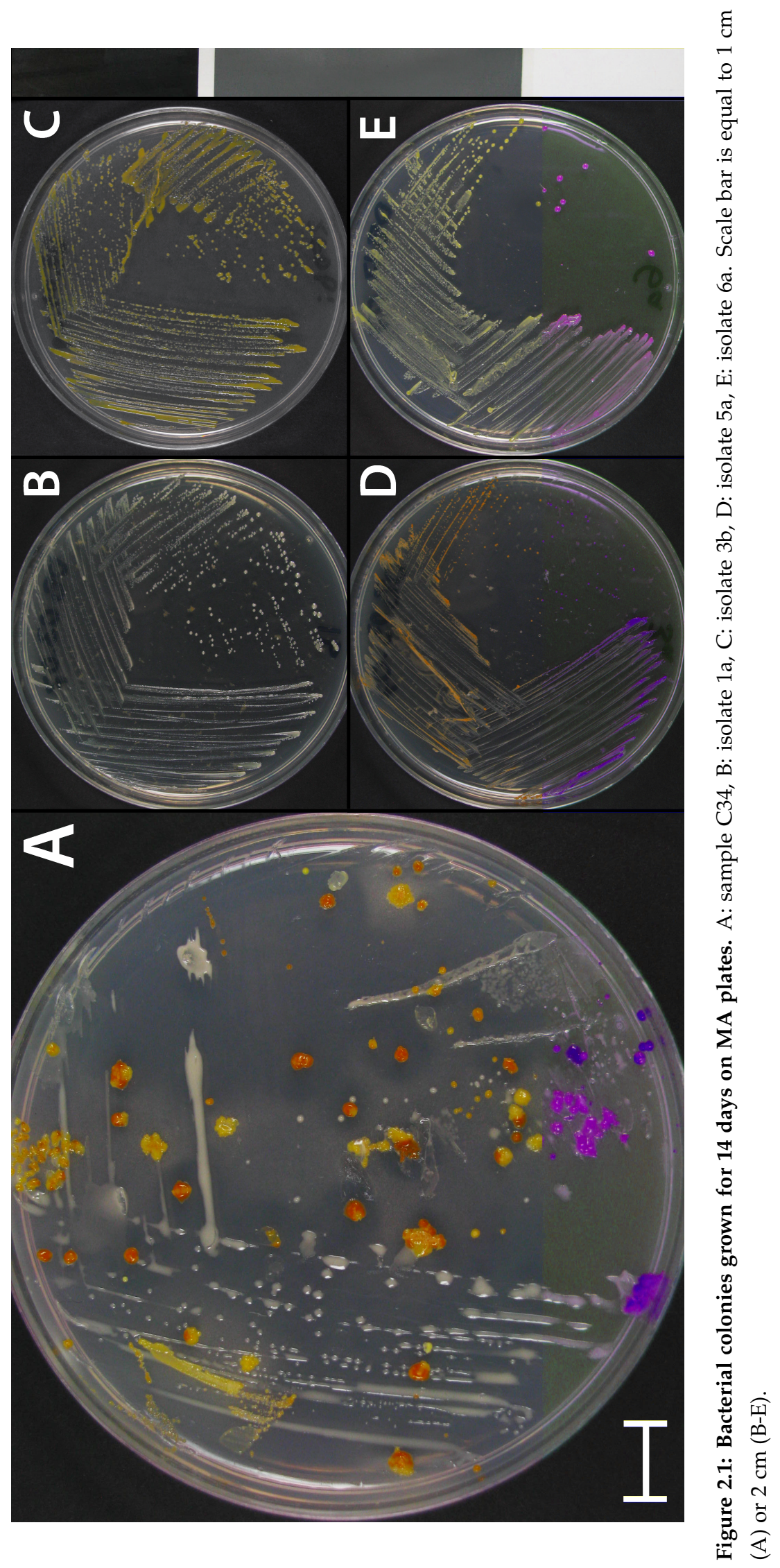


Chapter 2: Identification and Investigation of Cultured Antarctic Sea-ice Bacteria

Table 2.4: Colony morphology of bacterial isolates originating from sample C34.

\begin{tabular}{c|cccccc}
\hline \hline Isolate & Colour & Texture & Form & Elevation & Margin & Size (mm) \\
\hline 1a & Off-white, pearl & Glossy & Circular & Convex & Entire & $\geq 2$ \\
1b & Off-white, pearl & Glossy & Circular & Convex & Entire & $1-2$ \\
2a & Bright orange & Glossy & Punctiform & Pulvinate & Lobate & $0.5-1$ \\
2b & Bright orange & Glossy & Punctiform & Pulvinate & Entire & $0.5-1$ \\
3a & Dark orange & Glossy & Circular & Pulvinate & Entire & $0.5-1$ \\
3b & Dark orange & Glossy & Circular & Convex & Entire & $\leq 0.5$ \\
4a & Dark orange & Glossy & Circular & Pulvinate & Entire & $0.5-1$ \\
4b & Dark orange & Glossy & Circular & Pulvinate & Entire & $1-2$ \\
5a & Bright orange & Glossy & Punctiform & Pulvinate & Entire & $1-2$ \\
5b & Bright orange & Glossy & Punctiform & Pulvinate & Lobate & $0.5-1$ \\
6a & Pale yellow & Matt & Punctiform & Pulvinate & Entire & $\leq 0.5$ \\
6b & Pale yellow & Matt & Punctiform & Pulvinate & Entire & $\leq 0.5$ \\
\hline
\end{tabular}

orange colonies (visually identical to those in sample $\mathrm{C} 4^{*}$ ), whereas isolates 3 and 4 were a much darker shade of orange and produced a clear area in the agar surrounding each colony (Fig. 2.1A). Isolates 4 and 5 grew in close proximity to each other, despite their distinctly different colouring. Isolate 6 was extremely slow growing, yielding only a few bright yellow colonies, all $\leq 0.5 \mathrm{~mm}$. Each isolate is described in Table 2.4 and photographs of phenotypically distinct isolates are show in Figure 2.1B-E.

\subsubsection{Biochemical tests and cellular morphology}

\section{Gram stains}

Samples $\mathrm{C} 1, \mathrm{C}^{*}$, C73 and isolate 1 were all Gram-negative cocci. Sample C4*, as well as isolates 2 and 5 were Gram-negative long filamentous bacilli. Isolates 3 and 4 formed clusters of Gram-negative cocci, that ranged from dipilo- to staphylococci morphologies. Isolate 6 was the only Gram-positive bacteria, forming groups of coccoid tetrads (Table 2.5; Sup. Table 2).

\section{Oxidase and catalase reactions}

All samples and isolates were both oxidase and catalase positive. 
Table 2.5: Cellular morphology of bacterial isolates originating from sample C34. Size is given in width $\times$ length of an individual cell.

\begin{tabular}{c|ccc}
\hline \hline Isolate & Gram stain & Cell type & Size $(\boldsymbol{\mu m})$ \\
\hline $1 \mathrm{a}$ & - & Coccus & $1 \times 1$ \\
$1 \mathrm{~b}$ & - & Coccus & $1 \times 1$ \\
$2 \mathrm{a}$ & - & Curled filament & $1 \times$ varied \\
$2 \mathrm{~b}$ & - & Curled filament & $2 \times$ varied \\
$3 \mathrm{a}$ & - & Clustered cocci & $2 \times 2$ \\
$3 \mathrm{~b}$ & - & Clustered cocci & $2 \times 2$ \\
$4 \mathrm{a}$ & - & Clustered cocci & $2 \times 2$ \\
$4 \mathrm{~b}$ & - & Clustered cocci & $2 \times 2$ \\
$5 \mathrm{a}$ & - & Curled filament & $1 \times$ varied \\
$5 \mathrm{~b}$ & - & Curled filament & $2 \times$ varied \\
$6 \mathrm{a}$ & + & Coccoid tetrad & $1 \times 1$ \\
$6 \mathrm{~b}$ & + & Coccoid tetrad & $1 \times 1$ \\
\hline$-=$ negative & & & \\
$+=$ positive & & &
\end{tabular}

\subsubsection{S rRNA gene amplification and phylogenetic analysis}

$16 \mathrm{~S}$ rRNA gene amplification was successful in samples $\mathrm{C} 1, \mathrm{C} 1^{*}, \mathrm{C} 4^{*}$ and $\mathrm{C} 73$, as well as isolates 1, 3, 4 and 6, all producing bright electrophoresis bands at $\sim 1500$ bp (Fig. 2.2 $\mathrm{A}_{i}, \mathrm{~A}_{i i}$ ). Under normal conditions, isolates 2 and 5 produced very little to no amplification product (Fig. 2.2 $\mathrm{A}_{i i}$ ). Re-amplified of these isolates, using $16 \mathrm{~S} 1391^{R}$ as an alternative reverse primer also yielded minimal amplification product (Fig. 2.2B), however strong amplification was achieved using the alternative lysing method (Fig. 2.2C).

The 16S rRNA gene sequences of samples $\mathrm{C} 1, \mathrm{C} 1{ }^{*}$ and $\mathrm{C} 73$ clustered within the Gammaproteobacteria, showing $99.6-100 \%$ sequence similarity to Psychrobacter nivimaris (Table 2.6A). Sample $\mathrm{C}^{*}$ had $97.1-98.1 \%$ sequence similarity to Polaribacter dokdonensis, a member of the Flavobacteriaceae (Table 2.6C). 16S rDNA sequencing revealed four distinct species from sample C34. Isolate 1 clustered closely with samples $\mathrm{C} 1, \mathrm{C} 1^{*}$ and $\mathrm{C} 73$, showing $99.7-100 \%$ sequence similarity to Ps. nivimaris (Table 2.6A). Isolates 3 and 4 grouped with the Alphaproteobacterium, Paracoccus marcusii 

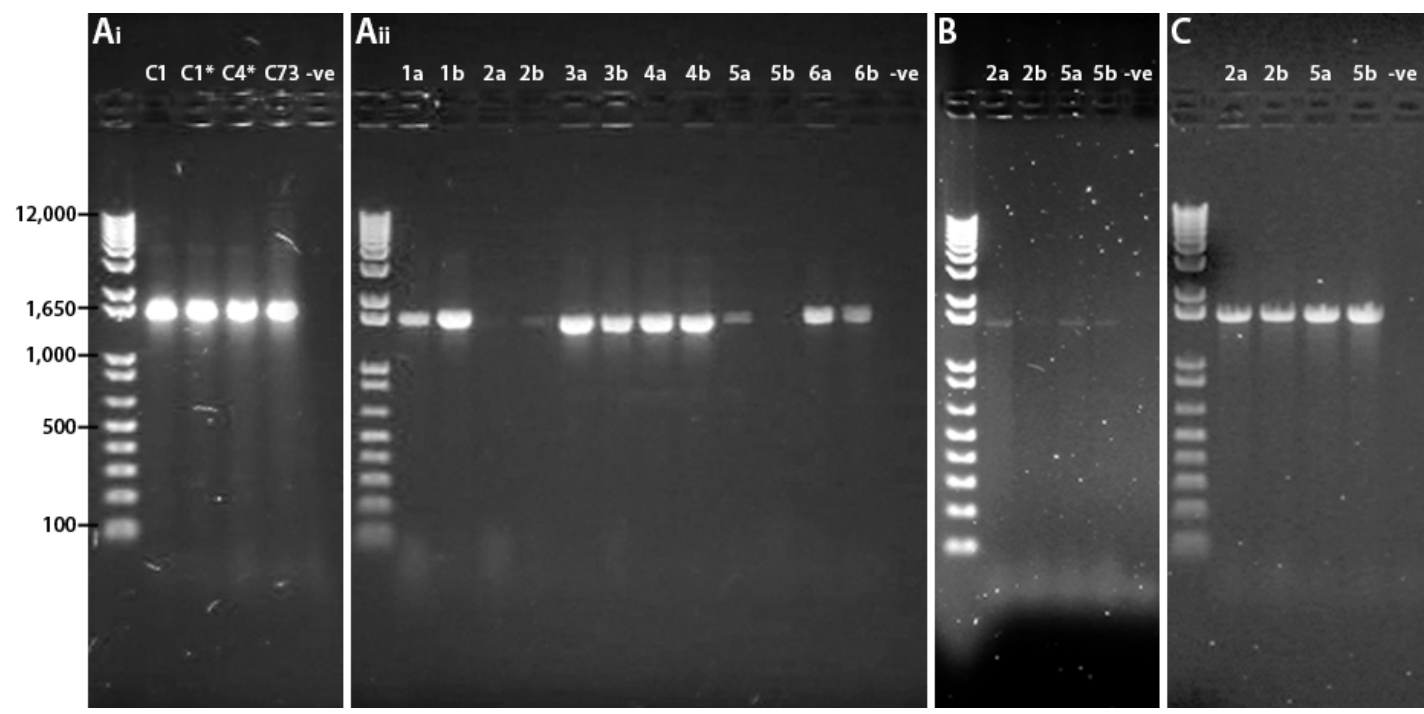

Figure 2.2: Electrophoresis gel showing 16s rRNA gene amplification bands. $A_{i}$ and $A_{i i}$ show amplification results using the standard amplification protocol; $\mathrm{B}$, amplification results using the alternate reverse primer $\left(16 \mathrm{~S} 1391^{\mathrm{R}}\right)$; C, amplification results using the modified lysing protocol. Bp positions of $1 \mathrm{~kb}$ Plus DNA Ladder are shown.

(97.7-100\% and $97.9-100 \%$ respective sequence similarities; Table 2.6B). Isolates 2 and 5 had $96.6-98.1 \%$ and $97.0-98.1 \%$ sequence similarity, respectively to Po. dokdonensis, clustering closely with sample $\mathrm{C}^{*}$ (Table 2.6C). Finally, isolate 6 grouped within the Gram-positive Actinobactium genus Micrococcus, sharing 99.6-99.9\% sequence similarity with $M$. antarcticus and 98.49-98.73 sequence similarity with $M$. luteus (Table 2.6D).

Four phylogenetic trees were constructed, grouping samples within the Gammaproteobacteria, the Alphaproteobacteria, the Bacteroidetes or the Actinobacteria (Fig. 2.3A-D). No major differences were observed between tree construction methods, thus the dendrograms presented in Figure 2.3A-D were built using neighbourjoining algorithms, with bootstrap values calculated through the majority rule extended method.

\subsubsection{Restriction fragment length polymorphism analysis}

RFLP profiles were created (in duplicate) for the four phylotypes identified through 16S rDNA sequencing; isolates 1, 2, 3 and 6. Each phylotype created a unique profiles consisting of 3-5 distinct bands ranging from $\sim 75-925 \mathrm{bp}$ in length (Sup. Fig. 2). 


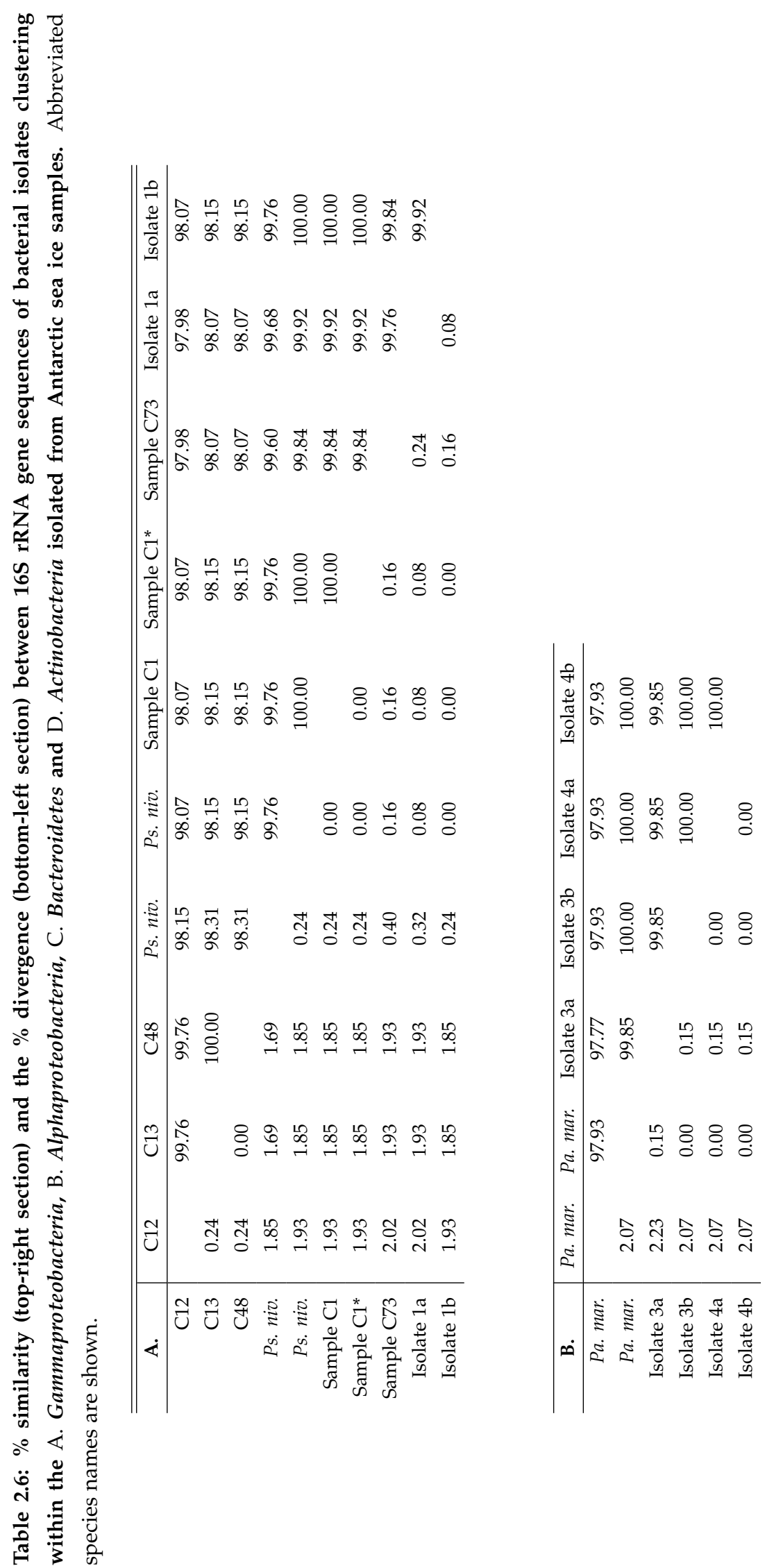




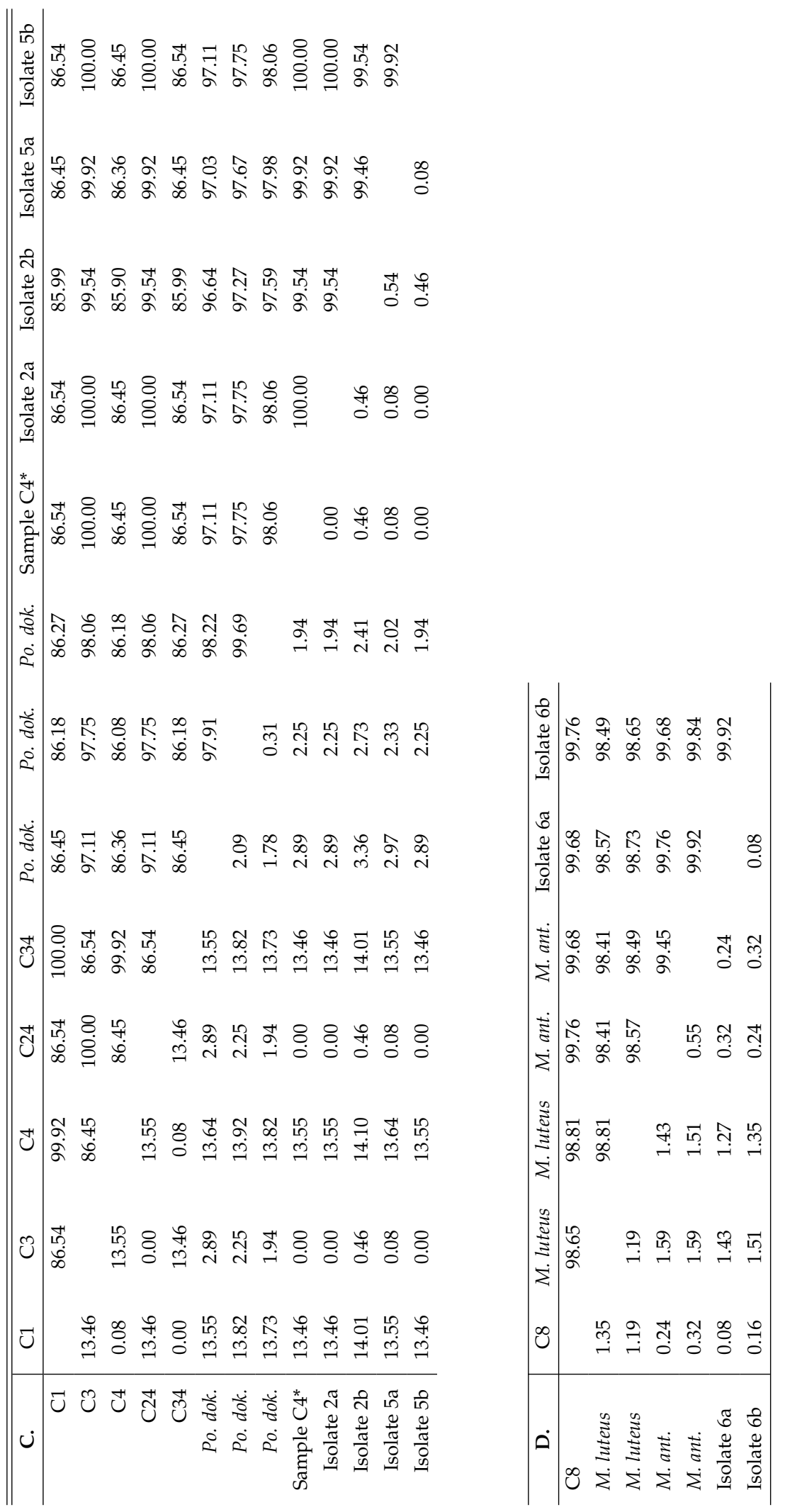




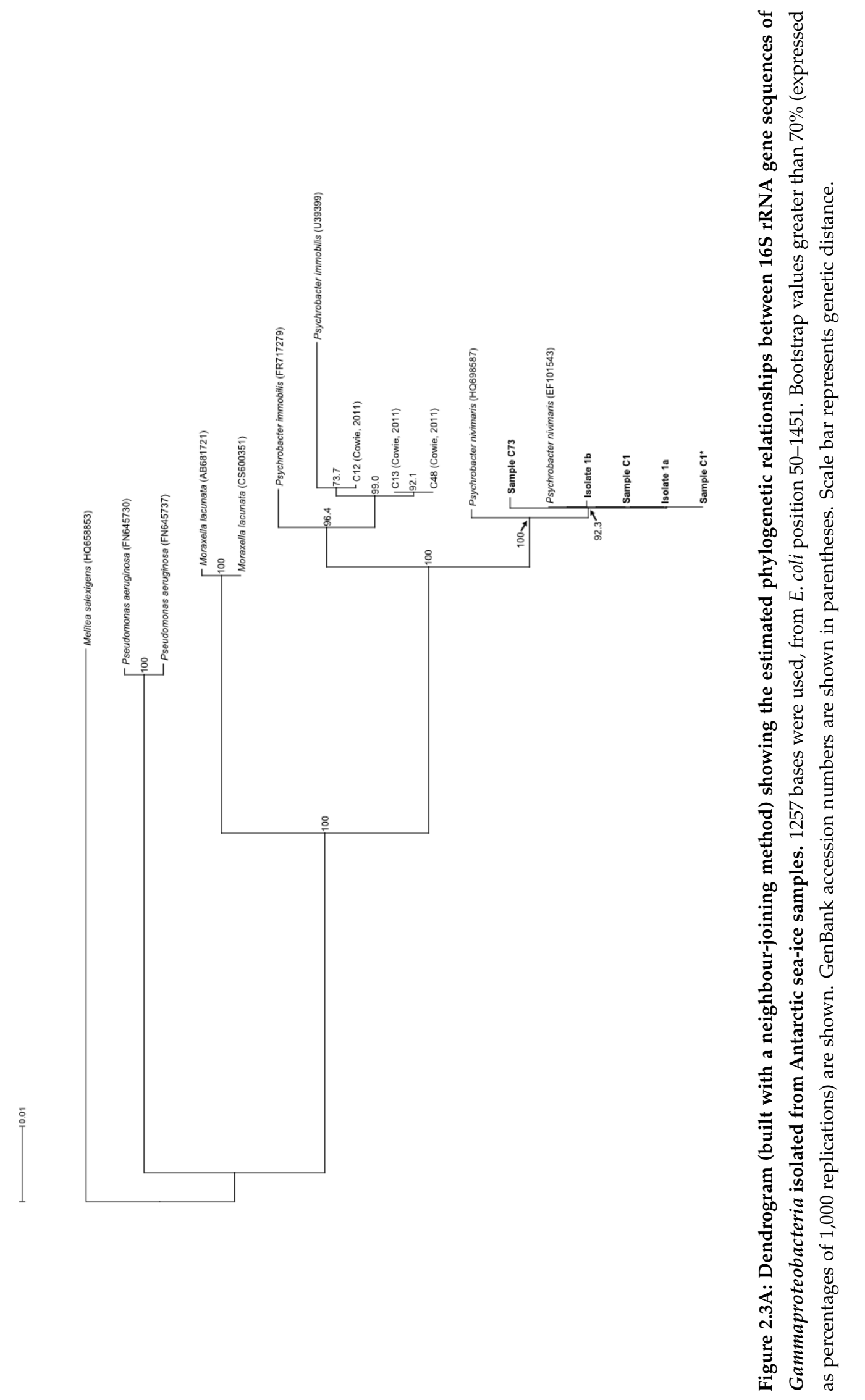




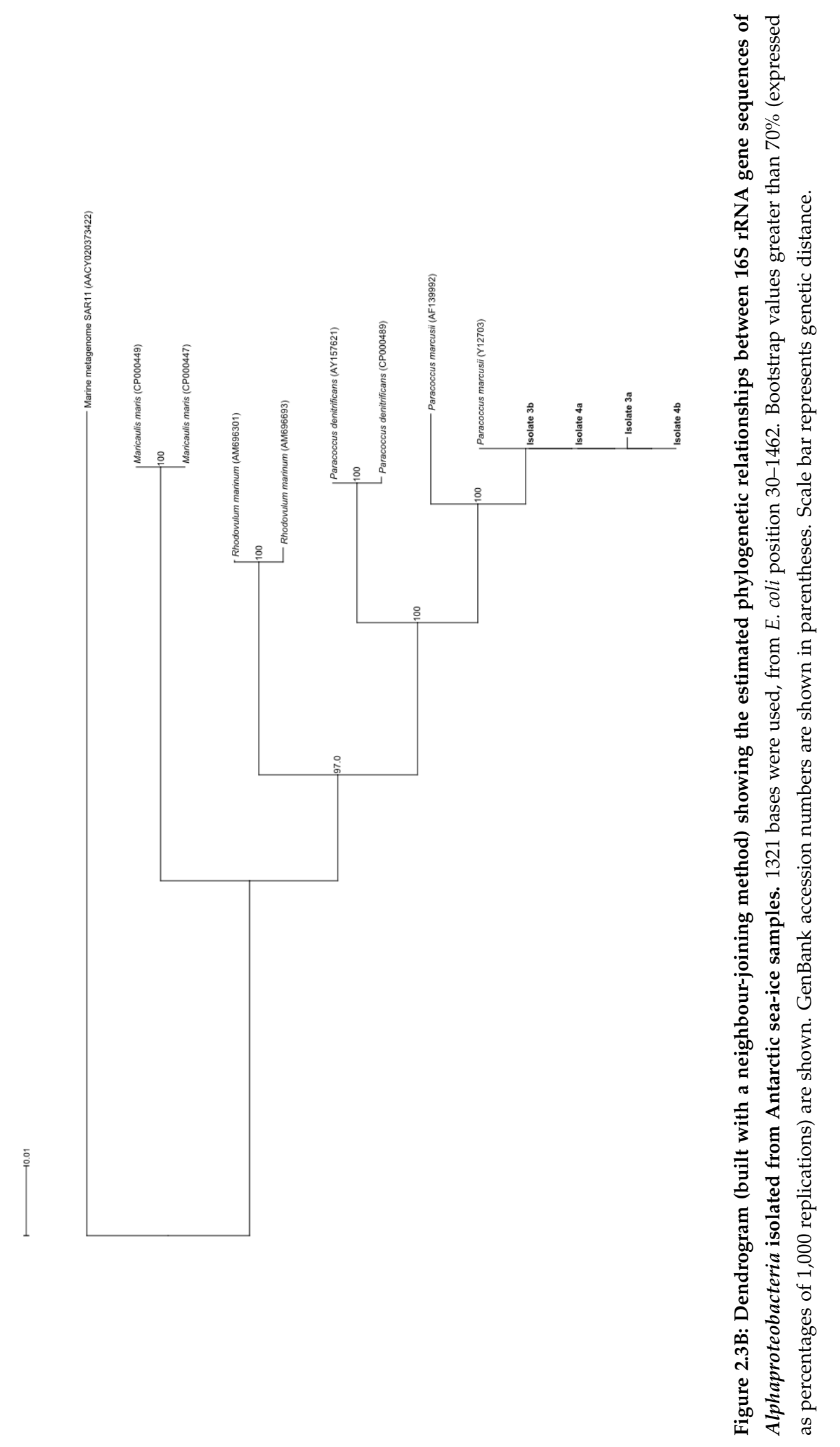




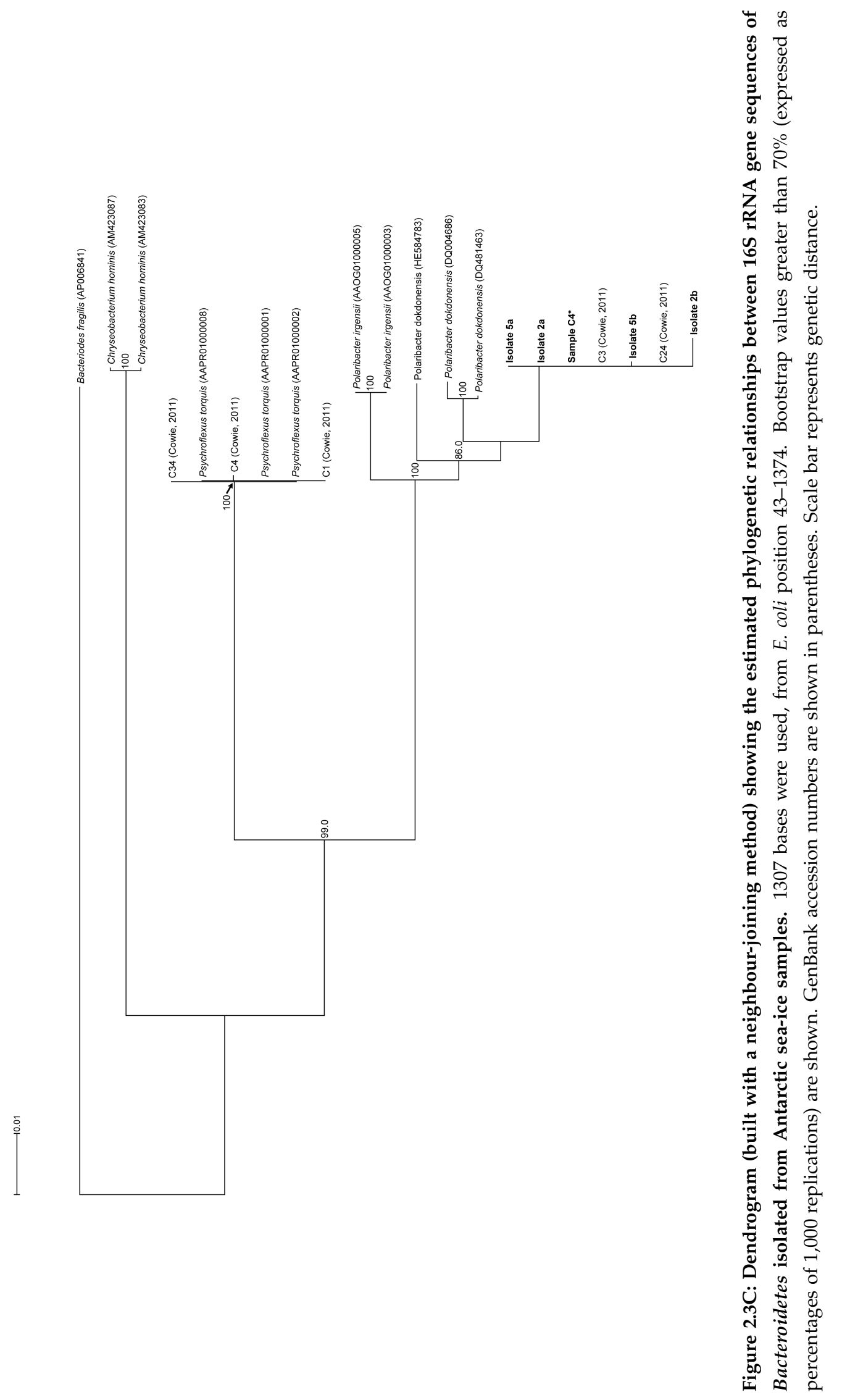




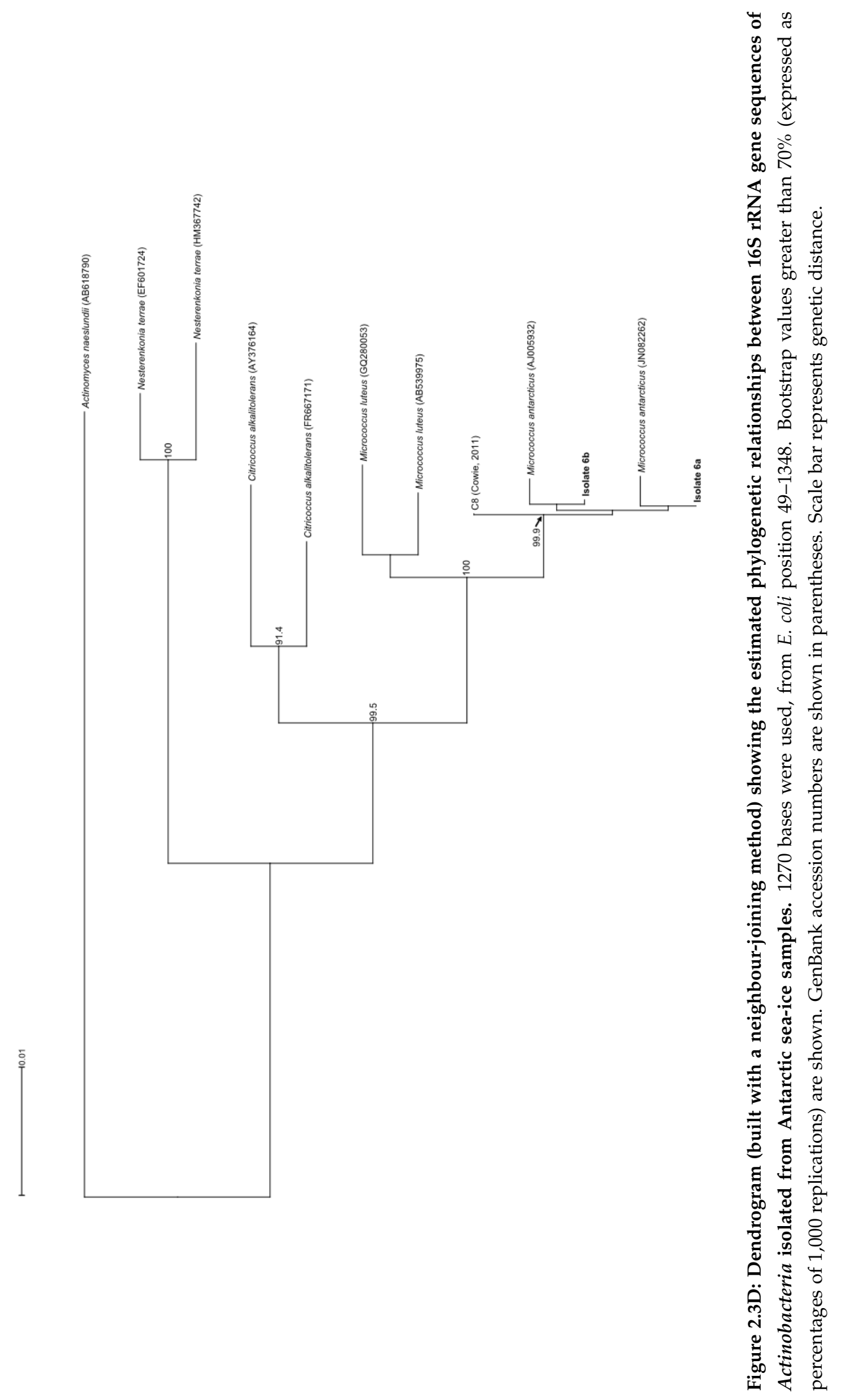




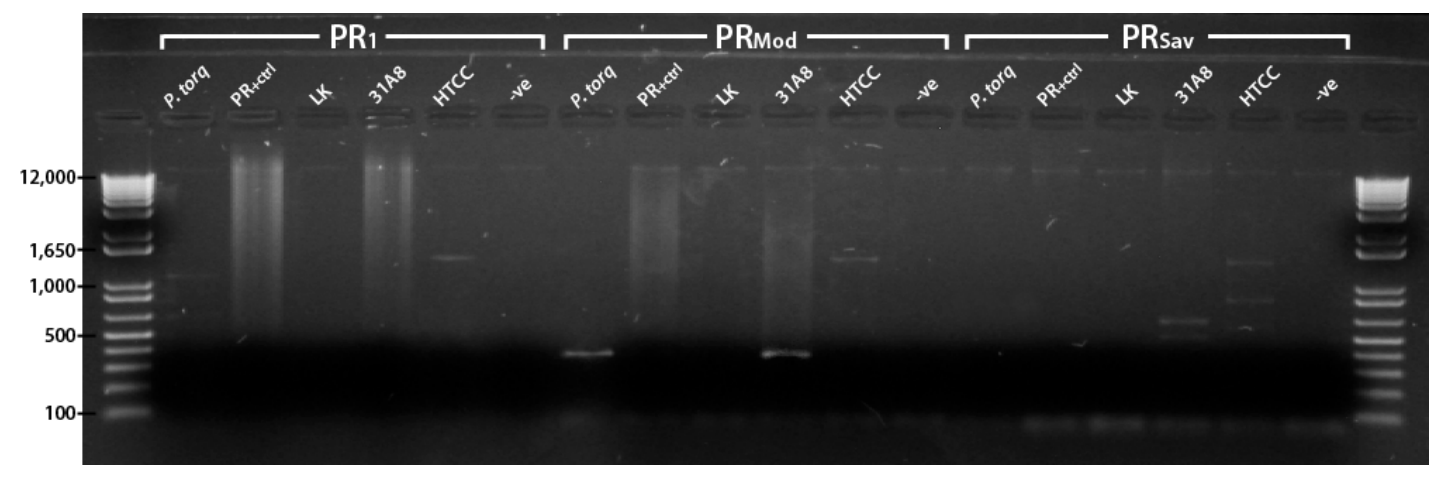

Figure 2.4: Electrophoresis gel showing PR gene amplification bands. Gel is divided into sections for each primer set used. Abbreviated species names are shown. Bp positions of $1 \mathrm{~kb}$ Plus DNA Ladder are shown.

\subsubsection{PR gene amplification}

\section{DNA extraction}

All preparations of DNA template using the phenol-chloroform extraction method were successful, with DNA concentrations varying from $0.360-89.862 \mathrm{ng} / \mu \mathrm{L}$ (Sup. Table 3). P. torquis replicate $\mathrm{b}$ and both replicates of $\mathrm{Pa}$. marcusii yielded less than $10 \mathrm{ng} / \mu \mathrm{L}$ of DNA, and consequently were not diluted.

\section{PCR optimisation}

PR rRNA gene amplification was successful using primer set $\mathrm{PR}_{\text {Mod }}$, however no amplification was achieved using either the $\mathrm{PR}_{1}$ or the $\mathrm{PR}_{\text {sav }}$ primer sets. Of the known PR-positive samples, PR rRNA gene amplification was only achieved using gDNA extracts from $P$. torquis and sample 31A8, with electrophoresis bands observed at $\sim 400$ bp (Fig. 2.4). Several other faint bands were observed, however these were deemed to be artefacts (as discussed in Section 2.4). Using an annealing temperature gradient qPCR, the earliest amplification for both 31A8 (19.8 cycles) and P. torquis (30.95 cycles) occurred at $48.1^{\circ} \mathrm{C}$ (Sup. Fig. 1; Sup. Table 4). This was deemed to be the optimum annealing temperature, and hence was used for all subsequent PR-qPCRs.

\section{qPCR of the PR gene}

Samples 31A8, P. torquis, Ps. nivimaris and Po. dokdonensis yielded positive PR gene amplification. The melt curve data supports this, with the amplification products of 31A8, P. torquis and Po. dokdonensis all melting at $79^{\circ} \mathrm{C}\left( \pm 1^{\circ} \mathrm{C}\right)$. Ps. nivimaris differs slightly from this, melting at $83^{\circ} \mathrm{C}$ (Fig. 2.5; Sup. Table 5). Although Pa. marcusii showed a similar melting range $\left(80.2^{\circ} \mathrm{C}\right)$, a very low yield of PCR product 


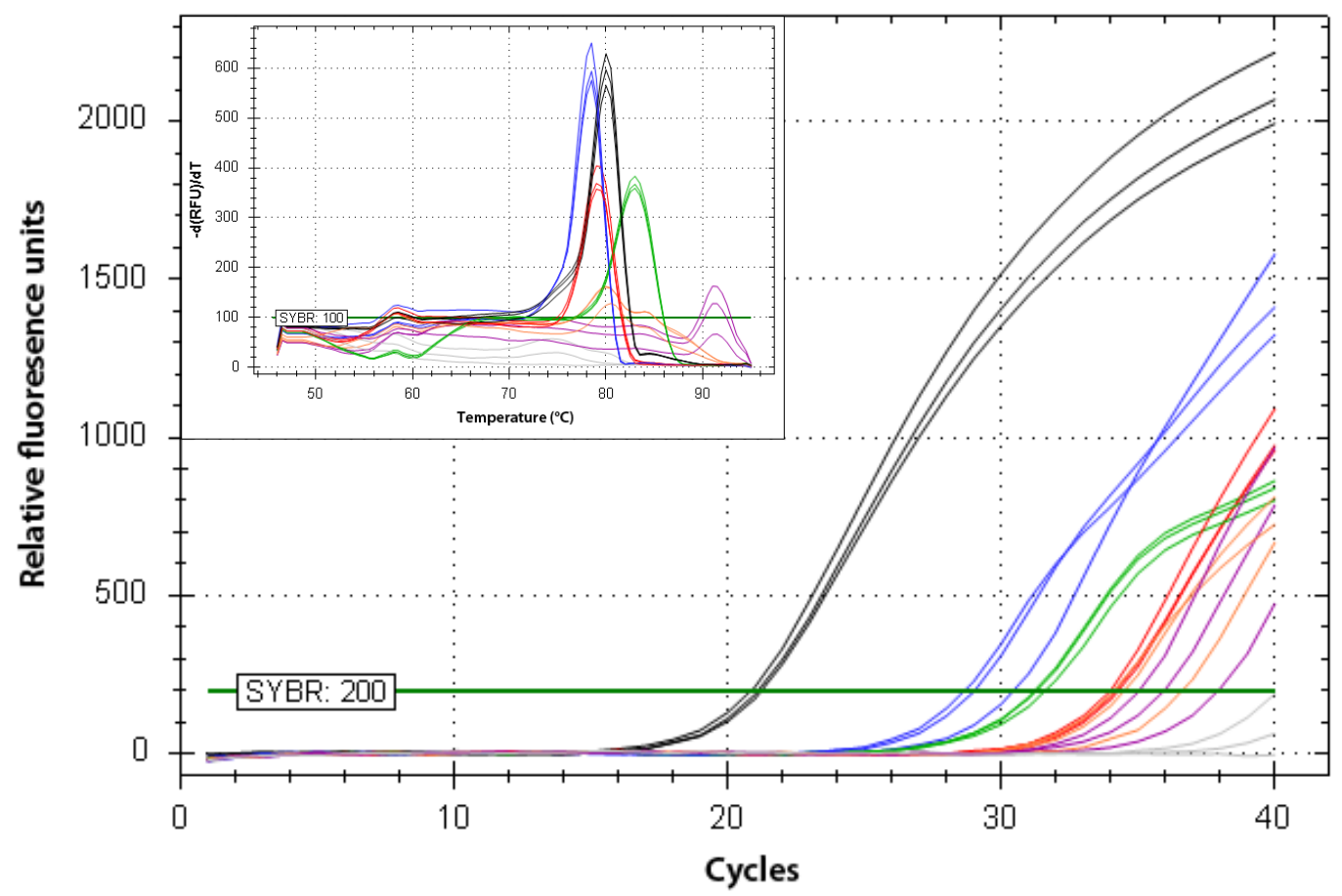

Figure 2.5: qPCR PR gene amplification. Melt curves profiles of each amplification product are presented in the insert. Sample 31A8 is shown in black, P. torquis red, Ps. nivimaris green, Po. dokdonensis blue, Pa. marcusii orange, Micrococcus sp. purple, and negative controls are in grey. All replicates are shown. SYBR autofluorescence threshold limit is set to 200 relative fluorescence units (RFU) in the PR gene amplification plot, and a change of $100 \mathrm{RFU}[-\mathrm{d}(\mathrm{RFU}) / \mathrm{dT}]$ for the melt curve profile insert.

was produced after $\sim 35$ cycles (Fig. 2.5; Sup. Table 5). Similarly, Micrococcus sp. yielded very low volumes of product, and did not begin to amplify until 36 cycles. In contrast to the other products, the melt profile of Micrococcus sp. was dramatically higher $\left(91^{\circ} \mathrm{C}\right.$; Fig. 2.5; Sup. Table 5).

\subsubsection{Growth curves}

Positive growth occurred in all samples over the 150 hour incubation. Neither the mean (MB: $M=0.004, S E=<0.001 ; 10 \% \mathrm{MB}: M=0.003, S E=0.001$ ) nor the line slope (MB: $F^{1,22}=2.099, p=0.162 ; 10 \% \mathrm{MB}: F^{1,22}=1.143, p=0.297$; Fig 2.6) of either negative control differed from zero. Plate streaking revealed replicate $b$ of $P_{s}$. nivimaris, grown in $10 \% \mathrm{MB}$ to contain a fungal contaminant, therefore this sample was excluded from all further analyses. The logistic model showed an extremely strong fit to all data sets, with all $\mathrm{R}^{2}$ values being $>0.95$ (Table 2.7). 


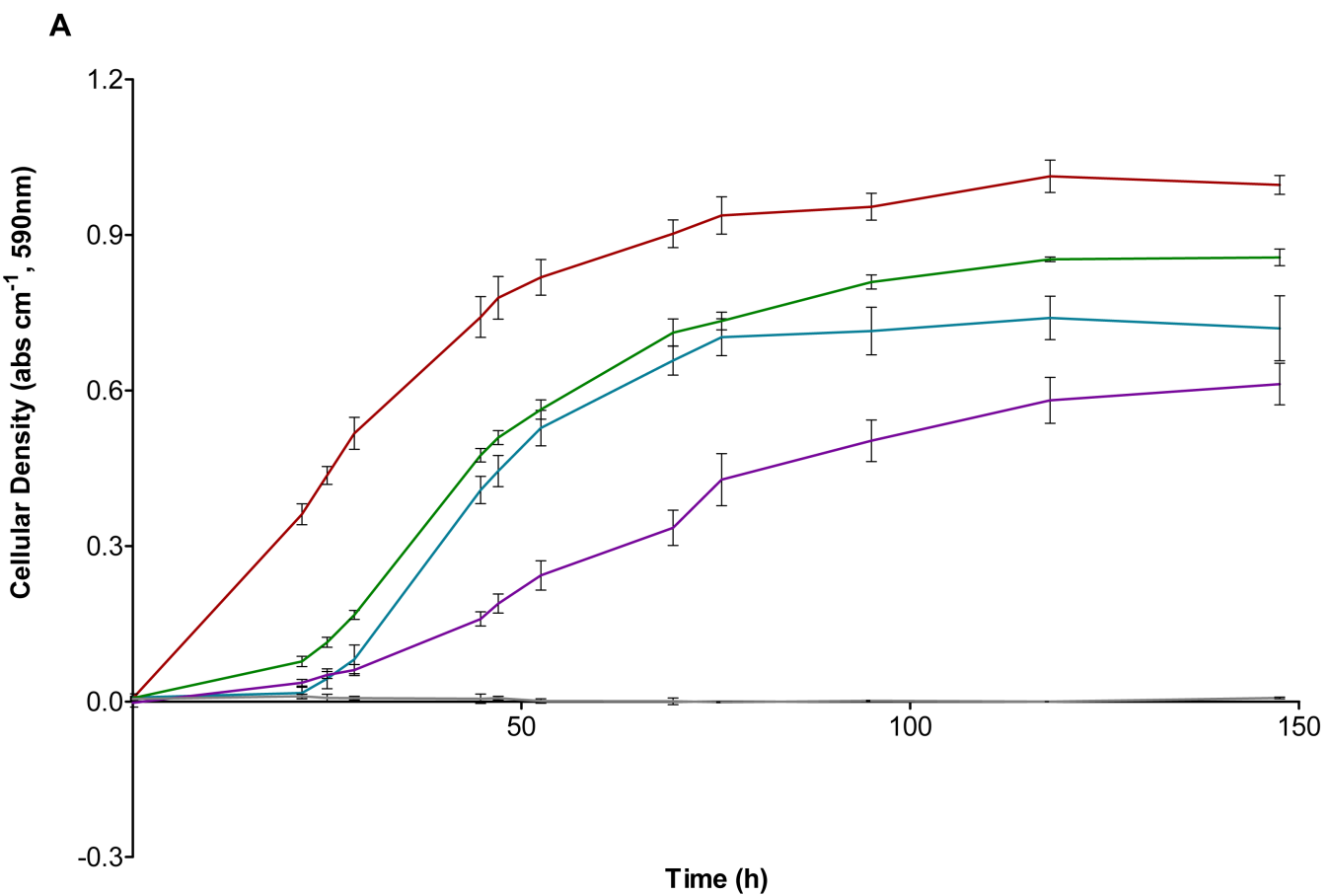

B

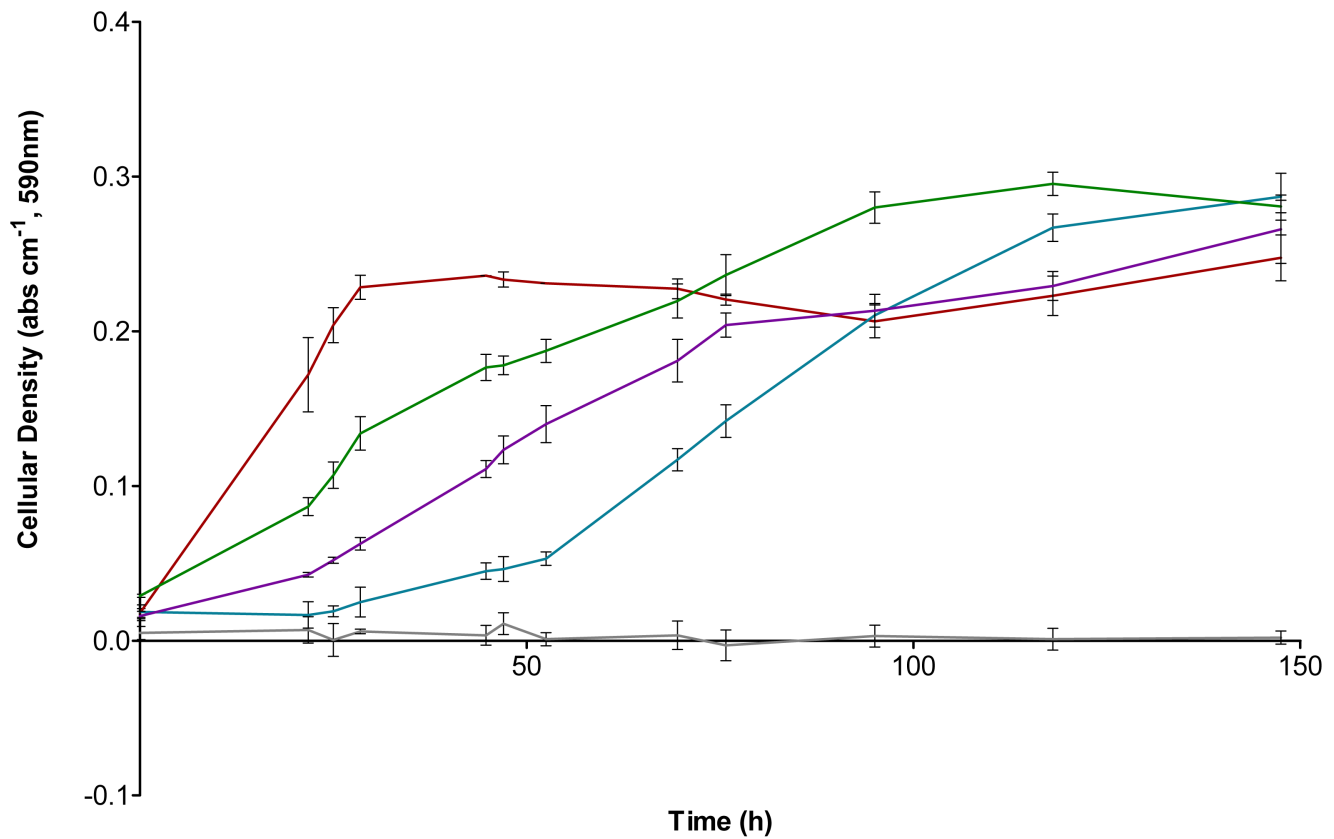

Figure 2.6: Mean growth curves of Antarctic sea-ice bacteria isolates grown in: A. full strength MB and B. $\mathbf{1 0} \%$ MB. Ps. nivimaris is shown in red, Po. dokdonensis blue, Pa. marcusii green, Micrococcus sp. purple, and negative controls are in grey. Error bars represent standard errors. 
Table 2.7: Variables derived from growth curve experiments. Values are means of data fitted to the logistical model, with standard errors in parentheses. Abbreviated species names are shown.

\begin{tabular}{|c|c|c|c|c|c|c|c|c|}
\hline Media & Species & $\mathbf{n}$ & df & $\mathbf{R}^{2}$ & Lag (h) & $Y_{m}\left(\right.$ abs cm $\left.{ }^{-1}\right)$ & $b\left(\mathrm{abs} \mathrm{cm} \mathrm{cm}^{-1}\right)$ & MGT (h) \\
\hline \multirow{4}{*}{ MB } & Ps. niv. & 3 & 9 & 0.987 & 21.75 & $0.972(0.013)$ & $0.008(<0.001)$ & 38.2 \\
\hline & Po. dok. & 3 & 9 & 0.995 & 44.75 & $0.713(0.024)$ & $0.013(<0.001)$ & 22.5 \\
\hline & Pa. mar. & 3 & 9 & 0.991 & 28.5 & $0.821(0.007)$ & $0.009(<0.001)$ & 33.3 \\
\hline & Microc. & 3 & 8 & 0.993 & 44.75 & $0.607(0.026)$ & $0.006(<0.001)$ & 52.8 \\
\hline \multirow{4}{*}{$10 \% \mathrm{MB}$} & Ps. niv. & 2 & 9 & 0.967 & 21.75 & $0.229(0.005)$ & $0.029(0.010)$ & 10.2 \\
\hline & Po. dok. & 3 & 10 & 0.995 & 69.5 & $0.293(0.008)$ & $0.005(<0.001)$ & 56.1 \\
\hline & Pa. mar. & 3 & 8 & 0.977 & 21.75 & $0.294(0.003)$ & $0.004(<0.001)$ & 73.0 \\
\hline & Microc. & 3 & 8 & 0.983 & 44.75 & $0.249(0.009)$ & $0.005(<0.001)$ & 58.7 \\
\hline
\end{tabular}

Regardless of media treatment, $P$ s. nivimaris and Pa. marcusii showed similar lagphases, lasting for $\sim 20-30$ hours. The lag-phases of Po. dokdonensis and Micrococcus sp. were also similar across media strengths, ranging from $\sim 45-55$ hours (Fig. 2.6; Table 2.7).

Media strength had a major effect on the maximum biomass across species $\left(F^{1,15}\right.$ $=2324, p<0.001)$, such that the mean maximum biomass was more than twice as high in full strength $\mathrm{MB}\left(M=0.778 \mathrm{abs} \mathrm{cm}^{-1}, S E=0.041\right)$ than in $10 \% \mathrm{MB}(M=$ $\left.0.270 \mathrm{abs} \mathrm{cm}^{-1}, S E=0.009\right)$. The effect of species $\left(F^{3,15}=47.97, p<0.001\right)$ and the interaction effect $\left(F^{3,15}=58.36, p<0.001\right)$ were both significant, indicating that the media strength affected species differently. This was confirmed by the Scheffe posthoc test, showing that the maximum biomass differed for every species when grown in full strength $\mathrm{MB}(p<0.001)$, as opposed to $10 \% \mathrm{MB}$ where the Po. dokdonensis and Pa. marcusii exhibited only slightly higher biomasses than Ps. nivimaris $(p<0.05$; Fig. 2.6; Sup. Table 6).

In contrast to the maximum biomass, the rate of growth was unaffected by the media concentration $\left(F^{1,15}=1.620, p=0.2225\right)$. Both the species $\left(F^{3,15}=12.93, p=\right.$ $0.0002)$ and the interaction $\left(F^{3,15}=52.75, p<0.0001\right)$ yielded a main effect. Post-hoc tests revealed the rate of growth in Ps. nivimaris grown in $10 \% \mathrm{MB}$ to be significantly higher than all other cultures, regardless of species or media strength $(p<0.001$; Fig. 2.6; Sup. Table 6). 


\subsection{Discussion}

When culturing samples of Antarctic sea-ice bacteria, full strength MB was the most suitable growth media, yielding growth in all samples with the exception of sample C4. Although no growth occurred, that does not necessarily mean no bacteria were present in this sample, rather the conditions investigated in this experiment were not favourable for growth of any species that may be present. There is potential to find bacteria in sample C4 using different incubation conditions, or through culture-independent sequencing techniques.

Using colony morphology and Gram staining, six isolates were separated from within sample C34. Dendrograms comparing the 16S rRNA gene sequences of these isolates confirmed that the initial phenotypic characterisations adequately distinguished different bacterial taxa. Furthermore, the unique RFLP fingerprints created for each isolate mirrored the results of the 16S rRNA gene sequencing. Interestingly, samples obtained from a mixed colony contained both the bright orange isolate 5 (grouping closely with Po. dokdonensis) and the darker orange isolate 4 (grouping with $P a$. marcusii). These two strains were isolated twice (i.e. isolates 2 and 5: Po. dokdonensis, and isolates 3 and 4: $\mathrm{Pa}$. marcusii) due to their tendency to grow in close proximity to one another (Fig. 2.1A).

The majority of the isolates grouped within three dominant Antarctic taxa; the Bacteroidetes, Alpha- and Gamma-proteobacteria. These three groups have also been identified as the dominant bacterial taxa present in Antarctic sea ice regardless of culture-based (Bowman et al., 1997; Staley and Gosink, 1999; Murray and Grzymski, 2007) or culture-independent (Brown and Bowman, 2001; Brinkmeyer et al., 2003; Cowie, 2011) methodology. Isolate 6, grouped within the Actinobacteria genus Micrococcus, a taxon that has also been previously identified in Antarctic sea-ice samples (Liu et al., 2000). The 3\% sequence dissimilarity criterion used in this study is typically indicative of species differentiation (Stackebrandt and Goebel, 1994), however sequence data alone can be misleading. For example Bacillus globisporus and Bacillus psychrophilus share 99.8\% 16S rRNA gene similarity (Fox et al., 1992) despite very low levels (23\%) of DNA-DNA hybridisation similarity that indicate they are separate species (Nakamura, 1984). To confirm the species identifications made thus far, a comparison of the phenotypic information and environmental ranges of genetically similar species were made: 
Ps. nivimaris is formally described as a Gram-negative, oxidase and catalase positive, psychro- and halo-tolerant coccoid which forms circular, cream coloured colonies (Heuchert et al., 2004); features that are all shared by samples C1, C1* , C73 and isolate 1. Ps. nivimaris was first isolated from POM originating from the Southern Ocean (Heuchert et al., 2004), with the Psychrobacter genus being wide spread across the Antarctic environment (Bowman et al., 1997).

Despite being initially isolated from the seawaters of Korea and growing optimally at $25-28^{\circ} \mathrm{C}, \mathrm{Po}$. dokdonensis is a common Antarctic species (Yoon et al., 2006). In fact, the Polaribacter genus accounted for $\sim 37 \%$ of the bacterial diversity in the Antarctic microbial survey of Cowie (2011). Interestingly, Po. dokdonensis (MED152) possesses a PR gene and fixes more bicarbonate when grown under light-exposed conditions (González et al., 2008). Yoon et al. (2006) described Po. dokdonensis as an oxidase and catalase positive, Gram-negative rod which forms circular, orange colonies; matching the phenotypic description of sample $\mathrm{C}^{*}$ and isolates 2 and 5 . However, the percent divergence of these isolates 16S rRNA gene sequences from that of Po. dokdonensis ranged from 1.94-3.36\% (Table 2.6C). This implies that these isolates may represent a different strain or perhaps species, than the Po. dokdonensis to which they were compared.

In general, the Paracoccus genus is highly metabolically versatile, with some members undergoing chemotrophic growth through use of hydrogen as an electron donor (Friedrich and Mitrenga, 1981). Pa. marcusii is unique amongst this genus, being the only species to synthesise carotenoids, giving this species its distinctive orange pigment (Harker et al., 1998). Pa. marcusii is formally described as a Gram-negative, oxidase and catalase positive, short chain forming coccoid or rod that grows as smooth, flat and bright orange colonies (Harker et al., 1998). Cellular morphology descriptions of isolates 3 and 4 are identical to this, however colonies of these isolates were raised to a convex-pulvinate level. Although this slightly differing phenotypic property suggest that isolates 3 and 4 do not group within $P a$. marcusii, the distinct orange pigment provides evidence to the contrary. Perhaps differentiation occurs at the strain level.

M. antarcticus utilises a unique cellular fatty acid profile allowing it to be the only cold adapted species of the Micrococcus genus (Liu et al., 2000). Despite this specialisation, $M$. antarcticus shares almost all of its phenotypic traits with its close relative, $M$. luteus. Both these species are oxidase, catalase and Gram-positive, both 
grow as coccoid tetrads and form bright yellow colonies (Liu et al., 2000; Wieser et al., 2002). Isolate 6 groups phenotypically and genetically with both of these species. Given that isolate 6 was isolated from Antarctic sea ice, combined with the small differences in 16S rRNA gene sequencing similarities, it is likely that this bacterium is M. antarcticus. Interestingly, Micrococcus is one of the few genera that Cowie (2011) identified in culture and not through use of pyrosequencing.

This last example emphasises the importance of utilising a polyphasic approach to characterisation (Pedrós-Alió, 2006; Donachie et al., 2007). As the genotypic, phenotypic and environmental evidence are for the most part in support of one another, I am confident in the identifications made, however further genetic investigation such as DNA-DNA hybridisation, is needed if these assignments are to be confirmed to the species level. Cowie (2011) cultured similar taxa, with six isolates grouping within the Psychrobacter, two identified as Po. dokdonensis, one likely to be Paracoccus sp. and three isolates classified as Micrococcus. However, as Cowie (2011) had initially identified all samples used throughout this study as pure cultures of $P$. torquis, it is peculiar that this species was not found in any of the samples investigated. Perhaps the culture conditions examined in this study were not advantageous to this particular species, resulting in $P$. torquis being outcompeted by the other species in these samples. There is also potential that $P$. torquis did not survive cryopreservation, or that the incubation time was not long enough for this species to come out of lagphase. Isolates of $P$. torquis have previously been cultured successfully when grown at $4^{\circ} \mathrm{C}$ over periods of time >two weeks (Bowman et al., 1998; Feng et al., 2013).

Highly varied concentrations of gDNA template were obtained using the phenolchloroform extraction $(0.360-89.862 \mathrm{ng} / \mu \mathrm{L})$. Similarly, when gDNA templates were extracted for 16S rRNA gene amplification, isolates 2 and 5 failed to amplify (Fig. 2.2A $\mathrm{A}_{i i}$ and B). Successful amplification was achieved when an 'enhanced lysing' (using proteinase $\mathrm{K}$, lysosome and SDS) method was used (Fig. 2.2C). However, these isolates grouped closely with sample $\mathrm{C}^{*}$, which was successfully amplified using the standard 16S rRNA gene amplification method, and it is likely members of the same species would amplify under the same conditions. Extraction of genetic material may have been affected by the metabolic capabilities or specific cellular processes (such as production of exopolysaccharides) of each species, or perhaps due to the age of the culture. Some species, such as Po. dokdonensis are highly viscous, and the suspension of these colonies in UltraPure ${ }^{\mathrm{TM}} \mathrm{H}_{2} \mathrm{O}$ may not have been conducted uniformly. 
Using qPCR, I identified the PR gene in P. torquis, Ps. nivimaris and Po. dokdonensis (Fig. 2.5). PR has been previously documented in P. torquis (Feng et al., 2013) and specific strains of Po. dokdonensis (Gómez-Consarnau et al., 2007; González et al., 2008). To my knowledge, this is the first time the PR gene has been found in Ps. nivimaris. Melt curve analyses have the potential to differentiate single bp changes (Ansevin et al., 1976), therefore the $\sim 4^{\circ} \mathrm{C}$ shift in the melt curve profile of Ps. nivimaris suggests that the gene sequence of this species differs from the others examined. As Po. dokdonensis and P. torquis are known to possess G-PR (González et al., 2008; Koh et al., 2010), I expect that Ps. nivimaris contains a B-PR variant. This is a likely assumption, given that other sea-ice Gammaproteobacteria, such as Glaciecola punicea possess B-PR (Qin et al., 2012). However, the PR assignment of Ps. nivimaris will need to be confirmed through gene sequencing and subsequent examination of amino acid position 105.

PR gene amplification results for $\mathrm{Pa}$. marcusii were inconclusive, in that amplification did not begin until $\sim 35$ cycles. This product showed a similar melt temperature to PR-positive products, however due to the minute amount of amplification, the melt curves for this species barely breached the SYBR threshold limit (Fig. 2.5). It is likely that this species does possess a PR gene, however specific PCR optimisation and primer design are necessary to confirm this.

Micrococcus sp. also did not begin to amplify until $\sim 35$ cycles, and after $40 \mathrm{cy}-$ cles each replicate had produced a variable amount ( $\sim 500-750 \mathrm{RFU})$ of amplification product (Fig. 2.5). Furthermore, the melt temperatures of Micrococcus sp. PR-qPCR products were $\sim 10^{\circ} \mathrm{C}$ higher than all other amplification products. Based on these observations Micrococcus sp. does not possess a PR gene, and the amplification is likely due to production of primer-dimer or non-specific primer annealing. Ambiguous annealing is a likely possibility due to the low annealing temperature used (Baumforth et al., 1999); $2{ }^{\circ} \mathrm{C}$ lower than other PR-PCR (Atamna-Ismaeel et al., 2008; Koh et al., 2010; Cowie, 2011).

PR gene amplification was only achieved using the $\mathrm{PR}_{\text {Mod }}$ primer set (Fig. 2.4). This result is curious as the only difference between this and the $\mathrm{PR}_{1}$ primer set is the addition of an EcoR1 restriction enzyme sequence (used for enzymatic digestion) to the 5' end of each primer (Koh, E., pers. comm., 2013). Therefore, this should not have affected the primers performance in regards to product amplification. There is potential that the $\mathrm{PR}_{1}$ primer set ordered may have been vitiated 
during creation, transport or storage, reducing its effectivity. All the primers used contain a very high proportion of ambiguous bases (M, N, S, W, Y), even being present at the ends of primers (Table 2.2). These are features that should be avoided when designing a primer as they can result in non-specific primer annealing (Baumforth et al., 1999). In Figure 2.4 multiple faint bands can be observed ranging from $\sim 650-1500$ bp (particularly in sample HTCC). These small amounts of amplification are likely due to the ambiguous nature of the primers being used. A primer set that avoids ambiguous bases, in favour of annealing specifically to the PR gene sequence, should result in greater amplification levels. Although the consistent melt temperatures and relatively high yields of PR amplification product suggest that my target gene was amplified, future PR gene identification studies should use a more specific primer design. For example, the primer set used by Feng et al. (2013) to amplify the PR gene of $P$. torquis: ${ }^{5^{\prime}}$ TATGGCCATGTTGGCTGCAT ${ }^{3^{\prime}}$ (forward), ${ }^{5}$ CTGAAGCTAGACCCCACTGC ${ }^{3^{\prime}}$ (reverse) may be a possible first step.

Data sets of the growth curves experiment have an excellent fit to the logistic model, with $\mathrm{R}^{2}$ values $>0.95$. This provides confidence in the growth rates and maximum biomass values obtained. As one replicate of $P_{s}$. nivimaris grown in $10 \%$ media was excluded (due to contamination), this lowered the replication of this treatment to two. Although this reduces confidence in the strength of this data, little variation was seen across replicates (Fig. 2.6) allowing for strong comparisons to still be made. To avoid this issue, future growth curves experiments will replicate to at least an $\mathrm{n}$ value of four.

The relatively long lag-phases ( $>20$ hours) observed in this culture experiment parallel trends seen in other bacterial species where downshifts in temperature increased lag-phases (Mellefont and Ross, 2003). The lag-phases observed during the growth curve experiment were highly similar across species, possibly as a result of the sampling frequency during this initial growth period. Increased sampling resolution has the potential to reveal finer differences between samples. For example, observations of Figure 2.6 indicate that Ps. nivimaris enters the exponential-phase before the first time-point measurement (21.75 hours).

The MGTs observed in this experiment ( $10-70$ hours; Table 2.7$)$ show a significantly broader and longer range than those observed for similar Antarctic sea-ice bacteria cultured at $13^{\circ} \mathrm{C}$ by Cowie (2011). For example, the MGT of Po. dokdonensis grown by Cowie (2011) was more than twice as fast as the MGT documented for 
the same species in this study, with the only differences in incubation conditions being one degree in temperature and the use of tryptic soy broth rather than MB. Perhaps another factor, such as the age of the inoculate culture could be responsible for this disparity (Kolter et al., 1993). Future studies, prior to growth curve analysis should passage the cultures serval times through a medium that results in successful growth. This will likely reduced the lag-phase variability and result in more consistent MGT calculations (J. Bowman, pers. comm., 2014).

When grown in full strength $\mathrm{MB}$, large differences in the maximum biomasses of each species were observed. In contrast, when samples were grown in $10 \% \mathrm{MB}$ only minimal differences occurred. This indicates that the reduced strength of the media has become the limiting factor in growth across species. Interestingly, all species (regardless of media strength) reach their maximum growth after $\sim 75$ hours of growth, with the notable exception of Ps. nivimaris grown in $10 \%$ media. The rate of growth is much faster in this treatment, reaching its maximum growth after only $\sim 25$ hours. This, along with the apparent short lag-phase of Ps. nivimaris provides this species with a distinct competitive advantage.

This study combines genetic, phenotypic, biochemical and ecological information, to identify the cultivable members of Antarctic sea-ice bacteria samples. The growth curves experiment provided an excellent baseline study, which is expanded through the manipulation of physicochemical variables in Chapter 3. As this is the first discovery of the PR gene in Ps. nivimaris, any light-response experiments using this isolate will be of great interest. 


\section{CHAPTER 3}

\section{Light Enhanced Growth of PR-bearing, Antarctic Sea-ice Bacteria}

\subsection{Introduction}

Heterotrophic bacteria that possess PR can theoretically use solar radiation to drive ATP synthesis, hence increasing their growth (Béjà et al., 2001; Fuhrman et al., 2008). Due to the lack of cultivable PR-bearing species, the in vivo influence of PR remains difficult to quantify. Several studies show that no light-induced growth occurs in PR-bearing bacteria (Giovannoni et al., 2005; Riedel et al., 2010), while other studies have reported a variety of irradiance effects, such as greater bicarbonate fixation (González et al., 2008), the upregulation of metabolic processes (Steindler et al., 2011), increased PR gene expression and transcription (Lami et al., 2009; Kimura et al., 2011), or the direct pumping of hydrogen ions (Yoshizawa et al., 2012). Furthermore, light-exposed PR-bearing bacteria increase in growth and survival when starved of nutrients or organic matter (Gómez-Consarnau et al., 2007, 2010). This has led to the general hypothesis that PR has the greatest influence under oligotrophic conditions. However, increased growth has recently been observed in light-treated samples of the PR-bearing bacteria, P. torquis, when grown under sub- or supraoptimal salinities (Feng et al., 2013). Therefore, PR may act as a broad response to physicochemical stressors.

As PR-bearing bacteria are prevalent throughout Antarctic sea ice (Koh et al., 2010), I suggest this protein may be increasing the growth of Antarctic sea-ice bacteria, as a response to the cold. As steep vertical gradients of light, temperature and salinity, as well as fluctuations in nutrients and organic matter are characteristic of annual Antarctic sea ice (Kottmeier and Sullivan, 1988; Thomas and Dieckmann, 2009), it is likely that PR contributes significantly to the ecology of this ecosystem. A photoheterotrophic lifestyle would be a large competitive advantage in a polar ecosystem, given the seasonal availability of light. 
Ice attenuates wavelengths at different rates, resulting in blue-light being predominant throughout an ice column (Buckley and Trodahl, 1987). This is an interesting variable for PR-bearing bacteria in Antarctic sea ice, theoretically favoring the B-PR variant. Koh et al. (2010) investigated the vertical distribution of PR variants, in annual Antarctic sea ice, finding a higher proportion of B-PR in the mid and top sections of the ice column, with G-PR bacteria being most prevalent at the bottom. Koh et al. (2010) attributed this bottom-associated G-PR dominance with a high accumulation of microalgae in the bottom $\sim 20 \mathrm{~cm}$ (Sullivan and Palmisano, 1981) reflecting a large amount of green light. Furthermore, the light enhanced growth of $D$. donghaensis (a G-PR-bearing, close relative of Po. dokdonensis) is caused almost exclusively the by absorption of green-light (Gómez-Consarnau et al., 2007).

Of the PR-bearing, Antarctic sea-ice bacteria isolated in Chapter 2, P. torquis and Po. dokdonensis both possess G-PR (González et al., 2008; Koh et al., 2010; Feng et al., 2013). The PR variant of Ps. nivimaris is unknown, as the PR gene of this species is yet to be sequenced. However, as the melt curve profile of the Ps. nivimaris PR amplification product is shifted (in comparison to P. torquis and Po. dokdonensis; Chapter 2, Fig. 2.5), this species may posses a B-PR. Furthermore, all three of these species are not known to possess any photo-pigments (such as bacteriochlorophyll) other than PR. Therefore, any light responses of these species is likely due to the influence of PR.

This study aimed to assess the influence of light on the growth of these PRbearing bacteria, previously isolated from Antarctic sea ice. To explore the hypothesis that PR is most influential under conditions of stress, incubations were conducted in a variety of media and across several temperatures. Furthermore, cultures were grown under specific wavelengths, assessing the influence of PR spectral tuning.

This study developed a novel method, in which bacterial cultures were incubated within annual Antarctic sea ice. This exposed cultures to the typical fluctuations of light and temperature of their natural environment, whilst still allowing the manipulation of test factors, such as media strength. Laboratory-based incubations were run concurrently, allowing finer manipulation of variables. 


\subsection{Materials and Methods}

This study used a mixed sample of Antarctic sea-ice bacteria [sample C34; Cowie (2011)] containing Ps. nivimaris, Po. dokdonensis, Pa. marcusii and Micrococcus sp. (as identified in Chapter 2), as well as isolated cultures of the PR-bearing, Antarctic seaice bacteria P. torquis, Ps. nivimaris and Po. dokdonensis. All samples were handled using aseptic technique throughout this study. Unless stated otherwise, all reagents were purchased from Sigma-Aldrich (USA).

\subsubsection{In situ incubations}

\section{Study site}

Incubations were undertaken within the annual sea ice at Cape Evans, Antarctica $\left(77^{\circ} 38^{\prime} \mathrm{S}, 166^{\circ} 24^{\prime} \mathrm{E}\right.$; Fig. 3.1). To minimise spatial variation, experiments were performed in adjacent sections of $1.7 \mathrm{~m}$ annual ice.

\section{2 incubation experiment}

From late November to early December 2012, the growth of the mixed Antarctic sea-ice bacteria culture was investigated. A $20 \mathrm{~mL}$ stock culture was grown to logphase at $12^{\circ} \mathrm{C}$, under constant illumination (5-20 $\mu \mathrm{mol}$ photons $\left.\mathrm{m}^{-2} \mathrm{~s}^{-1}\right)$, rotating at $70 \mathrm{rpm}$. In order to reduce cold shock, this culture was subsequently maintained at $4^{\circ} \mathrm{C}$ for $>7$ days. Following this period, $100 \mu \mathrm{L}$ of stock culture was used to inoculate $10 \mathrm{~mL}$ of sterile media, in $15 \mathrm{~mL}^{\text {Corning }^{\text {TM }}}$ Pyrex $^{\text {TM }}$ glass screw cap culture tubes (Fisher Scientific, USA) sealed with parafilm, replicated four times. The media used in this experiment were $\mathrm{M}_{0}$ (DOC and $\mathrm{NaCl}$ concentrations equivalent to $\mathrm{MB}$ ), $\mathrm{M}_{1}$ (reduced $\mathrm{NaCl}$ ), $\mathrm{M}_{2}$ (increased $\mathrm{NaCl}$ ) and $\mathrm{M}_{3}$ (reduced DOC). Concurrent to media treatments, cultures were incubated under the following light treatments: ambientlight, complete darkness, red-light ('021 Gold Amber' 640 nm), green-light ('122 Fern Green' $490 \mathrm{~nm}$ ) and blue-light ('141 Bright Blue' $440 \mathrm{~nm}$ ) using Live Performance polycarbonate filters (Chris James Lighting Filters). All light filters resulted in a $\sim 50 \%$ photon reduction from ambient light.

Using a $14 \mathrm{~cm}$ diameter Kovacs ice corer (Kovacs Enterprise, USA), a series of ice cores were drilled to depths of $0.3 \mathrm{~m}, 0.7 \mathrm{~m}$ and $1.0 \mathrm{~m}$, and extracted from the ice. A variety of methods were assessed as a means of sealing and preventing refreezing of these ice-core holes (Sup. Fig. 3), with a bung made from clear polyurethane and ice-shavings being utilised during these experiments. Bacterial cultures were grouped into light-treatment sets and incubated within these ice-core holes for 11 


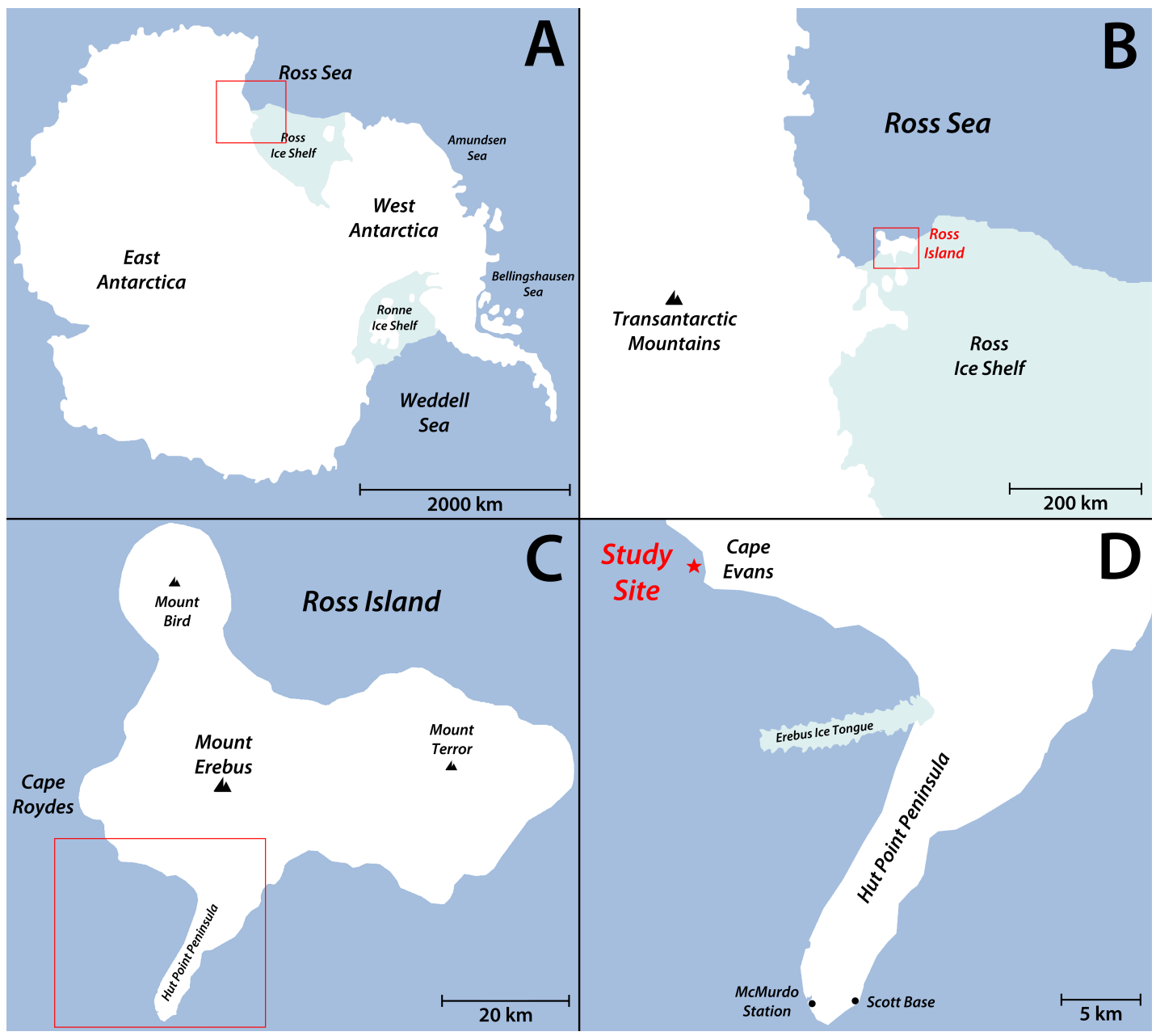

Figure 3.1: In situ incubation study site, Ross island, Antarctica. A: Antarctic continent; B: Ross Sea shoreline; C: Ross Island; D: Cape Evans. Adapted and redrawn from http://lima.usgs.gov.

days. Duplicate negative controls (un-inoculated samples of each media type) were also incubated in situ, under ambient-light conditions at each depth.

Samples were periodically removed from the ice and their absorbance was measured at $590 \mathrm{~nm}$, using the methods outlined in Chapter 2. A $250 \mu \mathrm{L}$ and duplicate $750 \mu \mathrm{L}$ subsamples were taken from each culture at each time point. $250 \mu \mathrm{L}$ subsamples were suspended in $50 \%$ glycerol and stored at $-80^{\circ} \mathrm{C}$, and $750 \mu \mathrm{L}$ subsamples were fixed in $2 \%$ formalin and stored at $-20^{\circ} \mathrm{C}$. To minimise variation during this sampling period, cultures were stored in an insulated, light proof container, and were promptly returned to their ice-core holes afterwards.

\section{3 incubation experiment}

The growth of $P$. torquis was investigated, from late November to early Decem- 

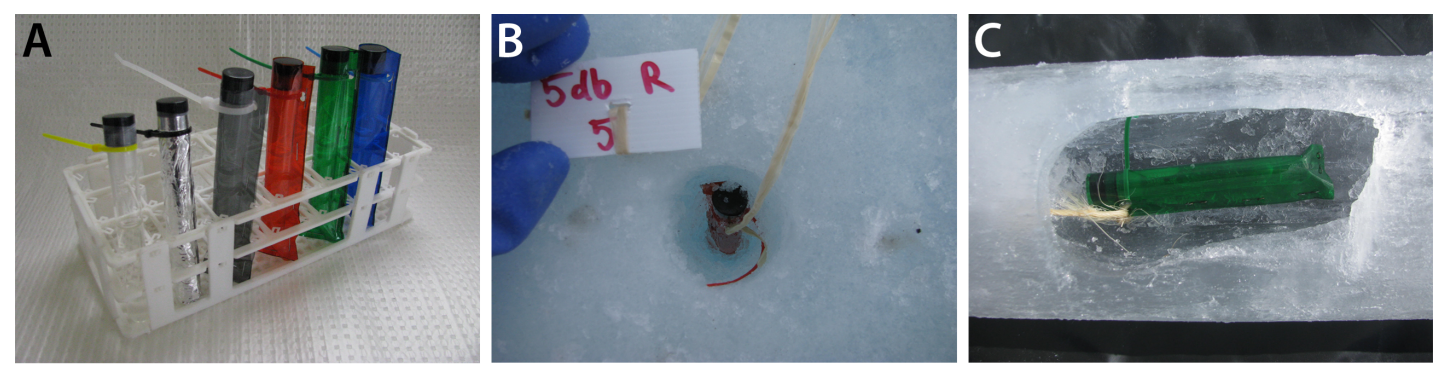

D

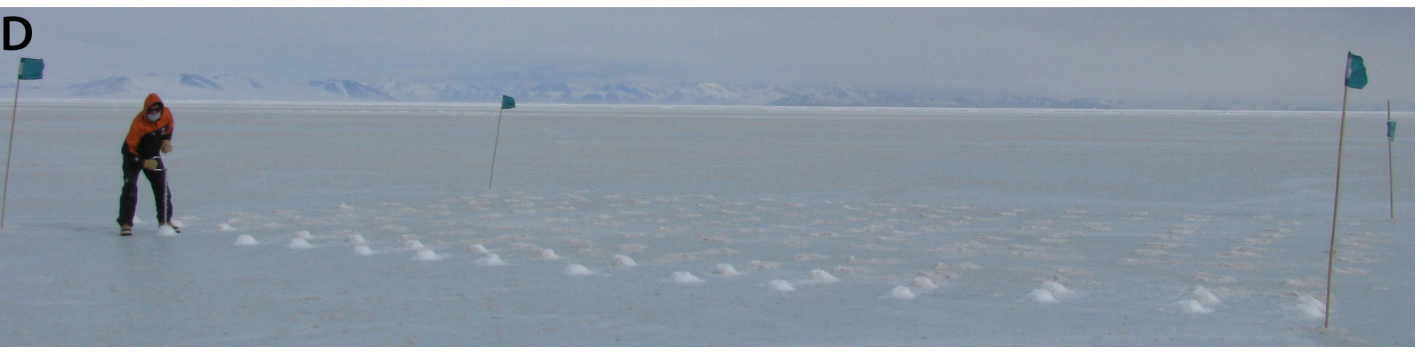

Figure 3.2: 2013 in situ incubation method. A: light treatments; B: sample being inserted into an ice auger hole; C: sample suspended within an ice core (shown in transection); D: Drilling ice auger holes in preparation for sample suspension.

ber, 2013. Samples of $P$. torquis were cultured in either $\mathrm{MB}$ or $10 \% \mathrm{MB}$, replicated five times, prepared under the conditions described previously. An additional light treatment was added using '209 0.3 Neutral Density' Live Performance polycarbonate filters (Chris James Lighting Filters; Fig. 3.2A-C), reducing ambient light by $\sim 50 \%$, whilst maintaining the proportions of ambient wavelengths.

Using a $5 \mathrm{~cm}$ diameter Kovacs ice auger (Kovacs Enterprise, USA), a series of holes were drilled to a depth of $0.7 \mathrm{~m}$ (Fig. 3.2D). Each sample was randomly allocated to an auger hole and suspended at $0.5 \mathrm{~m}$ within the sea ice (Fig. 3.2B). Each hole was then partially refilled using the ice shavings produced during the drilling process, 'sealing' the samples within the auger holes. This process was replicated for three separate incubation times: 6 days, 10 days and 13 days, allowing for independent sampling to occur at these different time points. This resulted in 180 independent bacterial cultures being incubated within the sea ice. Duplicate negative controls (un-inoculated samples of each media type) were also incubated in situ, under ambient light conditions for 13 days.

Following their incubation period, samples were removed from the ice by centring a Kovacs ice corer above each auger hole and extracting a $14 \mathrm{~cm}$ diameter ice core containing the suspended sample (Fig. 3.2C). Following extraction, the absorbance $(590 \mathrm{~nm})$ of each sample was measured, as previously described. A $4 \mathrm{~mL}$ 
and two $2 \mathrm{~mL}$ subsamples were taken from each culture. The first was fixed in $2 \%$ formalin, and the later two were fixed in 1\% formalin and suspended in $30 \%$ glycerol, respectively. Formalin-fixed subsamples were stored at $-20^{\circ} \mathrm{C}$, whereas subsamples in glycerol were stored at $-80^{\circ} \mathrm{C}$.

Metadata including light, cloud cover and snow depth was collected daily. See Supplementary Table 7.

\subsubsection{Laboratory-based incubations}

The growth of pure cultures of Antarctic sea-ice bacteria possessing a PR gene (P. torquis, Ps. nivimaris and Po. dokdonensis) was investigated. Samples were cultured in either $\mathrm{MB}$ or $10 \% \mathrm{MB}$, prepared under the conditions described previously (Section 3.2.1). Cultures were incubated for up to 870 hours, at three different temperatures $\left(12^{\circ} \mathrm{C}, 4^{\circ} \mathrm{C}\right.$ and $\left.-1^{\circ} \mathrm{C}\right)$, either constantly illuminated $(5-20 \mu \mathrm{mol}$ photons $\mathrm{m}^{-2} \mathrm{~s}^{-1}$ ) or in complete darkness, replicated four times. Duplicate negative controls (un-inoculated media samples) were incubated under the same conditions.

The absorbance (590 nm) of each sample was regularly measured, as previously described. $750 \mu \mathrm{L}$ subsamples were taken from each sample at exponential-phase. These subsamples were centrifuged at 13,000 xg for $15 \mathrm{~min}$ and the supernatant was discarded. The pellet was resuspended in $50 \mu \mathrm{L}$ of RNAlater ${ }^{\circledR}$ (Life Technologies, USA) and stored at $-80^{\circ} \mathrm{C}$. Following incubation, all samples were streak-plated and incubated on MA in order to confirm that samples remained free of contamination.

\subsubsection{Statistical analysis}

Initial analyses and graph construction was performed using GraphPad Prism ${ }^{\circledR}$ (version 5.01, 2007), and factorial ANOVA tests were conducted in IBM $^{\circledR}$ SPSS $^{\circledR}$ Statistics (version 20, 2011). Growth curves obtained from laboratory-based incubations were analysed using the method outlined in Chapter 2. Samples that exhibited a secondary stage of exponential growth (marked in text with an asterisk) were analysed in the same manner, with each stage of exponential growth individually fitted to the logistic model. In situ incubations had only four data points per treatment, meaning the logistic model could not be fitted to these data sets. Consequently, only factorial ANOVA tests were conducted using the final time point biomass for each treatment, rather than the $y_{m}$ value. 


\subsection{Results}

\subsubsection{2 in situ incubation}

The mean absorbance of all negative controls were consistently elevated above the zero measurements (Fig. 3.3), indicating that the process of in situ incubation has caused a small artefact, likely due to condensation or salt build up (as discussed in Section 3.4). However, the slope of each negative control did not differ from zero (Fig. 3.3; Sup. Table 8A), and as statistical analyses were performed by comparing treatments against negative controls (rather than the zero measurement), the results of this experiment were unaffected by this artefact. Cultures grown in $\mathrm{M}_{3}$ did not differ from their respective negative controls $(t=0.7934, p>0.05)$, therefore this media treatment was excluded from further analyses. Depth had no major effect when compared within each light and media treatment (Sup. Table 8A), therefore depth treatments were amalgamated.

Across light treatments, media had a significant effect $\left(F^{2,85}=9.70, p<0.001\right)$, with $\sim 1.5$ times greater absorbance occurring in $\mathrm{M}_{0}$ than in $\mathrm{M}_{1}$ and $\mathrm{M}_{2}$ (Fig. 3.3; Table 3.1). Light-treatment also had an effect $\left(F^{4,85}=20.08, p<0.001\right)$, with a significant interaction suggesting that the effect of light differs between media treatments $\left(F^{2,85}\right.$ $=5.29, p=0.007)$. Post-hoc testing revealed the least growth of $\mathrm{M}_{0}$-cultures consistently occurred under ambient-light incubation conditions, with all other irradiance treatments having similar levels of growth (Fig. 3.3A; Table 3.1). Cultures grown in both $\mathrm{M}_{1}$ and $\mathrm{M}_{2}$ also showed reduced growth under ambient-light (Fig. 3.3B; Table 3.1).

\subsubsection{3 in situ incubation}

As in the previous in situ incubation, the absorbance slope of each negative control did not differ from zero despite the means being consistently elevated above zero (Fig. 3.4; Sup. Table 8B). Cultures grown 10\% media showed no differences between treatments and negative controls $\left(F^{6,24}=0.649, p=0.690\right.$; Fig. 3.4B), subsequently, all 10\% MB cultures were excluded from further analyses.

In cultures grown in full strength media, light had a significant effect $\left(F^{6,24}=\right.$ $3.57, p=0.011$ ), with elevated growth occurring in blue- and $50 \%$ light treatments (Fig. 3.4; Table 3.2). Cultures grown in ambient-light reached a similar mean biomass to blue- and 50\% light treatments, but showed a large amount of variation, meaning 


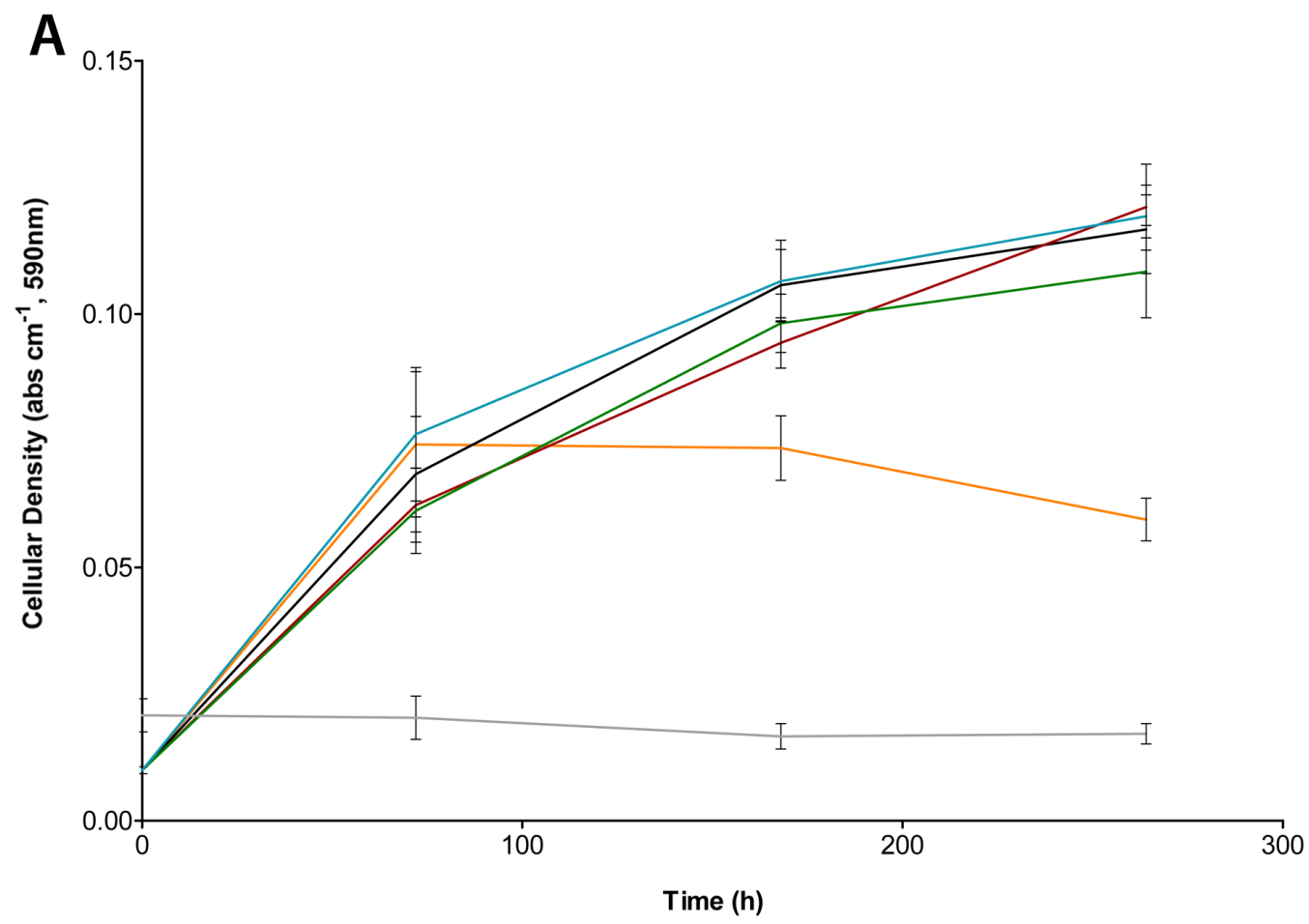

B

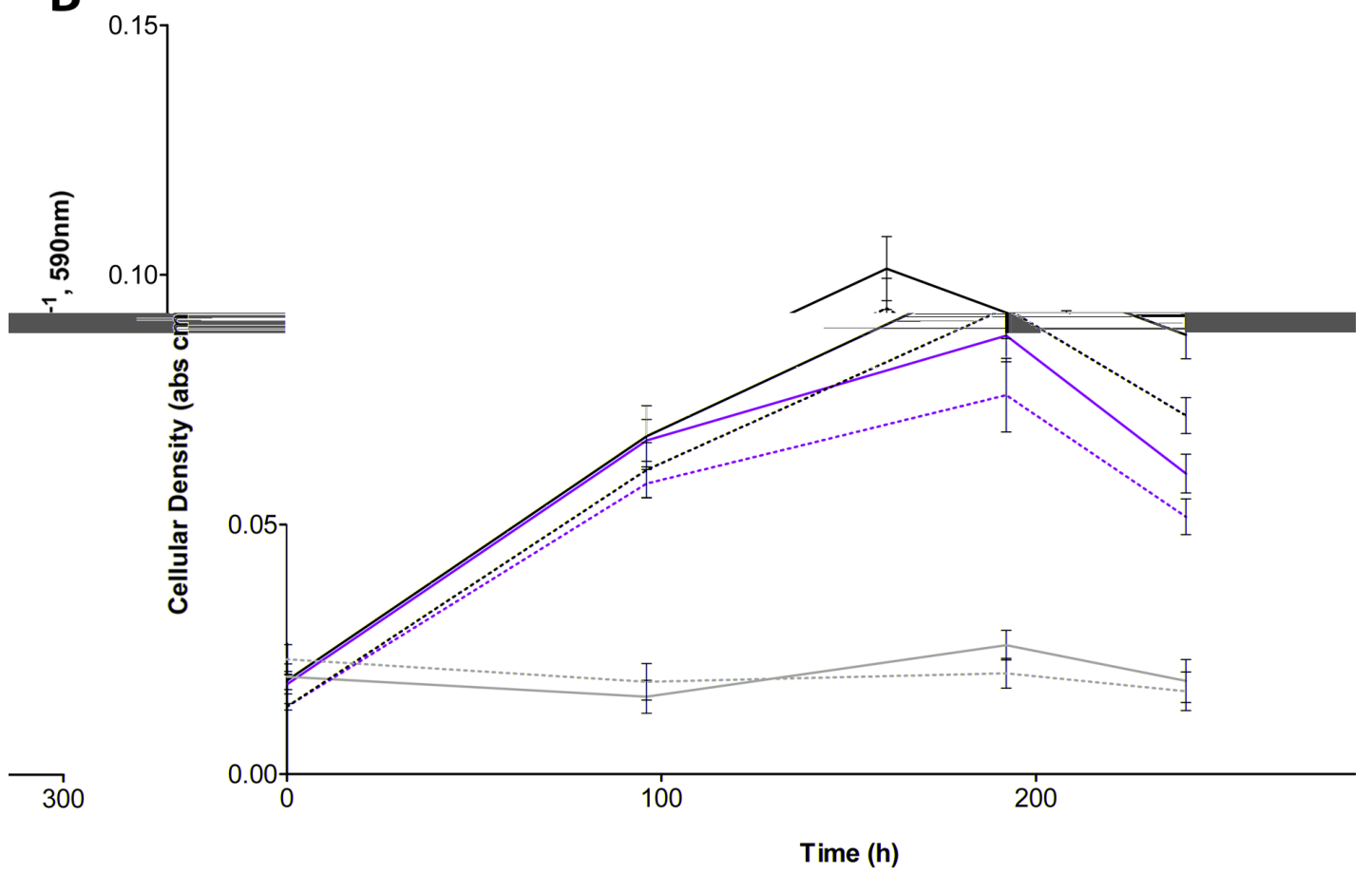

Figure 3.3: Mean growth curves of mixed cultures of Antarctic sea-ice bacteria, incubated in situ, in: A. $\mathbf{M}_{0}$ media and B. $\mathbf{M}_{1}$ and $\mathbf{M}_{2}$ media, under varying light treatments. Orange: ambient-light; black: complete darkness; red: red-light; green: green-light; blue: blue-light; grey: negative control. In $\mathrm{B}$, solid line: $\mathrm{M}_{1}$ media; dashed line: $\mathrm{M}_{2}$ media. Error bars represent standard errors. 
Table 3.1: Statistical information derived from 2012 in situ incubation experiments. Mean absorbance (at final time point) values and standard errors are presented.

\begin{tabular}{|c|c|c|c|c|}
\hline \multicolumn{2}{|c|}{ Treatment } & \multirow{2}{*}{$\frac{\mathbf{n}}{11}$} & \multirow{2}{*}{ 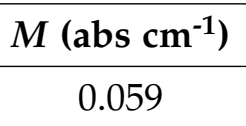 } & \multirow{2}{*}{$\frac{S E}{0.004}$} \\
\hline \multirow{6}{*}{$\mathbf{M}_{0}$} & Light & & & \\
\hline & Dark & 10 & 0.117 & 0.009 \\
\hline & Red & 10 & 0.121 & 0.008 \\
\hline & Green & 11 & 0.108 & 0.009 \\
\hline & Blue & 7 & 0.119 & 0.004 \\
\hline & Neg. ctrl & 6 & 0.017 & 0.002 \\
\hline \multirow{3}{*}{$\mathbf{M}_{1}$} & Light & 11 & 0.060 & 0.004 \\
\hline & Dark & 12 & 0.088 & 0.005 \\
\hline & Neg. ctrl & 6 & 0.019 & 0.004 \\
\hline \multirow{3}{*}{$\mathbf{M}_{2}$} & Light & 11 & 0.052 & 0.004 \\
\hline & Dark & 11 & 0.072 & 0.004 \\
\hline & Neg. ctrl & 5 & 0.017 & 0.004 \\
\hline
\end{tabular}

Table 3.2: Statistical information derived from 2013 in situ incubation experiments. Mean absorbance (at final time point) values and standard errors are presented.

\begin{tabular}{|c|c|c|c|c|}
\hline \multicolumn{2}{|c|}{ Treatment } & $\mathbf{n}$ & $M\left(\right.$ abs cm $\left.\mathrm{cm}^{-1}\right)$ & $S E$ \\
\hline \multirow{7}{*}{ MB } & Light & 5 & 0.082 & 0.026 \\
\hline & $50 \%$ light & 4 & 0.096 & 0.014 \\
\hline & Dark & 5 & 0.033 & 0.014 \\
\hline & Red & 5 & 0.042 & 0.007 \\
\hline & Green & 5 & 0.048 & 0.008 \\
\hline & Blue & 5 & 0.077 & 0.004 \\
\hline & Neg. ctrl & 2 & 0.010 & 0.004 \\
\hline \multirow{7}{*}{$10 \% \mathrm{MB}$} & Light & 5 & 0.025 & 0.007 \\
\hline & $50 \%$ light & 5 & 0.028 & 0.006 \\
\hline & Dark & 5 & 0.038 & 0.010 \\
\hline & Red & 4 & 0.033 & 0.003 \\
\hline & Green & 5 & 0.033 & 0.006 \\
\hline & Blue & 5 & 0.034 & 0.010 \\
\hline & Neg. ctrl & 2 & 0.015 & 0.007 \\
\hline
\end{tabular}




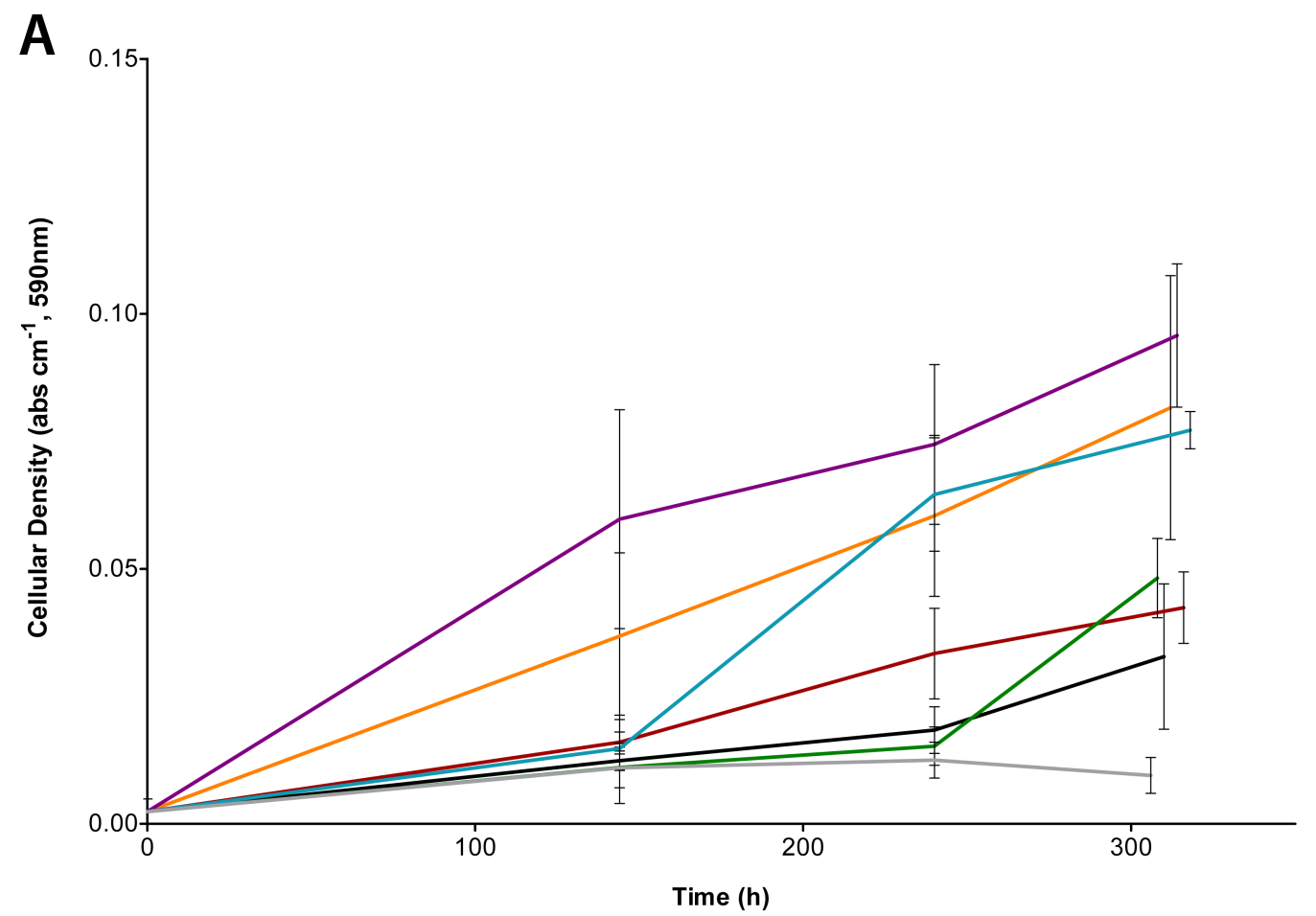

B

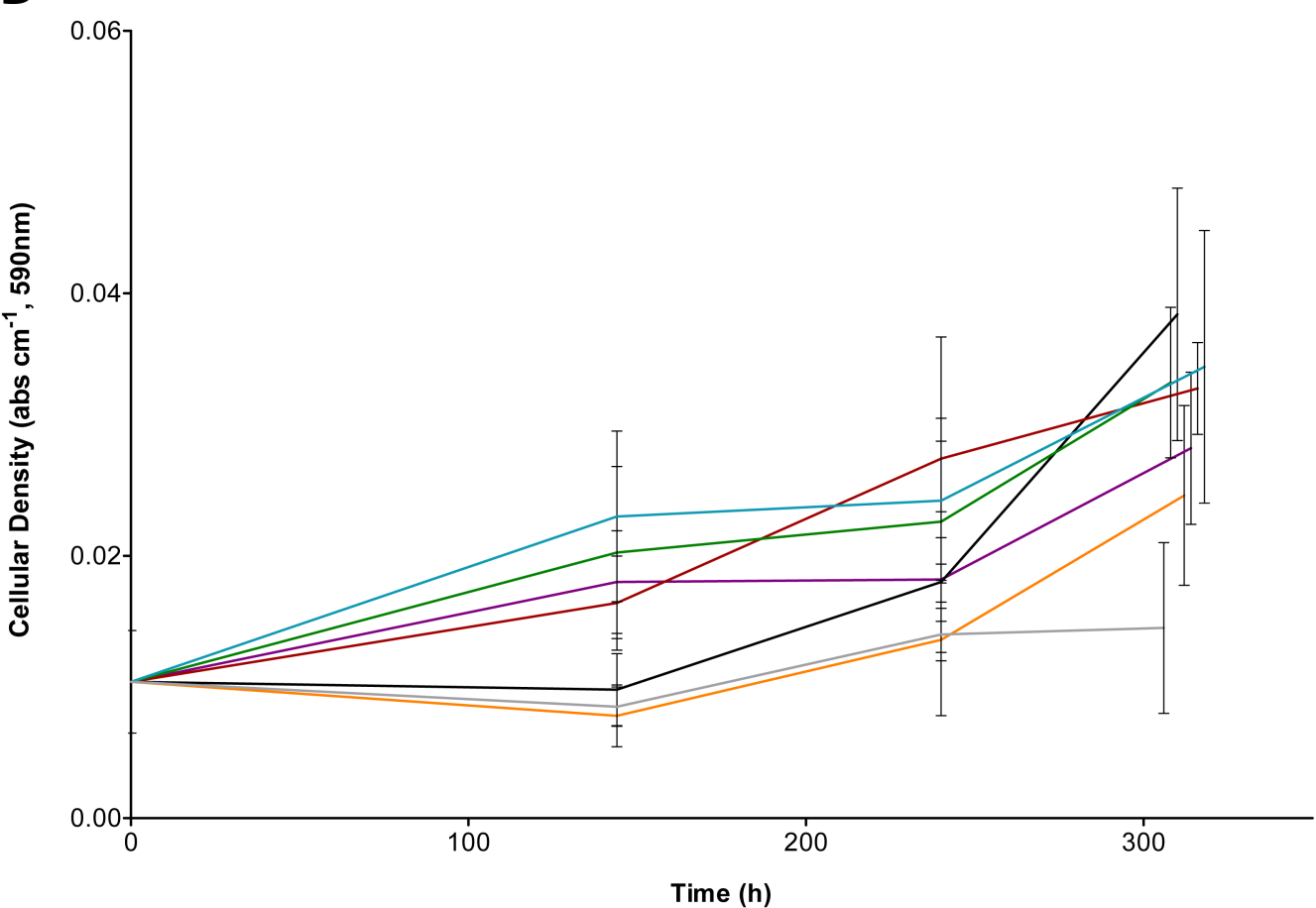

Figure 3.4: Mean growth curves of $P$. torquis, incubated in situ in: A. MB and B. 10\% MB, under varying light treatments. Orange: ambient-light; purple: $50 \%$ light; black: complete darkness; red: red-light; green: green-light; blue: blue-light; grey: negative control. Error bars represent standard errors. Final data points are offset to show error bars. 
this treatment did not statistically differ from any other light treatments. Furthermore, cultures grown in complete darkness did not differ significantly from negative controls (Fig. 3.4; Table 3.2).

\subsubsection{Laboratory-based incubations}

Neither the means nor the line slope of the negative controls differed from zero (Fig. 3.5-3.7; Sup. Fig. 4; Sup. Table 8C), and streak-plating revealed that all samples remained free from contamination. The logistical model showed an extremely strong fit to all data sets, with all $\mathrm{R}^{2}$ values $>0.95$ (excluding Ps. nivimaris, $10 \% \mathrm{MB}$, light ${ }^{*}$; Table 3.3). The maximum biomass and rate of growth both differed significantly across all four treatments and the majority of subsequent interactions (Sup. Table 9). Across species, cultures grown in $10 \%$ media reached absorbance values of $\sim 0.3$ abs $\mathrm{cm}^{-1}$, whereas full strength media resulted in typical absorbance values more than twice as high at that (Fig. 3.5-3.7; Table 3.3).

When cultured at $12^{\circ} \mathrm{C}, P$ s. nivimaris grew more in the light than the dark $\left(y_{m}\right.$ : $\left.F^{2,69}=35.49, p<0.001 ; b: F^{2,69}=88.49, p<0.001\right)$. This effect was most pronounced when samples were grown in $10 \%$ media, with cultures entering a secondary exponential growth phase after $\sim 75$ hours, raising the mean absorbance from 0.22 abs $\mathrm{cm}^{-1}$ to $0.35 \mathrm{abs} \mathrm{cm}^{-1}$ (Fig 3.5B; Table 3.3 'Light" ${ }^{* \prime}$. Illuminated samples of Ps. nivimaris grown in full strength media also reached a higher biomass than those grown in the dark, however a secondary growth phase did not occur (Fig. 3.5A). Decreasing temperature resulted in cultures of $P_{s}$. nivimaris increasing in lag-time and decreasing in the rate of growth. At both $4^{\circ} \mathrm{C}$ and $-1^{\circ} \mathrm{C}$ (regardless of media strength), $P$. nivimaris showed trends of increased growth in the dark, however this trend was only apparent during the exponential-phase (Fig. 3.5). Minor trends of diauxic growth also occurred at colder temperatures, regardless of illumination or media strength. Furthermore, the rate of growth of this species was unaffected by media strength, and the maximum biomass was not influenced by temperature (Fig. 3.5; Table 3.3).

Light-induced growth also occurred in cultures of Po. dokdonensis grown in 10\% media $\left(y_{m}: F^{1,10}=192.0, p<0.001\right)$, but not in full strength media $\left(y_{m}: F^{1,18}=0.669\right.$, $p<0.425$ ). This species only grew at $12^{\circ} \mathrm{C}$ (see Supplementary Figure $4 \mathrm{~A}$ for plots of cultures grown at $4^{\circ} \mathrm{C}$ and $-1^{\circ} \mathrm{C}$ ). Po. dokdonensis grown in full strength media had faster rates of growth and reached higher maximum biomasses, than cultures in 10\% media. 67.5 hour lag-phases occurred across both media treatments (Fig. 3.6; Table 3.3) 


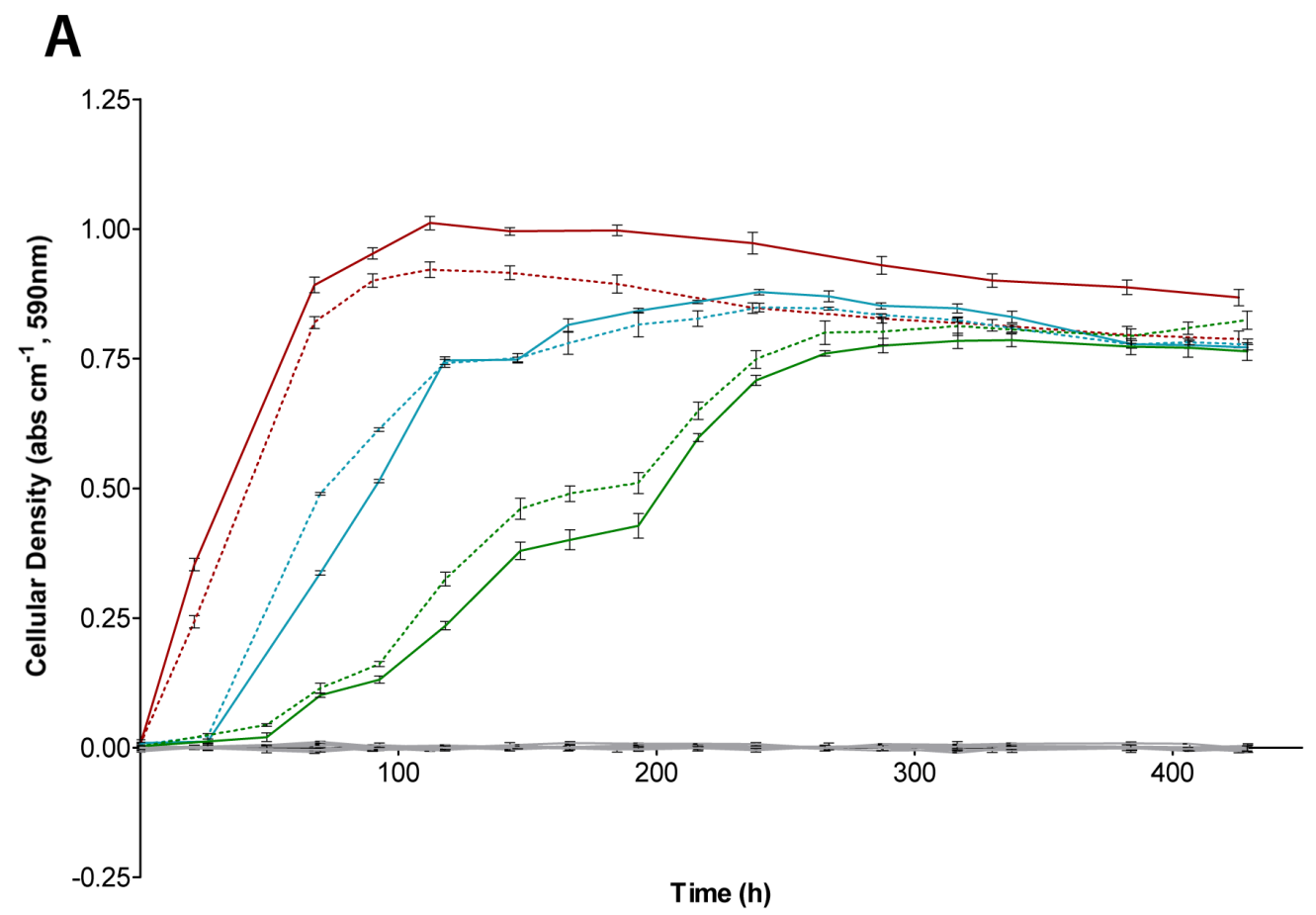

B

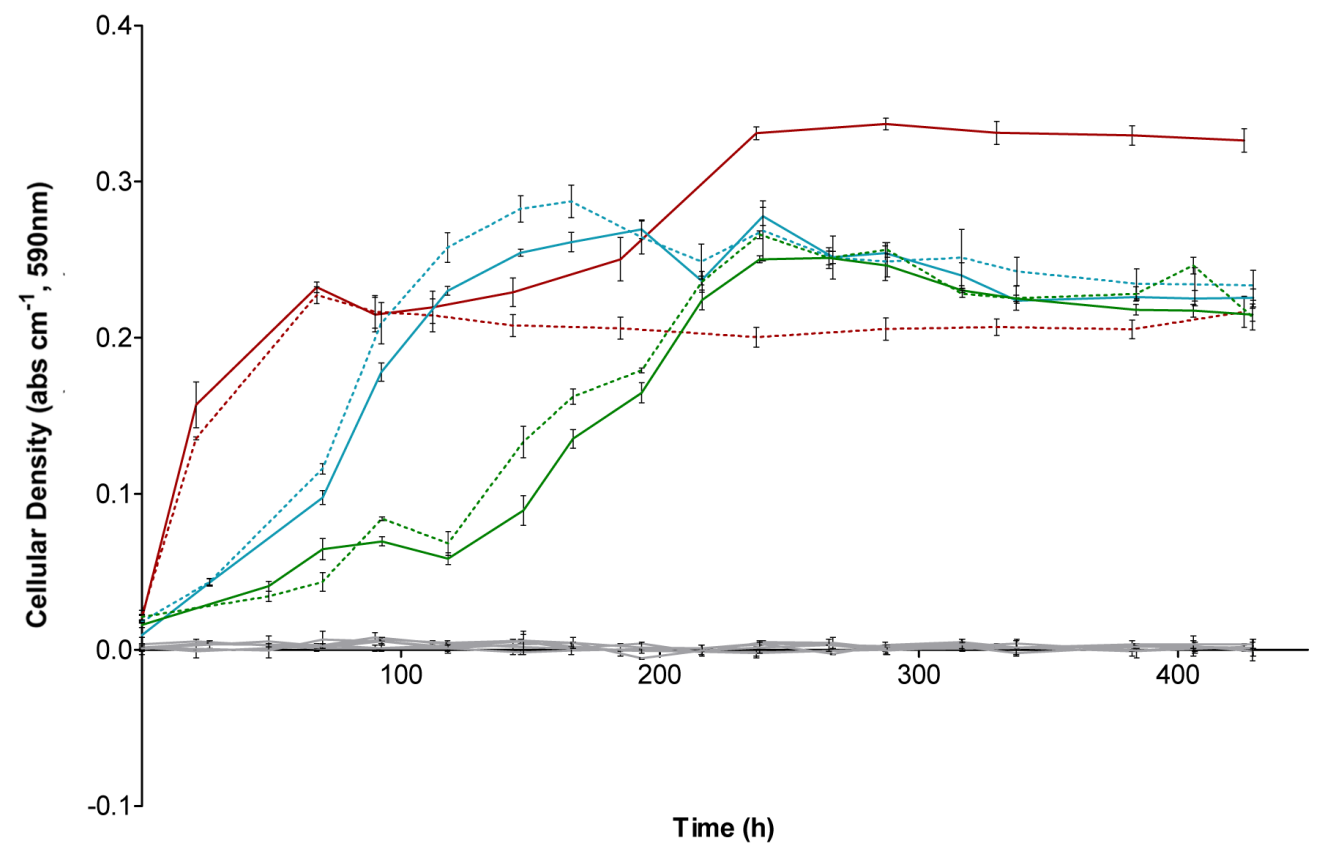

Figure 3.5: Mean growth curves of Ps. nivimaris, incubated in: A. MB or B. $10 \% \mathrm{MB}$, under varying light and temperature treatments. Solid line: light $\left(5-20 \mu \mathrm{mol}\right.$ photons $\left.\mathrm{m}^{-2} \mathrm{~s}^{-1}\right)$; dashed line: complete darkness. Red: $12^{\circ} \mathrm{C}$; blue: $4^{\circ} \mathrm{C}$; green: $-1^{\circ} \mathrm{C}$; grey: negative control. Error bars represent standard errors. 


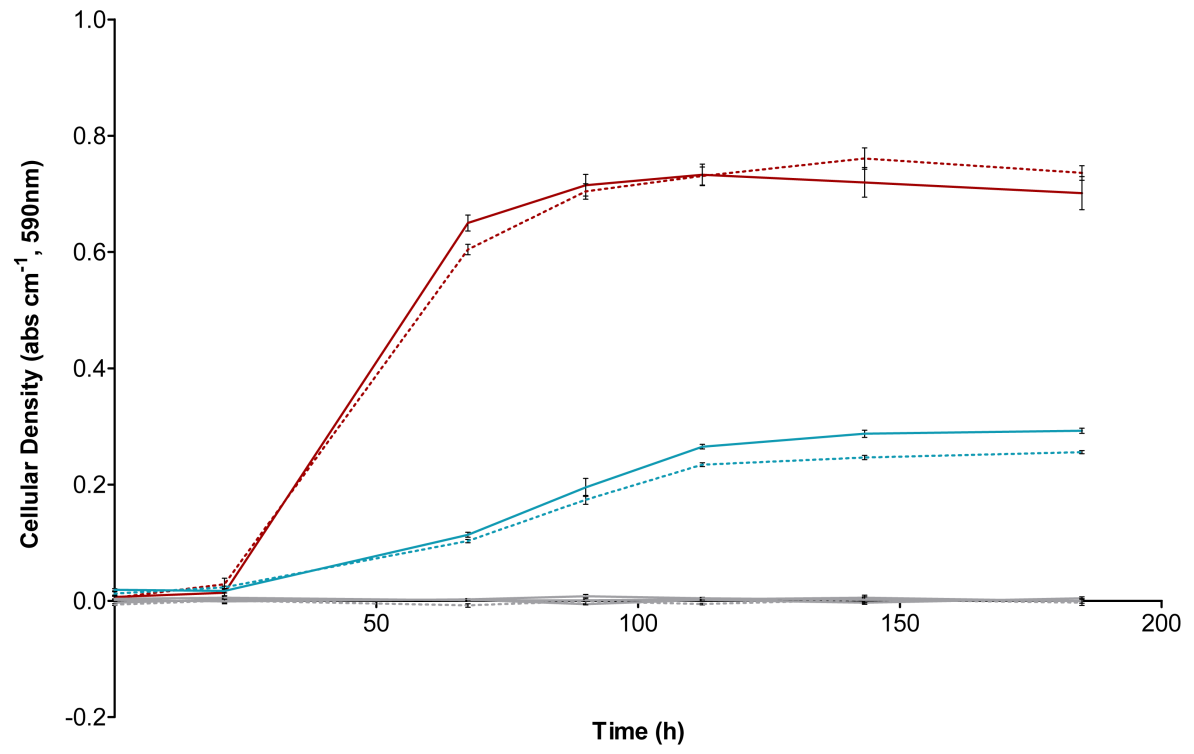

Figure 3.6: Mean growth curves of Po. dokdonensis, incubated at $12^{\circ} \mathrm{C}$, under varying light and media treatments. Solid line: light $\left(5-20 \mu \mathrm{mol}\right.$ photons $\left.\mathrm{m}^{-2} \mathrm{~s}^{-1}\right)$; dashed line: complete darkness. Red: MB; blue: 10\% MB; grey: negative control. Error bars represent standard errors.

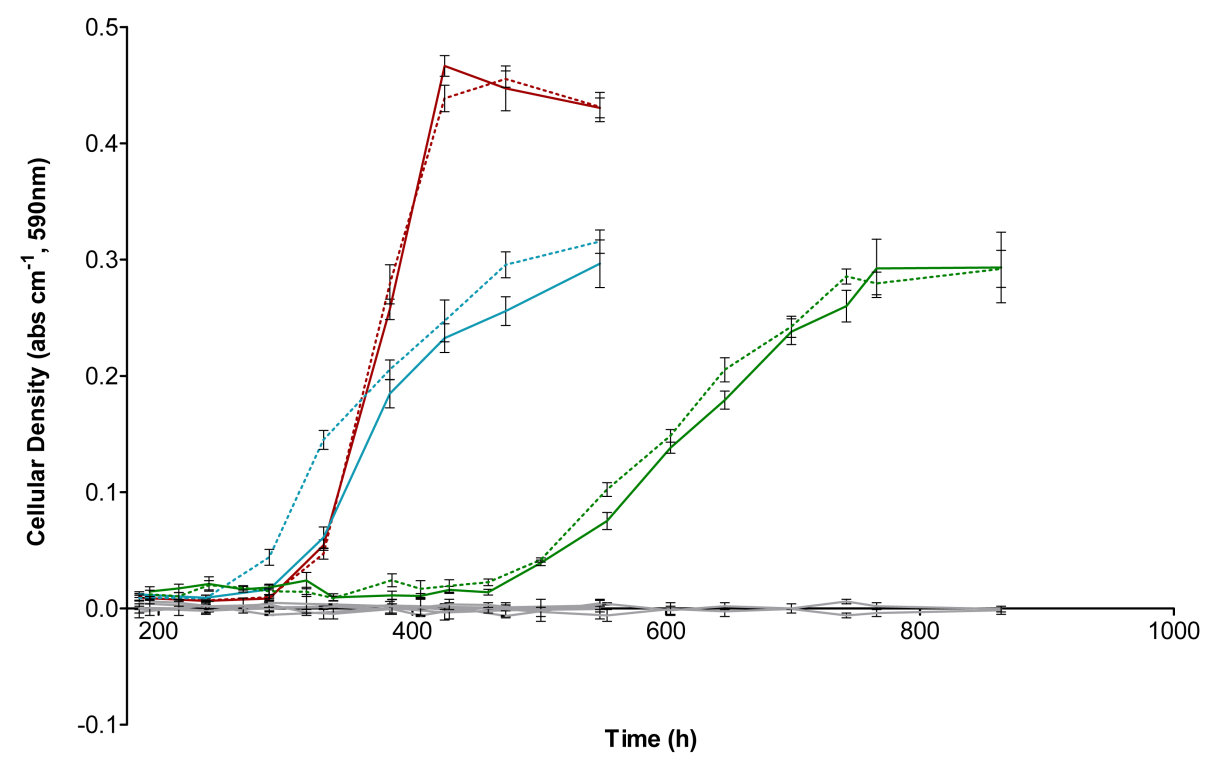

Figure 3.7: Mean growth curves of $P$. torquis, incubated under varying light, media and temperature treatments. Solid line: light $\left(5-20 \mu \mathrm{mol}\right.$ photons $\left.\mathrm{m}^{-2} \mathrm{~s}^{-1}\right)$; dashed line: complete darkness. Red: $12^{\circ} \mathrm{C}$, $\mathrm{MB}$; blue: $12^{\circ} \mathrm{C}, 10 \% \mathrm{MB}$; green: $4^{\circ} \mathrm{C}, \mathrm{MB}$; grey: negative control. Error bars represent standard errors. Data is trimmed to begin at 200 hours. 
政 t) 0 ○ 志 
P. torquis grew at $12^{\circ} \mathrm{C}$ regardless of media treatment, and at $4^{\circ} \mathrm{C}$ in full strength media only (see Supplementary Figure $4 \mathrm{~B}$ for plots of cultures grown at $-1^{\circ} \mathrm{C}$ and at $4^{\circ} \mathrm{C}$, in $10 \% \mathrm{MB}$ ), however no effect of light-treatment occurred (Fig. 3.7; Table 3.3). This species had a remarkably long lag-phase ( $>275$ hours), which increased with a reduction in temperature but was unaffected by media strength. Temperature also affected the maximum biomass and rate of growth of $P$. torquis, with cultures grown in full strength media at $4^{\circ} \mathrm{C}$ producing a similar growth pattern to those grown in $10 \%$ media at $12^{\circ} \mathrm{C}$ (Fig. 3.7; Table 3.3).

\subsection{Discussion}

Light affected the growth of PR-bearing, Antarctic sea-ice bacteria, having a varied influence depending on the species, media, temperature and wavelength. The strongest light responses occurred in cultures of Ps. nivimaris, grown at $12^{\circ} \mathrm{C}$. In $10 \%$ $\mathrm{MB}$, light and dark incubations had near identical growth patterns for the first $\sim 75$ hours, however irradiated samples entered a secondary exponential growth phase, almost doubling in biomass (Fig. 3.5B). This diauxic growth pattern suggests that PR became active upon the depletion of nutrients (Narang and Pilyugin, 2007), causing a shift to phototrophy. Furthermore, light also positively influenced the growth of Ps. nivimaris grown at $12^{\circ} \mathrm{C}$, in full strength media (Fig. 3.5A). Samples stored in RNAlater $^{\circledR}$ may be used in the future to quantify the expression and activity of PR during this phase. These results are of particular interest given that the PR gene was found in Ps. nivimaris for the first time, as described in Chapter 2.

As a trend of reduced exponential-growth was observed when Ps. nivimaris was incubated in the light and at colder temperatures (Fig. 3.5), it is unlikely that PR influences the ecology of this species within Antarctic sea ice. However, when grown at its optimal growth temperature $\left(10-15^{\circ} \mathrm{C}\right.$; Heuchert et al., 2004), PR likely has a large affect on the growth of Ps. nivimaris. As cold temperatures become a greater influence, perhaps this species focuses on the production of essential cold-survival mechanisms, such as antifreeze proteins (Gilbert et al., 2004) or membrane associated PUFA (Nichols et al., 1999a).

The maximum biomass of Ps. nivimaris was not affected by temperature, with nutrient concentration being the limiting factor in the growth of this species (Fig. 3.5). Prior to this study, the growth of Ps. nivimaris had been observed as low as $5^{\circ} \mathrm{C}$ (Heuchert et al., 2004). However, I have recorded strong growth of this species at 
$-1^{\circ} \mathrm{C}$ (Fig. 3.5A), extending the known lower threshold of Ps. nivimaris. Furthermore, cold temperature appears to induce diauxic growth trends in Ps. nivimaris (Fig. 3.5). This suggests that this species may be shifting metabolic processes (Narang and Pilyugin, 2007) as a cold-response.

Light-enhanced growth also occurred in Po. dokdonensis grown in 10\% media, but not in full strength media (Fig. 3.6). This result is similar to the findings of GómezConsarnau et al. (2007) who observed irradiated, low nutrient conditions resulted in an increase in the growth of Dokdonia sp. (MED134), a PR-bearing bacteria and close relative of Po. dokdonensis. González et al. (2008) also found Po. dokdonensis (MED152) fixed more bicarbonate in the light than the dark, however growth was not affected by irradiance. This disparity is likely the result of differences in culture conditions, however the origin of the Po. dokdonensis isolate (Northwestern Mediterranean Sea surface water) does differ between this study and that of González et al. (2008). The isolate used in this study may be a different strain than that used by González et al. (2008), potentially showing an adaptation of increased light use.

The lack of growth of Po. dokdonensis below $12^{\circ} \mathrm{C}$ is surprising, given that this is an Antarctic sea-ice isolate. However, as the optimal growth temperature of this species is $25-28^{\circ} \mathrm{C}$ (Yoon et al., 2006), it may enter a state of dormancy when exposed to cold temperatures. Although light did affect the growth of Po. dokdonensis, it is unclear how temperature affects the light-responses of this species. Furthermore, the lack of sampling from $\sim 25-75$ hours resulted in low resolution during the exponential growth phase of Po. dokdonensis. This is reflected when recorded lag times of 67.5 hours (regardless of treatment) are compared against Figure 3.6, where full strength media treatments clearly enter the exponential-phase earlier.

Using laboratory-based incubations, P. torquis did not show any response to light, regardless of treatment. Growth did not occur at $-1^{\circ} \mathrm{C}$, and only occurred in full strength media at $4^{\circ} \mathrm{C}$. Other studies show that under illuminated, high salinity conditions, the PR pumping of this species increases and growth is stimulated (Feng et al., 2013). Furthermore, Bowman et al. (1998) estimated the minimal growth temperature of $P$. torquis to be $-16^{\circ} \mathrm{C}$. This, along with the observed growth of $P$. torquis during this studies in situ incubation experiment, suggests that the cultures used during the laboratory-based incubation were impeded. It is possible that the stock culture used had decreased metabolic viability, due to its age (Kolter et al., 1993). 
In contrast, light responses were observed when P. torquis was incubated in situ, despite being exposed to an estimated minimum temperature of $-7^{\circ} \mathrm{C}$ (Ryan et al., 2009). Elevated growth was observed under blue- and 50\% light treatments, with lower levels occurring in red- and green-light treatments. No significant growth occurred in dark incubated samples. As wavelength attenuation through sea ice results in blue light being predominant (Buckley and Trodahl, 1987), the blue- and $50 \%$ light treatments likely resulted in near identical growth conditions. Due to a combination of sea-ice wavelength attenuation and the wavelength filtering of the red- and green-light treatments, these two treatments would have resulted in very low light levels. Therefore, the growth of $P$. torquis is correlated with light availability (at low intensities), suggesting that PR positively influences the growth of $P$. torquis when exposed to the physical stressors of Antarctic sea ice.

The growth of $P$. torquis in sea ice varied dramatically within samples grown under ambient light. This is likely a photo-induced growth-inhibitory effect, as Feng et al. (2013) has found the growth of this species is reduced in light greater than $27.7 \mu \mathrm{mol}$ photons $\mathrm{m}^{-2} \mathrm{~s}^{-1}$. Similarly, the 2012 in situ incubation experiment showed the least growth of mixed cultures of Antarctic sea-ice bacteria occurred under ambient-light treatments, across media treatments (Fig. 3.3). These results suggest that growth-inhibition is occurring in multiple species, under the light conditions up to $1 \mathrm{~m}$ deep in the ice column. Therefore, this study is consistent with Thomas and Dieckmann (2002), in that members of the SIMCO are typically adapted to low-light regimes. The vertical gradient of light through an ice column is likely a key driver of biological distribution, with high light reducing upper-ice biological abundances (Sullivan and Palmisano, 1981; Koh et al., 2010), and the lower light of bottom sea ice allowing some species, such as P. torquis to adopt a photoheterotrophic lifestyle.

Previous Antarctic research has utilised microcosms to investigate in situ responses, typically examining the influence of solar radiation on micro-algae incubations (Davidson et al., 1996; McMinn et al., 2014). This study however, developed and refined a novel method, whereby bacterial samples were incubated in situ in Antarctic sea ice, allowing cultures to be exposed to natural fluctuations in temperature and light, whilst using a defined media and without introducing foreign species. This is an ecologically relevant microbial culture technique that is not limited to Antarctic microbiology. Fields such as marine, aquatic or soil microbiology could easily adapt this technique to suit their specific requirements. 
There are several methodological differences between the 2012 and 2013 in situ incubations, with the most important being a change from incubation of treatment groups in a single ice corer hole (Sup. Fig. 3), to individual samples being incubated in single ice auger holes (Fig. 3.2). This changed this experiment from an 'unreplicated block design' (Ryan and Morgan, 2007) to each treatment being randomised and independent of one another. In addition, shifting from a mixed population of Antarctic sea-ice bacteria to monocultures of $P$. torquis, allowed the aims of this experiment to be addressed more accurately. Furthermore, when fitted with a linear regression, the slope of all negative controls used in both the 2012 and 2013 in situ incubations did not differ from zero. The elevated means of these negative controls are therefore an artefact, such as condensation or salt build-up on the sample vial. As treatments were compared against negative controls (rather than a $t_{0}$ measurement), the results of these incubations would not have been affected.

It is likely that more growth (and hence more pronounced results) would occur over a longer incubation period. As PR has the greatest influence at lower media concentrations (Gómez-Consarnau et al., 2007, 2010; Steindler et al., 2011), in situ growth in $10 \% \mathrm{MB}$ would be particularly interesting. However, long term incubations are particularly challenging given that gas exchange between the culture medium and the head space would eventually be exhausted (Kolter et al., 1993), potentially causing conditions to become anaerobic. Alternatively, the subsamples taken during these experiments may allow future studies to obtain higher resolution data through direct cell counts.

This study assessed the influence of light on the growth of PR-bearing, Antarctic sea-ice bacteria, finding the irradiance effect varied with physicochemical factors and among species. PR appears to enhance the growth of Ps. nivimaris and Po. dokdonensis, particularly under limited nutrients and organic matter. In contrast to my initial hypothesis, PR had no effect on the growth of Ps. nivimaris at colder temperatures, with light at reduced temperatures being detrimental during the exponential-phase. Finally, P. torquis demonstrated light-enhanced growth when incubated in situ. This effect was negated at higher light levels, due to a light-induced growth-inhibitory effect. These results suggest that PR is utilised within Antarctic sea-ice, but to varying efficiencies depending on species. The ability to adopt a photoheterotrophic lifestyle would certainly provide a selective advantage in the highly competitive, lower sections of the ice column. 


\section{CHAPTER 4}

\section{Overview and Conclusion}

\subsection{Outline of Research Findings}

Bacterial harvesting of solar energy through the use of PR is a relatively recent discovery (Béjà et al., 2000), with subsequent research offering mixed results regarding the benefits of PR (Table 1.1). Several studies show that this protein is most influential under conditions of environmental stress (Gómez-Consarnau et al., 2007, 2010; Steindler et al., 2011; Feng et al., 2013). The discovery of PR-bearing bacteria in Antarctic sea ice (Koh et al., 2010) suggests that this protein may be utilised to survive the stressors of this environment. To explore this hypothesis, I examined the influence of light on PR-bearing bacteria found in Antarctic sea ice. Three research questions were proposed in Chapter 1 . The following sections address these questions through a summary of the findings of this thesis.

\subsubsection{What cultivable bacteria are present in the previously collected sam- ples of Antarctic sea-ice bacteria?}

Using 16S rRNA gene sequencing, along with a comparison of phenotypical and environmental characteristics, four species were isolated from the Antarctic sea-ice bacteria samples collected by Cowie (2011). These isolates included the common Antarctic species Ps. nivimaris, Pa. marcusii and Po. dokdonensis, all members of the three most common Antarctic taxa (the Gamma- and Alpha-proteobacteria, and the Bacteroidetes, respectively). A strain of the Gram-positive Micrococcus was also isolated. This isolate grouped phenotypically and genetically ( $<3 \%$ sequence dissimilarity) with both $M$. luteus and $M$. antarcticus. As $M$. antarcticus is the only known coldadapted Micrococcus species (Liu et al., 2000), isolate 6 is likely to be this species. However, there is potential that this is a cold-adapted strain of M. luteus, or perhaps a new species. The isolates identified are similar to those found in Antarctic sea-ice surveys (Cowie, 2011), however it is peculiar that no P. torquis was cultured, given that these samples were originally identified as monocultures of this species.

\subsubsection{Do these isolated taxa contain the PR gene?}

The four isolated Antarctic sea-ice bacteria, as well as additional monocultures of $P$. torquis were examined for the presence of the PR gene. In accordance with 
previous studies (González et al., 2008; Feng et al., 2013), PR was identified in Po. dokdonensis and P. torquis. I also demonstrated, for the first time, the presence of the PR gene in Ps. nivimaris (Fig. 2.5). Identification of PR in these three cultivable Antarctic sea-ice bacteria allowed for physiological experiments to be conducted, examining the ecological influence of light.

\subsubsection{Is the growth of these PR-bearing bacteria affected by light under varying conditions of environmental stress?}

Samples were suspended in situ, within annual Antarctic sea ice, utilising the natural fluctuations of light and temperature that occur in this habitat. Based on the measurements of Ryan et al. (2009), these in situ incubations may have occurred at temperatures as cold as $-7^{\circ} \mathrm{C}$ and at an ambient irradiance $\sim 80 \mu \mathrm{mol}$ photons $\mathrm{m}^{-2}$ $\mathrm{s}^{-1}$. To my knowledge, this the first time this approach has been used to culture sea-ice bacteria. Due to a combination of wavelength attenuation through sea ice (Buckley and Trodahl, 1987), and the polycarbonate light filters reducing photon availability, light treatments fell into four broad categories; high irradiance (ambientlight), moderate irradiance (blue- and 50\% light), low irradiance (red- and greenlight) and complete darkness. In cultures of mixed Antarctic sea-ice bacteria, as well as monocultures of $P$. torquis, ambient sea-ice irradiance resulted in growthinhibition or high variation in biomass. The highest growth of in situ incubated $P$. torquis occurred under moderate-irradiance, with lower yields at low-irradiance and no growth in the dark. This result complements the work of Feng et al. (2013), who also found the growth of $P$. torquis increased under dim-illumination, with light intensities $>27.7 \mu \mathrm{mol}$ photons $\mathrm{m}^{-2} \mathrm{~s}^{-1}$ resulting in growth-inhibition. These results suggest that $P$. torquis utilises PR in the low light of bottom sea ice, providing this species with an alternate means of energy capture.

In contrast, no growth of $P$. torquis occurred during laboratory-based incubations at $-1^{\circ} \mathrm{C}$ in either media treatment, or when cultured at $4^{\circ} \mathrm{C}$ in $10 \%$ media. Growth did occur in both full strength $\mathrm{MB}$ and $10 \% \mathrm{MB}$ at $12^{\circ} \mathrm{C}$, as well as in full strength $\mathrm{MB}$ at $4^{\circ} \mathrm{C}$. However, lag-phases lasted more than 300 hours, and light had no influence on the growth of these cultures. This suggests that initial cultures of mixed Antarctic sea-ice bacteria (Chapter 2) may not have been incubated for long enough to reveal P. torquis.

Strong light responses were observed in laboratory-based cultures of Ps. nivimaris grown at $12^{\circ} \mathrm{C}$, with no light-induced differences occurring at either $4^{\circ} \mathrm{C}$ or 
$-1^{\circ} \mathrm{C}$. The most pronounced light-effect occurred in $10 \%$ media, with light inducing a secondary exponential growth phase in Ps. nivimaris cultures after $\sim 75$ hours. This resulted in almost twice the biomass in light-incubated, $10 \%$ media cultures, than the dark (Fig. 3.5B). Light also positively influenced the growth of Ps. nivimaris grown in full strength media, although to much less extent. Furthermore, cold temperatures induced trends of diauxic growth (regardless of media strength and irradiance), suggesting that reduced temperatures induce a metabolic switch in Ps. nivimaris.

During laboratory-based incubations, Po. dokdonensis only grew at $12^{\circ} \mathrm{C}$, however a similar trend to the light-induced growth of Ps. nivimaris was observed. Po. dokdonensis increased in growth in the light when incubated in $10 \%$ media, with no effect of light evident in full strength MB (Fig. 3.6). The MGT and maximum biomass values of Po. dokdonensis and Ps. nivimaris are consistent with those obtained during the preliminary incubation in Chapter 2. Thus, as both Ps. nivimaris and Po. dokdonensis demonstrated light-induced growth more prevalently in dilute media, PR is most influential under conditions of nutrient or carbon stress.

\subsection{The Overall Picture}

The sea-ice ecosystem is host to numerous microbial organisms, which support many other marine life forms in the Southern Ocean. Understanding microbial responses to physicochemical changes is critical, particularly in a highly variable and at risk ecosystem such as annual Antarctic sea ice (Petit et al., 1999; Vaughan et al., 2003; Thomas and Dieckmann, 2009). As brine channels form a near-closed environment, nutrient cycling becomes essential for sustaining life. Therefore, the role of heterotrophic bacteria, given their high metabolic activity (Martin et al., 2008; Koh et al., 2010), must play a particularly important role in sea-ice microbial loop dynamics. A photoheterotrophic lifestyle allows bacteria to acquire energy through solar radiation, as well as through the consumption of organic matter. Photoheterotrophy can theoretically be adopted by bacteria possessing a PR gene, however the limited number of cultivable bacteria has resulted in few examples of PR conferring an in vivo advantage (Table 1.1). My discovery of the PR gene in Ps. nivimaris provides an easily cultivated species, which can be used to further study the ecological impact of PR.

This thesis observed several examples of light-enhanced growth in PR-bearing, 
Antarctic sea-ice bacteria. The influence of this protein varied with species, as well as with different physicochemical factors. The most prominent trends occurred in cultures of Ps. nivimaris grown in $10 \%$ media, with light increasing growth when samples were incubated at optimum temperatures $\left(12^{\circ} \mathrm{C}\right)$. There are few documented examples of PR influencing growth as dramatically as this (Gómez-Consarnau et al., 2007; Feng et al., 2013). As no light-induced growth occurred at colder temperatures, Ps. nivimaris must increase PR activity specifically as a response to nutrient or carbon limitation, rather than as a general stress response. As environmental nutrient and carbon concentrations are typically lower than 10\% MB (Bowman et al., 1997), the effect of PR is potentially more pronounced in the natural environment.

The lack of light-response of Ps. nivimaris at lower temperatures, raises the question as to why a bacterium extracted from Antarctic sea-ice would possess a gene that cannot be used in this environment. Factors such as wavelength availability, light intensity and diurnal light fluctuations differ between laboratory-based incubations and in situ conditions. Perhaps these factors alter the activity of PR in Ps. nivimaris. For example, PR may influence the growth of Ps. nivimaris at cold temperatures only when this species is exposed to high salinity, blue-light or other conditions typical of sea-ice brine channels. This theory is similar to the findings of Feng et al. (2013), where PR only influenced P. torquis when exposed to a combination of dimlight and sub- or supra-optimal salinities. The cold-temperature diauxic growth of Ps. nivimaris (Fig. 3.5) suggests that reduced temperatures affect the metabolic processes of this species. This provides circumstantial evidence for an alternate theory, in that Ps. nivimaris may rely on heterotrophism whilst sympagic, and shift to a more pronounced phototrophic lifestyle when in temperate waters.

In accord with previous studies (Gómez-Consarnau et al., 2007, 2010; Steindler et al., 2011), Po. dokdonensis yielded a higher biomass when illuminated, but only when grown in low concentration media. This is similar to the results of Ps. nivimaris, suggesting that PR-bearing bacteria obtain energy from solar radiation when nutrients or organic matter are depleted. As Po. dokdonensis only grew at $12^{\circ} \mathrm{C}$, it is unclear how temperature affects the activity of PR in this species. The optimal growth of Po. dokdonensis is $25-28^{\circ} \mathrm{C}$ (Yoon et al., 2006), suggesting that this species may enter a state of dormancy in temperatures $<12^{\circ} \mathrm{C}$. However, the isolates of Yoon et al. (2006) were extracted from Korean seas, and their genetic divergence from the isolates used in my study ranges from 1.9-3.4\% (Table 2.6C). It is highly likely that these isolates represent different strains (or species), adapted to different ecological 
conditions. Perhaps the cold-temperature lag-phases of the Po. dokdonensis isolates used during this study, exceed the time of my incubations ( $>870$ hours). Therefore, no growth would be observed at low temperatures.

When incubated in situ, ambient sea-ice irradiance resulted in reduced growth of mixed cultures of Antarctic sea-ice bacteria and high variation in the growth of $P$. torquis. As growth-inhibition of $P$. torquis occurs at irradiances $>27.7 \mu \mathrm{mol}$ photons $\mathrm{m}^{-2} \mathrm{~s}^{-1}$ (Feng et al., 2013), a growth-inhibitory effect likely occurred during it situ incubations. However, it is interesting that the outcome was an increase in variation, rather than uniform growth-inhibition. This suggests that despite selecting a homogenously formed section of sea ice, the micro-habitat of each auger hole may have differed, exposing some treatments to harsher conditions than others.

Excluding ambient-light treatments, the in situ growth of $P$. torquis was positively correlated with irradiance. PR activation in this species is known to associated with an increase in salinity, and not nutrient deprivation (Feng et al., 2013). Therefore, P. torquis is likely adapted to use PR under the low light, relatively high salinity and plentiful nutrient conditions in the lower sections of sea ice. This correlates well with the vertical distribution survey conducted by Cowie (2011), in that $56.9 \%$ of DNA obtained from lower-ice sections was from the same order as P. torquis, (Flavobacteriales).

P. torquis grew during in situ incubations at estimated minimum temperature of $-7^{\circ} \mathrm{C}$. This is supported by minimum growth temperature estimates of this species equalling $-16^{\circ} \mathrm{C}$ (Bowman et al., 1998). In contrast, the laboratory-based incubations of this study found $P$. torquis grew at temperatures no colder than $4^{\circ} \mathrm{C}$ and had lag-phases in excess of 300 hours. Furthermore, no light responses occurred under any treatments. There is potential that the differences in culture conditions are responsible for the disparity between the results of laboratory-based incubations and those obtained during in situ incubations. However, this is unlikely due to the two incubations using the same media, multiple temperatures, and similar irradiances. These differences are more likely caused by the age of the stock culture used. As bacteria in their natural environment rarely enter the log-phase, extended periods at this growth stage may decrease metabolic activity (Kolter et al., 1993). Repetition of these laboratory-based incubations, using new P. torquis stock culture would likely produce similar results to those of the in situ incubation. 
This thesis provides evidence that PR is enhancing bacterial growth to a varying level, depending on species and a variety of physicochemical factors. Specifically, PR is used to enhance growth at low temperatures by P. torquis, but not Ps. nivimaris. This suggests that $P$. torquis has a selective advantage in the Antarctic sea-ice ecosystem. Therefore, it is likely that this species plays a critical role in Antarctic sea-ice microbial loop dynamics (see Martin et al., 2008).

\subsection{Future Research Directions}

This thesis investigated the influence of PR on heterotrophic bacteria found in Antarctic sea ice, and in doing so has provided a new and unique insight into the physicochemical factors that affect phototrophism. Throughout the course of this research a number of new questions have arisen, that may extend the findings of this study.

Taxonomic assignments of the isolates of Antarctic sea-ice bacteria could be refined further using information from additional biochemical tests (such as glucose oxidation and fermentation, or sole carbon source testing) or DNA-DNA hybridisation (Moore et al., 1987). Variation in culture conditions, along with the investigation of the un-cultivable diversity, may reveal a greater number of species in the samples of Antarctic sea-ice bacteria (Brinkmeyer et al., 2003).

Sequencing of the PR gene of each species is an important step to follow this study, potentially offering insight into the evolution and acquisition of PR. As this study discovered PR in Ps. nivimaris for the first time, PR gene sequencing in this species is of particular interest. Amino acid position 105 could be examined for the presence of glutamine (Man et al., 2003), verifying my melt curve profile-based assignment of Ps. nivimaris as a B-PR-bearing bacteria (Fig. 2.5). However, a more specific PR primer set is needed to obtain a clean sequence from PR amplification products (Baumforth et al., 1999).

Wavelength treatments were initially intended to be used in laboratory-based incubations in addition to in situ incubations. However, the long incubation times required to culture these Antarctic sea-ice bacteria, meant this work was beyond the scope and time available for this thesis. As in situ incubations under different wavelengths were confounded by the wavelength attenuation of sea ice (Buckley and Trodahl, 1987), future laboratory-based incubations could correlate the PR variant of 
each species with growth under specific wavelengths. Furthermore, the influence of PR on bacterial survival could be examined by extending incubations into the deathphase (Kolter et al., 1993) and using epifluorescence dyes such as the LIVE/DEAD ${ }^{\circledR}$ BacLight $^{\mathrm{TM}}$ Bacterial viability kit (Life Technologies, USA) or 5-cyano-2,3-ditolyl tetrazolium chloride, to assess the proportions of live and dead bacteria (Créach et al., 2003; Martin et al., 2008).

As subsamples from the laboratory-based incubation are stored in RNAlater ${ }^{\circledR}, \mathrm{PR}$ RNA expression could be correlated with the light-induced growth observed. The formalin-fixed subsamples acquired during in situ incubations can be used for direct cell counts, using flow cytometry or fluorescence microscopy (Martin et al., 2008). This could be used to assess the accuracy of absorbance measurements, and in the case of the 2012 mixed-species in situ incubation, changes in population dynamics could be examined. Theoretically, the PR-bearing species in these culture would become more prevalent with exposure to light.

There is potential to expand the in situ incubation method developed in this study, in that a 'natural culture medium' could be utilised by melting and $0.22 \mu \mathrm{m}$ filtering sea-ice. This would result in conditions even more similar to that of the natural sea-ice environment, hence incubations conducted using this method would be highly ecologically relevant. Longer in situ incubations would likely produce more growth, and hence more pronounced trends, however long-term incubations are complicated by factors such as the lack of gas exchange, producing anaerobic conditions. As $P$. torquis had an extremely long lag-phase and variable growth rates during laboratory-based incubations, a faster growing and more robust PR-bearing Antarctic sea-ice bacterium, such as Ps. nivimaris, would potentially be better suited to this in situ incubation method. Ryan et al. (2002) fixed large UVB filters to the surface of Antarctic sea ice and assessed changes in microalgae populations. Replacing the UVB filters with the polycarbonate light filters used in my in situ incubation provides an alternative method to long-term incubations. This would allow the influence of wavelength and irradiance to be tested in situ, on a large population of the SIMCO.

Finally, the annual fluctuations in Antarctic light availability raises several questions in regards to the nature of PR in this environment. The proportions of PRbearing bacteria may vary with season, or individuals may adopt a heterotrophybased lifestyle during periods of reduced light availability in the winter. This could 
potentially affect the expression and transcription of PR. However, moonlight may provide enough illumination to be utilised by PR-bearing bacteria in the upper sea ice. If this did occur, there would likely be a change in vertical species distribution of PR-bearing, Antarctic sea-ice bacteria. Furthermore, the high metabolic activity of sea-ice bacteria observed by Martin et al. (2008) and Koh et al. (2010) has only been observed in the summer. Therefore, there is potential that this metabolic activity is linked with the contributions of PR.

\subsection{Conclusion}

This thesis provides new insights into the presence and contribution of PR in Antarctic sea-ice bacteria. Quantifying the contribution of PR in vivo remains a challenge, particularly given the limited number of cultivable PR-bearing species. However, the discovery made in this study, of the PR-gene in Ps. nivimaris provides another model organism in which to explore the physiological effects of PR. The development of a novel, in situ incubation method offers a new tool that can be adapted for use across several fields of microbiology. This study found light enhanced the growth of several PR-bearing bacteria and in accord with other research, PR was most influential under oligotrophic or carbon limited conditions. Temperature had a varying influence on the effect of PR, suggesting the use of this protein in Antarctic sea ice is limited to specially adapted species. Given the light-induced growth observed in this study, along with the broad range of ecosystems and species bearing $\mathrm{PR}$, it is highly likely that PR provides a selective advantage, with species utilising this protein to different efficiencies. 


\section{Bibliography}

Ackley, S. F. and Sullivan, C. W. (1994), 'Physical controls on the development and characteristics of Antarctic sea ice biological communities - a review and synthesis', Deep-Sea Research I 41(10), 1583-1604.

Akram, N., Palovaara, J., Forsberg, J., Lindh, M. V., Milton, D. L., Luo, H., González, J. M. and Pinhassi, J. (2013), 'Regulation of proteorhodopsin gene expression by nutrient limitation in the marine bacterium Vibrio sp. AND4', Environmental Microbiology 15(5), 1400-1415.

Andreoli, C., Moro, I., La Rocca, N., Valle, L. D., Masiero, L., Rascio, N. and Vecchia, F. D. (2000), 'Ecological, physiological, and biomolecular surveys on microalgae from Ross Sea (Antarctica)', Italian Journal of Zoology 67(S1), 147-156.

Ansevin, A. T., Vizard, D. L., Brown, B. W. and McConathy, J. (1976), ‘High-resolution thermal denaturation of DNA. I. Theoretical and practical considerations for the resolution of thermal subtransitions', Biopolymers 15(1), 153-174.

Atamna-Ismaeel, N., Sabehi, G., Sharon, I., Witzel, K.-P., Labrenz, M., Jürgens, K., Barkay, T., Stomp, M., Huisman, J. and Béjà, O. (2008), 'Widespread distribution of proteorhodopsins in freshwater and brackish ecosystems', The ISME Journal 2(6), 656-662.

Azam, F., Fenchel, T., Field, J. G., Gray, J. S., Meyerreil, L. A. and Thingstad, F. (1983), 'The ecological role of water-column microbes in the sea', Marine Ecology-Progress Series 10(3), 257-263.

Azam, F. and Malfatti, F. (2007), 'Microbial structuring of marine ecosystems', Nature Reviews Microbiology 5(10), 782-791.

Azam, F., Smith, D. C. and Hollibaugh, J. T. (1991), 'The role of the microbial loop in Antarctic pelagic ecosystems', Polar Research 10(1), 239-244.

Balashov, S. P., Imasheva, E. S., Boichenko, V. A., Antón, J., Wang, J. M. and Lanyi, J. K. (2005), 'Xanthorhodopsin: a proton pump with a light-harvesting carotenoid antenna', Science 309(5743), 2061-2064.

Baldwin, J. M., Schertler, G. F. and Unger, V. M. (1997), 'An alpha-carbon template for the transmembrane helices in the rhodopsin family of G-protein-coupled receptors', Journal of Molecular Biology 272(1), 144-164. 
Baumforth, K., Nelson, P., Digby, J., O’Neil, J. and Murray, P. (1999), 'Demystified... the polymerase chain reaction.', Molecular Pathology 52(1), 1-10.

Béjà, O., Aravind, L., Koonin, E. V., Suzuki, M. T., Hadd, A., Nguyen, L. P., Jovanovich, S. B., Gates, C. M., Feldman, R. A., Spudich, J. L., Spudich, E. N. and DeLong, E. F. (2000), 'Bacterial rhodopsin: evidence for a new type of phototrophy in the sea', Science 289(5486), 1902-1906.

Béjà, O., Spudich, E. N., Spudich, J. L., Leclerc, M. and DeLong, E. F. (2001), 'Proteorhodopsin phototrophy in the ocean', Nature 411(6839), 786-9.

Bielawski, J. P., Dunn, K. A., Sabehi, G. and Béjà, O. (2004), 'Darwinian adaptation of proteorhodopsin to different light intensities in the marine environment', Proceedings of the National Academy of Sciences of the United States of America 101(41), 1482414829.

Bowman, J. P., McCammon, S. A., Brown, M. V., Nichols, D. S. and McMeekin, T. A. (1997), 'Diversity and association of psychrophilic bacteria in Antarctic sea ice', Applied and Environmental Microbiology 63(8), 3068-78.

Bowman, J. P., McCammon, S. A., Lewis, T., Skerratt, J. H., Brown, J. L., Nichols, D. S. and McMeekin, T. A. (1998), 'Psychroflexus torquis gen. nov., sp. nov. a psychrophilic species from Antarctic sea ice, and reclassification of Flavobacterium gondwanense (Dobson et al., 1993) as Psychroflexus gondwanense gen. nov., comb. nov', Microbiology 144(6), 1601-1609.

Brinkmeyer, R., Knittel, K., Jürgens, J., Weyland, H., Amann, R. and Helmke, E. (2003), 'Diversity and structure of bacterial communities in Arctic versus Antarctic pack ice', Applied and Environmental Microbiology 69(11), 6610-6619.

Brown, M. V. and Bowman, J. P. (2001), 'A molecular phylogenetic survey of sea-ice microbial communities (SIMCO)', FEMS Microbiology Ecology 35(3), 267-275.

Buckley, R. G. and Trodahl, H. J. (1987), 'Scattering and absorption of visible light by sea ice', Nature 326(6116), 867-869. 10.1038/326867a0.

Campbell, B. J., Waidner, L. A., Cottrell, M. T. and Kirchman, D. L. (2008), 'Abundant proteorhodopsin genes in the North Atlantic Ocean', Environmental Microbiology 10(1), 99-109.

Chase, E. and Harwood, V. J. (2011), 'Comparison of the effects of environmental parameters on growth rates of Vibrio vulnificus biotypes i, ii, and iii by culture and 
quantitative PCR analysis', Applied and Environmental Microbiology 77(12), 42004207.

Collins, S. (2012), 'Marine microbiology: evolution on acid', Nature Geoscience 5(5), 310-311.

Cottrell, M. T. and Kirchman, D. L. (2009), 'Photoheterotrophic microbes in the Arctic Ocean in summer and winter', Applied and Environmental Microbiology 75(15), 49584966.

Cowan, S. T. and Steel, K. J. (1965), 'Manual for the identification of medical bacteria', Manual for the Identification of Medical Bacteria .

Cowie, R. O. M. (2011), Bacterial community structure, function and diversity in Antarctic sea ice, PhD thesis, Victoria University of Wellington.

Créach, V., Baudoux, A.-C., Bertru, G. and Rouzic, B. L. (2003), 'Direct estimate of active bacteria: CTC use and limitations', Journal of Microbiological Methods 52(1), 1928.

Daly, K. L. (1990), 'Overwintering development, growth, and feeding of larval Euphausia superba in the Antarctic marginal ice zone', Limnology and Oceanography 35(7), 1564-1576.

Davidson, A., Marchant, H. and De la Mare, W. (1996), 'Natural UVB exposure changes the species composition of Antarctic phytoplankton in mixed culture', Aquatic Microbial Ecology 10(3), 299-305.

de la Torre, J. R., Christianson, L. M., Béjà, O., Suzuki, M. T., Karl, D. M., Heidelberg, J. and DeLong, E. F. (2003), ‘Proteorhodopsin genes are distributed among divergent marine bacterial taxa', Proceedings of the National Academy of Sciences of the United States of America 100(22), 12830-5.

Delille, D. (1992), 'Marine bacterioplankton at the Weddell Sea ice edge, distribution of psychrophilic and psychrotrophic populations', Polar Biology 12(2), 205-210.

Dioumaev, A. K., Brown, L. S., Shih, J., Spudich, E. N., Spudich, J. L. and Lanyi, J. K. (2002), 'Proton transfers in the photochemical reaction cycle of proteorhodopsin', Biochemistry 41(17), 5348-5358.

Donachie, S. P., Foster, J. S. and Brown, M. V. (2007), 'Culture clash: challenging the dogma of microbial diversity', The ISME Journal 1(2), 97. 
Feng, S., Powell, S. M., Wilson, R. and Bowman, J. P. (2013), 'Light-stimulated growth of proteorhodopsin-bearing sea-ice psychrophile Psychroflexus torquis is salinity dependent', The ISME Journal 7, 2206-2213.

Finkel, O. M., Béjà, O. and Belkin, S. (2013), 'Global abundance of microbial rhodopsins', The ISME Journal 7(2), 448-451.

Fong, N., Burgess, M., Barrow, K. and Glenn, D. (2001), 'Carotenoid accumulation in the psychrotrophic bacterium Arthrobacter agilis in response to thermal and salt stress', Applied Microbiology and Biotechnology 56(5-6), 750-756.

Fox, G. E., Wisotzkey, J. D. and Jurtshuk, P. J. (1992), 'How close is close: 16s rRNA sequence identity may not be sufficient to guarantee species identity', International Journal of Systematic Bacteriology 42(1), 166-170.

Friedrich, C. and Mitrenga, G. (1981), 'Oxidation of thiosulfate by Paracoccus denitrificans and other hydrogen bacteria', FEMS Microbiology Letters 10(2), 209-212.

Friedrich, T., Geibel, S., Kalmbach, R., Chizhov, I., Ataka, K., Heberle, J., Engelhard, M. and Bamberg, E. (2002), 'Proteorhodopsin is a light-driven proton pump with variable vectoriality', Journal of Molecular Biology 321(5), 821-838.

Frigaard, N.-U., Martinez, A., Mincer, T. J. and DeLong, E. F. (2006), 'Proteorhodopsin lateral gene transfer between marine planktonic Bacteria and Archaea', Nature 439(7078), 847-850.

Fuhrman, J. A., Schwalbach, M. S. and Stingl, U. (2008), 'Proteorhodopsins: an array of physiological roles?', Nature Reviews Microbiology 6(6), 488-494.

Garrison, D. L. (1991), 'Antarctic sea ice biota', American Zoologist 31(1), 17-33.

Garrison, D. L., Ackley, S. F. and Buck, K. R. (1983), 'A physical mechanism for establishing algal populations in frazil ice', Nature 306(5941), 363-365.

Garrison, D. L., Buck, K. R. and Fryxell, G. A. (1987), 'Algal assemblages in Antarctic pack ice and in ice-edge plankton', Journal of Phycology 23(4), 564-572.

Gilbert, J. A., Hill, P. J., Dodd, C. E. R. and Laybourn-Parry, J. (2004), ‘Demonstration of antifreeze protein activity in Antarctic lake bacteria', Microbiology 150(1), 171180.

Giovannoni, S. J., Bibbs, L., Cho, J.-C., Stapels, M. D., Desiderio, R., Vergin, K. L., Rappe, M. S., Laney, S., Wilhelm, L. J., Tripp, H. J., Mathur, E. J. and Barofsky, 
D. F. (2005), 'Proteorhodopsin in the ubiquitous marine bacterium SAR11', Nature 438(7064), 82-85.

Gómez-Consarnau, L., Akram, N., Lindell, K., Pedersen, A., Neutze, R., Milton, D. L., González, J. M. and Pinhassi, J. (2010), 'Proteorhodopsin phototrophy promotes survival of marine bacteria during starvation', PLoS Biology 8(4), e1000358.

Gómez-Consarnau, L., González, J. M., Coll-Lladó, M., Gourdon, P., Pascher, T., Neutze, R., Pedrós-Alió, C. and Pinhassi, J. (2007), 'Light stimulates growth of proteorhodopsin-containing marine Flavobacteria', Nature 445(7124), 210-213.

González, J. M., Fernández-Gómez, B., Fernández-Guerra, A., Gómez-Consarnau, L., Sánchez, O., Coll-Lladó, M., del Campo, J., Escudero, L., Rodríguez-Martínez, R., Alonso-Sáez, L., Latasa, M., Paulsen, I., Nedashkovskaya, O., Lekunberri, I., Pinhassi, J. and Pedrós-Alió, C. (2008), 'Genome analysis of the proteorhodopsincontaining marine bacterium Polaribacter sp. MED152 (Flavobacteria)', Proceedings of the National Academy of Sciences 105(25), 8724-8729.

González, J. M., Pinhassi, J., Fernández-Gómez, B., Coll-Lladó, M., GonzálezVelázquez, M., Puigbó, P., Jaenicke, S., Gómez-Consarnau, L., Fernàndez-Guerra, A., Goesmann, A. and Pedrós-Alió, C. (2011), 'Genomics of the proteorhodopsincontaining marine Flavobacterium Dokdonia sp. strain MED134', Applied and Environmental Microbiology 77(24), 8676-8686.

Grossi, S. M., Kottmeier, S. T. and Sullivan, C. W. (1984), 'Sea ice microbial communities. III. Seasonal abundance of microalgae and associated bacteria, McMurdo Sound, Antarctica', Microbial Ecology 10(3), 231-242.

Hanson, R., Shafer, D., Ryan, T., Pope, D. H. and Lowery, H. K. (1983), ‘Bacterioplankton in Antarctic ocean waters during late austral winter: abundance, frequency of dividing cells, and estimates of production', Applied and Environmental Microbiology 45(5), 1622-1632.

Harker, M., Hirschberg, J. and Oren, A. (1998), 'Paracoccus marcusii sp. nov., an orange Gram-negative coccus', International Journal of Systematic Bacteriology 48(2), 543548.

Harley, J. P. and Prescott, L. M. (1993), Laboratory exercises in microbiology, 2nd edition edn, Wm. C. Brown Publishers, USA. 
Heuchert, A., Glöckner, F. O., Amann, R. and Fischer, U. (2004), 'Psychrobacter nivimaris sp. nov., a heterotrophic bacterium attached to organic particles isolated from the South Atlantic (Antarctica)', Systematic and Applied Microbiology 27(4), 399-406.

Holt, J. G., Krieg, N. R., Sneath, P. H. A., Staley, J. T. and Williams, S. T. (1994), 'Bergey's manual of determinative bacteriology', Williams and Wilkins, Baltimore 787.

Horner, R. (1985), 'Ecology of sea ice microalgae', Sea Ice Biota. CRC Press, Boca Raton, Florida pp. 83-103.

Inoue, K., Ono, H., Abe-Yoshizumi, R., Yoshizawa, S., Ito, H., Kogure, K. and Kandori, H. (2013), 'A light-driven sodium ion pump in marine bacteria', Nature Communications 4, 1678.

Johnson, E. T., Baron, D. B., Naranjo, B., Bond, D. R., Schmidt-Dannert, C. and Gralnick, J. A. (2010), 'Enhancement of survival and electricity production in an engineered bacterium by light-driven proton pumping', Applied and Environmental Microbiology 76(13), 4123-4129.

Junge, K., Imhoff, F., Staley, T. and Deming, J. W. (2002), 'Phylogenetic diversity of numerically important Arctic sea-ice bacteria cultured at subzero temperature', Microbial Ecology 43(3), 315-328.

Kimura, H., Young, C. R., Martinez, A. and DeLong, E. F. (2011), 'Light-induced transcriptional responses associated with proteorhodopsin-enhanced growth in a marine flavobacterium', The ISME Journal 5(10), 1641-1651.

Kiorboe, T. and Jackson, G. A. (2001), 'Marine snow, organic solute plumes, and optimal chemosensory behavior of bacteria', Limnology and Oceanography 46(6), 1309_ 1318.

Kirchman, D. L. (2008), 'New light on an important microbe in the ocean', Proceedings of the National Academy of Sciences 105(25), 8487-8488.

Koch, A. L. (1968), 'Theory of the angular dependence of light scattered by bacteria and similar-sized biological objects', Journal of Theoretical Biology 18(1), 133-156.

Koh, E. Y., Atamna-Ismaeel, N., Martin, A., Cowie, R. O. M., Béjà, O., Davy, S. K., Maas, E. W. and Ryan, K. G. (2010), 'Proteorhodopsin-bearing bacteria in Antarctic sea ice', Applied and Environmental Microbiology 76(17), 5918-5925. 
Koh, E. Y., Martin, A. R., McMinn, A. and Ryan, K. G. (2012), 'Recent advances and future perspectives in microbial phototrophy in Antarctic sea ice', Biology 1(3), 542556.

Koh, E. Y., Phua, W. and Ryan, K. G. (2011), 'Aerobic anoxygenic phototrophic bacteria in Antarctic sea ice and seawater', Environmental Microbiology Reports 3(6), 710716.

Kolber, Z. S., Gerald, F., Lang, A. S., Beatty, J. T., Blankenship, R. E., VanDover, C. L., Vetriani, C., Koblizek, M., Rathgeber, C. and Falkowski, P. G. (2001), 'Contribution of aerobic photoheterotrophic bacteria to the carbon cycle in the ocean', Science 292(5526), 2492-2495.

Kolter, R., Siegele, D. A. and Tormo, A. (1993), 'The stationary phase of the bacterial life cycle', Annual Reviews in Microbiology 47(1), 855-874.

Kottmeier, S. and Sullivan, C. (1988), 'Sea ice microbial communities (SIMCO)', Polar Biology 8(4), 293-304.

Kottmeier, S. T. and Sullivan, C. W. (1987), 'Late winter primary production and bacterial production in sea ice and seawater west of the Antarctic Peninsula', Marine Ecology Progress Series 36, 287-298.

Krembs, C. E., Eicken, H., Junge, K. and Deming, J. (2002), 'High concentrations of exopolymeric substances in Arctic winter sea ice: implications for the polar ocean carbon cycle and cryoprotection of diatoms', Deep Sea Research Part I: Oceanographic Research Papers 49(12), 2163-2181.

Laguerre, G., Allard, M.-R., Revoy, F. and Amarger, N. (1994), 'Rapid identification of rhizobia by restriction fragment length polymorphism analysis of PCR-amplified 16S rRNA genes', Applied and Environmental Microbiology 60(1), 56-63.

Lami, R., Cottrell, M. T., Campbell, B. J. and Kirchman, D. L. (2009), 'Light-dependent growth and proteorhodopsin expression by Flavobacteria and SAR11 in experiments with Delaware coastal waters', Environmental Microbiology 11(12), 3201-3209.

Lane, D. (1991), '16s/23s rRNA sequencing', Nucleic Acid Techniques in Bacterial Systematics pp. 125-175.

Legendre, L., Ackley, S., Dieckmann, G., Gulliksen, B., Horner, R., Hoshiai, T., Melnikov, I., Reeburgh, W., Spindler, M. and Sullivan, C. (1992), 'Ecology of sea ice biota', Polar Biology 12(3-4), 429-444. 
Littlepage, J. L. (1965), 'Oceanographic investigations in McMurdo sound, Antarctica', Antarctic Research Series 5, 1-37.

Liu, H., Xu, Y., Ma, Y. and Zhou, P. (2000), 'Characterization of Micrococcus antarcticus sp. nov., a psychrophilic bacterium from Antarctica.', International Journal of Systematic and Evolutionary Microbiology 50(2), 715-9.

Lizotte, M. P. (2001), 'The contributions of sea ice algae to Antarctic marine primary production', American Zoologist 41(1), 57-73.

Longnecker, K., Sherr, B. F. and Sherr, E. (2005), 'Activity and phylogenetic diversity of bacterial cells with high and low nucleic acid content and electron transport system activity in an upwelling ecosystem', Applied and Environmental Microbiology 71(12), 7737-7749.

Ludwig, W., Strunk, O., Westram, R., Richter, L., Meier, H., Buchner, A., Lai, T., Steppi, S., Jobb, G. and Förster, W. (2004), 'ARB: a software environment for sequence data', Nucleic Acids Research 32(4), 1363-1371.

Man-Aharonovich, D., Sabehi, G., Sineshchekov, O. A., Spudich, E. N., Spudich, J. L. and Béjà, O. (2004), 'Characterization of RS29, a blue-green proteorhodopsin variant from the Red Sea', Photochemical and Photobiological Sciences 3(5), 459-462.

Man, D., Wang, W., Sabehi, G., Aravind, L., Post, A. F., Massana, R., Spudich, E. N., Spudich, J. L. and Béjà, O. (2003), 'Diversification and spectral tuning in marine proteorhodopsins', The EMBO Journal 22(8), 1725-1731.

Martin, A., Anderson, M. J., Thorn, C., Davy, S. K. and Ryan, K. G. (2011), 'Response of sea-ice microbial communities to environmental disturbance: an in situ transplant experiment in the Antarctic', Marine Ecology Progress Series 424, 25-37.

Martin, A., Hall, J. A., O'Toole, R., Davy, S. K. and Ryan, K. G. (2008), 'High single-cell metabolic activity in Antarctic sea ice bacteria', Aquatic Microbial Ecology 52(1), 25-31.

Martin, A., Hall, J. and Ryan, K. (2009), 'Low salinity and high-level UV-B radiation reduce single-cell activity in Antarctic sea ice bacteria', Applied and Environmental Microbiology 75(23), 7570-3.

Martinez, A., Bradley, A., Waldbauer, J., Summons, R. and DeLong, E. (2007), 'Proteorhodopsin photosystem gene expression enables photophosphorylation in a heterologous host', Proceedings of the National Academy of Sciences 104(13), 5590-5595. 
McMinn, A., Müller, M. N., Martin, A. and Ryan, K. G. (2014), 'The response of Antarctic sea ice algae to changes in $\mathrm{pH}$ and $\mathrm{CO}_{2}{ }^{\prime}$, PloS One 9(1), e86984.

McMinn, A., Pankowskii, A., Ashworth, C., Bhagooli, R., Ralph, P. and Ryan, K. (2010), 'In situ net primary productivity and photosynthesis of Antarctic sea ice algal, phytoplankton and benthic algal communities', Marine Biology 157(6), 13451356.

Mellefont, L. and Ross, T. (2003), 'The effect of abrupt shifts in temperature on the lag phase duration of Escherichia coli and Klebsiella oxytoca', International Journal of Food Microbiology 83(3), 295-305.

Moore, L., Moore, E., Murray, R., Stackebrandt, E. and Starr, M. (1987), 'Report of the ad hoc committee on reconciliation of approaches to bacterial systematics', International Journal of Systematic Bacteriology pp. 463-464.

Morita, R. Y. (1975), 'Psychrophilic bacteria', Bacteriological Reviews 39(2), 144.

Murray, A. E. and Grzymski, J. J. (2007), 'Diversity and genomics of Antarctic marine micro-organisms', Philosophical Transactions of the Royal Society B: Biological Sciences 362(1488), 2259-2271.

Nakamura, L. (1984), 'Bacillus psychrophilus sp. nov., nom. rev.', International Journal of Systematic Bacteriology 34(2), 121-123.

Narang, A. and Pilyugin, S. S. (2007), 'Bacterial gene regulation in diauxic and nondiauxic growth', Journal of Theoretical Biology 244(2), 326-348.

Nichols, D., Bowman, J., Sanderson, K., Nichols, C. M., Lewis, T., McMeekin, T. and Nichols, P. D. (1999a), 'Developments with Antarctic microorganisms: culture collections, bioactivity screening, taxonomy, PUFA production and cold-adapted enzymes', Current Opinion in Biotechnology 10(3), 240-246.

Nichols, D. S., Greenhill, A. R., Shadbolt, C. T., Ross, T. and McMeekin, T. A. (1999b), 'Physicochemical parameters for growth of the sea ice bacteria Glaciecola punicea ACAM 611T and Gelidibacter sp. strain IC158', Applied and Environmental Microbiology 65(8), 3757-3760.

Oesterhelt, D. and Stoeckenius, W. (1971), 'Rhodopsin-like protein from the purple membrane of Halobacterium halobium', Nature 233(39), 149-152. 
Olsen, G. J., Lane, D. J., Giovannoni, S. J., Pace, N. R. and Stahl, D. A. (1986), 'Microbial ecology and evolution: a ribosomal RNA approach', Annual Reviews in Microbiology 40(1), 337-365.

Pedrós-Alió, C. (2006), 'Marine microbial diversity: can it be determined?', Trends in Microbiology 14(6), 257-263.

Peplies, J., Kottmann, R., Ludwig, W. and Glöckner, F. O. (2008), 'A standard operating procedure for phylogenetic inference (SOPPI) using (rRNA) marker genes', Systematic and Applied Microbiology 31(4), 251-257.

Petit, J.-R., Jouzel, J., Raynaud, D., Barkov, N. I., Barnola, J.-M., Basile, I., Bender, M., Chappellaz, J., Davis, M., Delaygue, G. et al. (1999), 'Climate and atmospheric history of the past 420,000 years from the Vostok ice core, Antarctica', Nature 399(6735), 429-436.

Pontarp, M., Canback, B., Tunlid, A. and Lundberg, P. (2012), 'Phylogenetic analysis suggests that habitat filtering is structuring marine bacterial communities across the globe', Microbial Ecology 64(1), 8-17.

Powell, E. (1956), 'Growth rate and generation time of bacteria, with special reference to continuous culture', Journal of General Microbiology 15(3), 492-511.

Pruesse, E., Quast, C., Knittel, K., Fuchs, B. M., Ludwig, W., Peplies, J. and Glöckner, F. O. (2007), 'SILVA: a comprehensive online resource for quality checked and aligned ribosomal RNA sequence data compatible with ARB', Nucleic Acids Research 35(21), 7188-7196.

Qin, Q.-L., Xie, B.-B., Shu, Y.-L., Rong, J.-C., Zhao, D.-L., Zhang, X.-Y., Chen, X.L., Zhou, B.-C. and Zhang, Y.-Z. (2012), 'Genome sequence of proteorhodopsincontaining sea ice bacterium Glaciecola punicea ACAM 611T', Journal of bacteriology 194(12), 3267-3267.

Riedel, T., Gómez-Consarnau, L., Tomasch, J., Martin, M., Jarek, M., González, J. M., Spring, S., Rohlfs, M., Brinkhoff, T., Cypionka, H. et al. (2013), 'Genomics and physiology of a marine Flavobacterium encoding a proteorhodopsin and a xanthorhodopsin-like protein', PloS One 8(3), e57487.

Riedel, T., Tomasch, J., Buchholz, I., Jacobs, J., Kollenberg, M., Gerdts, G., Wichels, A., Brinkhoff, T., Cypionka, H. and Wagner-Döbler, I. (2010), 'Constitutive expression of the proteorhodopsin gene by a Flavobacterium strain representative of the 
proteorhodopsin-producing microbial community in the North Sea', Applied and Environmental Microbiology 76(10), 3187-3197.

Rothschild, L. J. and Mancinelli, R. L. (2001), 'Life in extreme environments', Nature 409(6823), 1092-101.

Rusch, D. B., Halpern, A. L., Sutton, G., Heidelberg, K. B., Williamson, S., Yooseph, S., Wu, D., Eisen, J. A., Hoffman, J. M., Remington, K. et al. (2007), 'The Sorcerer II global ocean sampling expedition: northwest Atlantic through eastern tropical Pacific', PLoS Biology 5(3), e77.

Ryan, K. G., Cowie, R. O., Liggins, E., McNaughtan, D., Martin, A. and Davy, S. K. (2009), 'The short-term effect of irradiance on the photosynthetic properties of Antarctic fast-ice microalgal communities', Journal of Phycology 45(6), 1290-1298.

Ryan, K. G., McMinn, A., Mitchell, K. A. and Trenerry, L. (2002), 'Mycosporinelike amino acids in Antarctic sea ice algae, and their response to UVB radiation', Zeitschrift fur Naturforschung C 57(5/6), 471-477.

Ryan, T. P. and Morgan, J. (2007), 'Modern experimental design', Journal of Statistical Theory and Practice 1(3-4), 501-506.

Sabehi, G., Kirkup, B. C., Rozenberg, M., Stambler, N., Polz, M. F. and Béjà, O. (2007), 'Adaptation and spectral tuning in divergent marine proteorhodopsins from the eastern Mediterranean and the Sargasso Seas', The ISME Journal 1(1), 48-55.

Sabehi, G., Loy, A., Jung, K.-H., Partha, R., Spudich, J. L., Isaacson, T., Hirschberg, J., Wagner, M. and Béjà, O. (2005), 'New insights into metabolic properties of marine bacteria encoding proteorhodopsins', PLoS Biology 3(8), e273.

Sabehi, G., Massana, R., Bielawski, J. P., Rosenberg, M., Delong, E. F. and Béjà, O. (2003), 'Novel proteorhodopsin variants from the Mediterranean and Red Seas', Environmental Microbiology 5(10), 842-849.

Sharma, A. K., Zhaxybayeva, O., Papke, R. T. and Doolittle, W. F. (2008), 'Actinorhodopsins: proteorhodopsin-like gene sequences found predominantly in nonmarine environments', Environmental Microbiology 10(4), 1039-1056.

Slamovits, C. H., Okamoto, N., Burri, L., James, E. R. and Keeling, P. J. (2011), 'A bacterial proteorhodopsin proton pump in marine eukaryotes', Nature Communications 2, 183. 
Stackebrandt, E. and Goebel, B. M. (1994), 'Taxonomic note: a place for DNA-DNA reassociation and 16S rRNA sequence analysis in the present species definition in bacteriology', International Journal of Systematic Bacteriology 44(4), 846-849.

Staley, J. T. and Gosink, J. J. (1999), ‘Poles apart: biodiversity and biogeography of sea ice bacteria', Annual Reviews in Microbiology 53, 189-215.

Steindler, L., Schwalbach, M. S., Smith, D. P., Chan, F. and Giovannoni, S. J. (2011), 'Energy starved candidatus Pelagibacter Ubique substitutes light-mediated ATP production for endogenous carbon respiration', PLoS One 6(5), e19725.

Stewart, F. J. and Fritsen, C. H. (2004), 'Bacteria-algae relationships in Antarctic sea ice', Antarctic Science 16(2), 143-156.

Sullivan, C. and Palmisano, A. (1981), 'Sea-ice microbial communities in McMurdo Sound.', Antarctic Journal of the United States 16(5), 126-127.

Sullivan, C. W. and Palmisano, A. C. (1984), 'Sea ice microbial communities: distribution, abundance, and diversity of ice bacteria in McMurdo Sound, Antarctica, in 1980', Applied and Environmental Microbiology 47(4), 788-795.

Thomas, D. N. and Dieckmann, G. S. (2002), 'Antarctic sea ice - a habitat for extremophiles', Science 295(5555), 641-644.

Thomas, D. N. and Dieckmann, G. S. (2009), Sea ice, 2nd edition edn, WileyBlackwell, USA.

Thomas, D. N., Kattner, G., Engbrodt, R., Giannelli, V., Kennedy, H., Haas, C. and Dieckmann, G. S. (2001), 'Dissolved organic matter in Antarctic sea ice', Annals of Glaciology 33(1), 297-303.

Trevors, J. T., Bej, A. K., Mojib, N., Elsas, J. D. and Overbeek, L. (2012), 'Bacterial gene expression at low temperatures', Extremophiles 16(2), 167-176.

Váró, G., Brown, L. S., Lakatos, M. and Lanyi, J. K. (2003), 'Characterization of the photochemical reaction cycle of proteorhodopsin', Biophysical Journal 84(2), 12021207.

Vaughan, D. G., Marshall, G. J., Connolley, W. M., Parkinson, C., Mulvaney, R., Hodgson, D. A., King, J. C., Pudsey, C. J. and Turner, J. (2003), 'Recent rapid regional climate warming on the Antarctic Peninsula', Climatic Change 60(3), 243274. 
Venter, J. C., Remington, K., Heidelberg, J. F., Halpern, A. L., Rusch, D., Eisen, J. A., Wu, D., Paulsen, I., Nelson, K. E. and Nelson, W. (2004), 'Environmental genome shotgun sequencing of the Sargasso Sea', Science 304(5667), 66-74.

Walter, J. M., Greenfield, D., Bustamante, C. and Liphardt, J. (2007), 'Light-powering Escherichia coli with proteorhodopsin', Proceedings of the National Academy of Sciences 104(7), 2408-2412.

Wang, G. P. and Bushman, F. D. (2006), 'A statistical method for comparing viral growth curves', Journal of Virological Methods 135(1), 118-123.

Wang, W. W., Sineshchekov, O. A., Spudich, E. N. and Spudich, J. L. (2003), 'Spectroscopic and photochemical characterization of a deep ocean proteorhodopsin', Journal of Biological Chemistry 278(36), 33985-91.

Wei, B. (2012), 'Diversity and distribution of proteorhodopsin-containing microorganisms in marine environments', Frontiers of Environmental Science $\mathcal{E}$ Engineering 6(1), 98-106.

Wieser, M., Denner, E. B., Kämpfer, P., Schumann, P., Tindall, B., Steiner, U., Vybiral, D., Lubitz, W., Maszenan, A. and Patel, B. (2002), 'Emended descriptions of the genus Micrococcus, Micrococcus luteus (Cohn, 1872) and Micrococcus lylae (Kloos et al. 1974).', International Journal of Systematic and Evolutionary Microbiology 52(2), 629637.

Wilson, K. (1987), 'Preparation of genomic DNA from bacteria', Current Protocols in Molecular Biology pp. 2-4.

Woese, C. R., Kandler, O. and Wheelis, M. L. (1990), 'Towards a natural system of organisms: proposal for the domains Archaea, Bacteria, and Eucarya.', Proceedings of the National Academy of Sciences 87(12), 4576-4579.

Yoon, J.-H., Kang, S.-J. and Oh, T.-K. (2006), 'Polaribacter dokdonensis sp. nov., isolated from seawater', International Journal of Systematic and Evolutionary Microbiology 56(6), 1251-1255.

Yoshizawa, S., Kawanabe, A., Ito, H., Kandori, H. and Kogure, K. (2012), 'Diversity and functional analysis of proteorhodopsin in marine Flavobacteria', Environmental Microbiology 14(5), 1240-1248.

Yoshizawa, S., Kumagai, Y., Kim, H., Ogura, Y., Hayashi, T., Iwasaki, W., DeLong, E. F. and Kogure, K. (2014), 'Functional characterization of Flavobacteria rhodopsins 
reveals a unique class of light-driven chloride pump in bacteria', Proceedings of the National Academy of Sciences 111(18), 6732-6737.

Yutin, N. and Koonin, E. V. (2012), 'Proteorhodopsin genes in giant viruses', Biology Direct 7(1), 1-6.

Zhao, M., Chen, F. and Jiao, N. (2009), 'Genetic diversity and abundance of Flavobacterial proteorhodopsin in China seas', Applied and Environmental Microbiology 75(2), 529-533.

Zwietering, M., Jongenburger, I., Rombouts, F. and Van't Riet, K. (1990), 'Modeling of the bacterial growth curve', Applied and Environmental Microbiology 56(6), 18751881. 


\section{Appendices}

\section{Appendix A: Media Recipes}

Unless stated otherwise, all reagents were purchased from Sigma-Aldrich (USA). All reagents were combined and heated until dissolved. Media were sterilised through heating to $121^{\circ} \mathrm{C}$ at 15 psi.

10\% Marine Broth 2216

Difco $^{\mathrm{TM}}$ Marine Broth $2216 \quad 3.75 \mathrm{~g}$

$\mathrm{ddH}_{2} \mathrm{O}$

$1 \mathrm{~L}$

Marine Broth 2216

Difco $^{\text {TM }}$ Marine Broth $2216 \quad 37.5 \mathrm{~g}$

$\mathrm{ddH}_{2} \mathrm{O} \quad 1 \mathrm{~L}$

Marine Broth 2216 glycerol mix

Difco $^{\mathrm{TM}}$ Marine Broth $2216 \quad 37.5 \mathrm{~g}$

Glycerol $200 \mathrm{~mL}$

$\mathrm{ddH}_{2} \mathrm{O} \quad 1 \mathrm{~L}$

Reasoner's 2A broth

Yeast extract (Oxoid, UK) $\quad 0.5 \mathrm{~g}$

Peptone (Oxoid, UK) $0.5 \mathrm{~g}$

Casein (Oxoid, UK) $\quad 0.5 \mathrm{~g}$

Glucose $\quad 0.5 \mathrm{~g}$

Starch $0.5 \mathrm{~g}$

Sodium pyruvate $\quad 0.3 \mathrm{~g}$

Distilled sea water $\quad 750 \mathrm{~mL}$

$\mathrm{ddH}_{2} \mathrm{O} \quad 250 \mathrm{~mL}$

Seawater Complete broth

Peptone (Oxoid, UK) $5 \mathrm{~g}$

Yeast extract (Oxoid, UK) $3 \mathrm{~g}$

Glycerol $3 \mathrm{~mL}$

Distilled sea water $\quad 750 \mathrm{~mL}$

$\mathrm{ddH}_{2} \mathrm{O} \quad 250 \mathrm{~mL}$ 
Modified Marine Broth 2216 stock solution

$\begin{array}{ll}\text { Magnesium chloride } & 5.9 \mathrm{~g} \\ \text { Sodium sulfate } & 3.24 \mathrm{~g} \\ \text { Calcium chloride } & 1.8 \mathrm{~g} \\ \text { Ferric citrate } & 0.1 \mathrm{~g} \\ \text { Potassium chloride } & 0.55 \mathrm{~g} \\ \text { Sodium bicarbonate } & 0.16 \mathrm{~g} \\ \text { Potassium bromide } & 0.08 \mathrm{~g} \\ \text { Strontium chloride } & 0.034 \mathrm{~g} \\ \text { Boric acid } & 0.022 \mathrm{~g} \\ \text { Disodium phosphate } & 0.008 \mathrm{~g} \\ \text { Sodium silicate } & 0.004 \mathrm{~g} \\ \text { Sodium fluoride } & 0.0024 \mathrm{~g} \\ \text { Ammonium nitrate } & 0.0016 \mathrm{~g} \\ \text { dd }{ }_{2} \mathrm{O} & 1 \mathrm{~L}\end{array}$

Modified Marine Broth 2216 treatments

$\begin{array}{lllll} & \mathbf{M}_{0} & \mathbf{M}_{1} & \mathbf{M}_{2} & \mathbf{M}_{3} \\ \text { Sodium chloride } & 19.45 \mathrm{~g} & 0 \mathrm{~g} & 99.84 \mathrm{~g} & 19.45 \mathrm{~g} \\ \text { Peptone (Oxoid, UK) } & 5 \mathrm{~g} & 5 \mathrm{~g} & 5 \mathrm{~g} & 0 \mathrm{~g} \\ \text { Yeast extract (Oxoid, UK) } & 1 \mathrm{~g} & 1 \mathrm{~g} & 1 \mathrm{~g} & 0 \mathrm{~g} \\ \text { Modified MB stock solution } & 1 \mathrm{~L} & 1 \mathrm{~L} & 1 \mathrm{~L} & 1 \mathrm{~L} \\ M_{0}: \text { MB control media } & & & & \\ M_{1}: \text { Reduced sodium chloride media } & & & & \\ M_{2}: \text { Increased sodium chloride media } & & & & \\ M_{3}: \text { Reduced carbon media } & & & \end{array}$




\section{Appendix B: Supplementary Data}

\section{Chapter 2}

Sup. Table 1: Colony morphology of bacterial samples originally labeled as P. torquis.

\begin{tabular}{c|cccccc}
\hline \hline Isolate & Colour & Texture & Form & Elevation & Margin & Size (mm) \\
\hline C1 & Off-white, pearl & Glossy & Circular & Convex & Entire & $1-2$ \\
C1* & Off-white, pearl & Glossy & Circular & Convex & Entire & $0.5-1$ \\
C4* & Bright orange & Glossy & Punctiform & Pulvinate & Entire & $\leq 0.5$ \\
C73 & Off-white, pearl & Glossy & Circular & Convex & Entire & $0.5-1$ \\
\hline
\end{tabular}

Sup. Table 2: Cellular morphology of bacterial samples originally labeled as $P$. torquis. Size is given in width $\times$ length of an individual cell.

\begin{tabular}{c|ccc}
\hline \hline Isolate & Gram stain & Cell type & Size $(\boldsymbol{\mu m})$ \\
\hline $\mathrm{C} 1$ & - & Coccus & $1 \times 1$ \\
$\mathrm{C}^{*}$ & - & Coccus & $1 \times 1$ \\
$\mathrm{C} 4^{*}$ & - & Curled filament & $2 \times$ varied \\
$\mathrm{C} 73$ & - & Coccus & $1 \times 1$ \\
\hline \multicolumn{2}{l}{$=$ negative } \\
$+=$ positive
\end{tabular}

Sup. Table 3: DNA concentrations following phenol-chloroform DNA extraction.

\begin{tabular}{ccc}
\hline \hline Species & Replicate & DNA (ng/ $\mathbf{L L})$ \\
\hline P. torquis & $\mathrm{a}$ & 13.448 \\
Ps. nivimaris & $\mathrm{b}$ & 4.431 \\
& $\mathrm{a}$ & 71.124 \\
Po. dokdonensis & $\mathrm{b}$ & 44.524 \\
& $\mathrm{a}$ & 15.149 \\
Pa. marcusii & $\mathrm{b}$ & 89.862 \\
& $\mathrm{a}$ & 0.360 \\
Micrococcus sp. & $\mathrm{b}$ & 5.340 \\
& $\mathrm{a}$ & 71.339 \\
& $\mathrm{~b}$ & 71.421
\end{tabular}




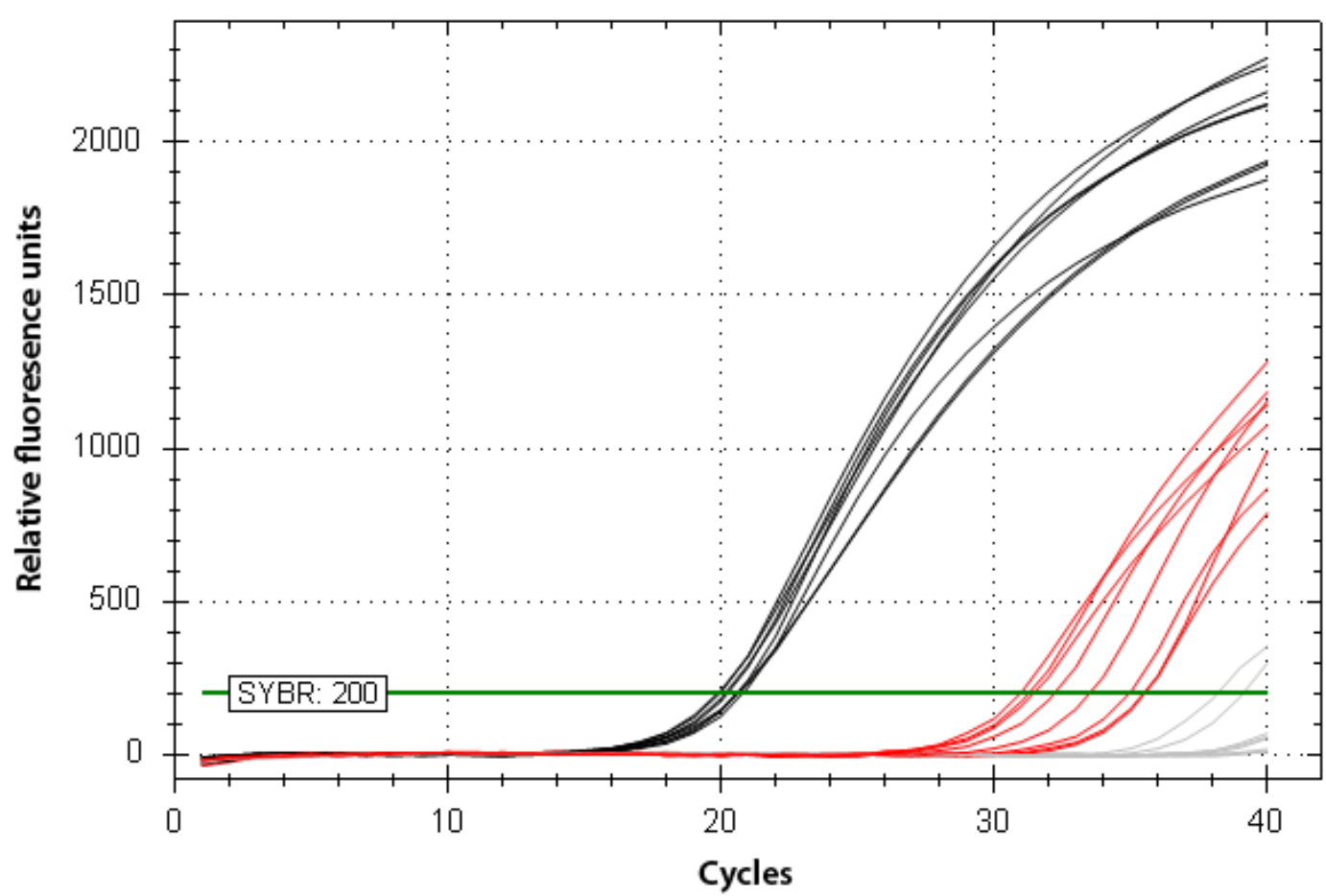

Sup. Figure 1: Annealing temperature qPCR PR gene amplification results. Sample 31A8 is shown in black, P. torquis in red, and negative controls in grey. All replicates are shown. SYBR autofluorescence threshold limit is set to 200 RFU.

Sup. Table 4: Annealing temperature qPCR PR gene amplification results. Data presented is the mean number of cycles before amplification occurred.

\begin{tabular}{c|ccc}
\hline \hline Temp $\left({ }^{\circ} \mathbf{C}\right)$ & 31A8 & P. torquis & Neg ctrl \\
\hline 53 & 20.77 & 35.5 & 39.1 \\
52.6 & 20.57 & 35.45 & 38.17 \\
51.7 & 20.22 & 34.95 & N/A \\
50.1 & 19.95 & 32.19 & N/A \\
48.1 & 19.86 & 30.95 & N/A \\
46.6 & 20.15 & 31.25 & N/A \\
45.5 & 20.63 & 31.42 & N/A \\
45 & 20.56 & 33.47 & N/A \\
\hline
\end{tabular}



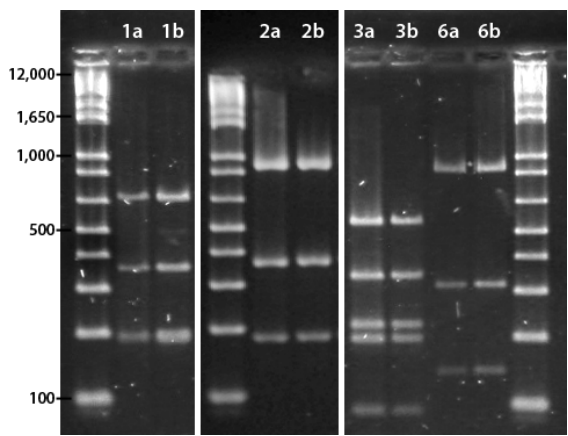

Sup. Figure 2: Unique RFLP profiles of the four phylotypes isolated from sample C34 (in duplicate). Bp positions of $1 \mathrm{~kb}$ Plus DNA Ladder are shown.

Sup. Table 5: qPCR PR gene amplification product melt curve profile data. Mean number of cycles is presented, with standard errors in parentheses.

\begin{tabular}{c|ccc}
\hline \hline Sample & Cycles & Temp. $\left({ }^{\circ} \mathrm{C}\right)$ & Peak Height (RFU) \\
\hline 31A8 & $21.07(0.111)$ & 80 & 597.21 \\
P. torquis & $34.16(0.079)$ & 79 & 376.81 \\
Ps. nivimaris & $31.37(0.119)$ & 83 & 370.01 \\
Po. dokdonensis & $29.38(0.546)$ & 78.5 & 606.78 \\
Pa. marcusii & $35.08(0.778)$ & 80.2 & 150.47 \\
Micrococcus sp. & $36.31(0.850)$ & 91 & 145.21 \\
\hline
\end{tabular}

Sup. Table 6: Statistical interactions of $y_{m}$ (top-right section) and $b$ (bottom-left section) from bacterial growth curves, as determined by a Bonferroni post-test. ns: $p>0.05,{ }^{*}: p<0.05,{ }^{* *}: p<0.01$, ***: $p<0.001$

\begin{tabular}{|c|c|c|c|c|c|c|c|c|c|}
\hline & \multicolumn{4}{|c|}{ MB } & \multicolumn{4}{|c|}{$10 \% \mathrm{MB}$} \\
\hline & & Ps. niv. & Po. dok. & Pa. mar. & Microc. & Ps. niv. & Po. dok. & Pa. mar. & Microc. \\
\hline \multirow{4}{*}{ MB } & Ps. niv. & & $* * *$ & $* * *$ & $* * *$ & $* * *$ & & & \\
\hline & Po. dok. & ns & & $* * *$ & $* * *$ & & $* * *$ & & \\
\hline & Pa. mar. & ns & ns & & $* * *$ & & & $* * *$ & \\
\hline & Microc. & ns & ns & ns & & & & & $* * *$ \\
\hline \multirow{4}{*}{$10 \% \mathrm{MB}$} & Ps. niv. & $* * *$ & & \multirow{4}{*}{ ns } & & & * & * & ns \\
\hline & Po. dok. & & ns & & & $* * *$ & & ns & ns \\
\hline & Pa. mar. & & & & & $* * *$ & ns & & ns \\
\hline & Microc. & & & & ns & $* * *$ & ns & ns & \\
\hline
\end{tabular}




\section{Chapter 3}

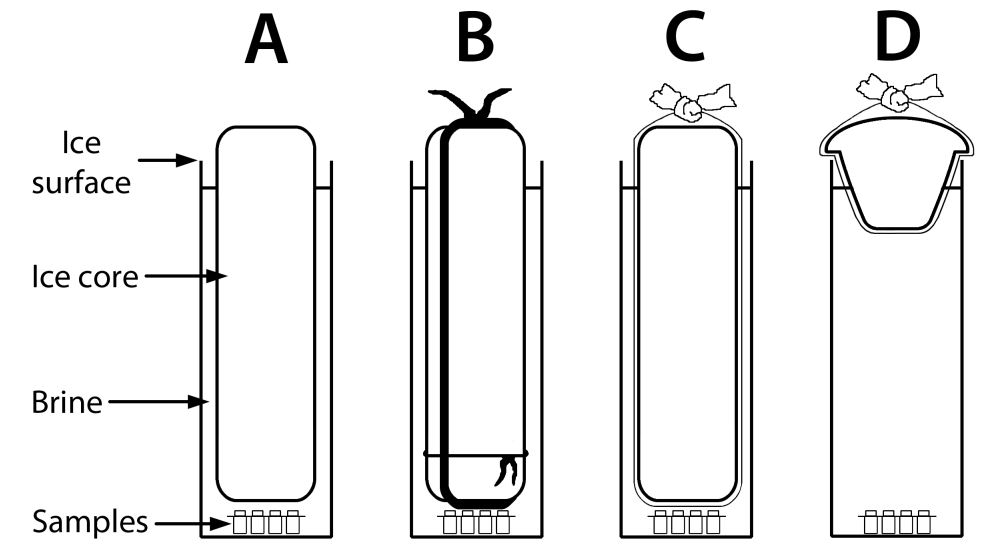

Sup. Figure 3: Experimental treatment of extracted and replaced ice cores used in the 2012 in situ incubation experiment. A: no treatment; B: bound with twine; C: wrapped with clear polyurethane; D: replaced with a 'bung' of clear polyurethane containing ice shavings.

Sup. Table 7: Daily weather measurements made at Cape Evans. Light was measured between 12pm and $1 \mathrm{pm}$. Cloud cover was estimated visually. Clear $<10 \%$, minimally overcast $=10-30 \%$, partially overcast $=31-60 \%$, and overcast $>60 \%$.

\begin{tabular}{c|ccc}
\hline \hline Date & Light $\left(\boldsymbol{\mu m o l}\right.$ photons $\left.\mathbf{~ m}^{-2} \mathbf{s}^{-1}\right)$ & Cloud cover & Snow cover $(\mathbf{c m})$ \\
\hline 19.11 .13 & 1523.0 & Clear & 0 \\
20.11 .13 & 1043.7 & Partially overcast & 0 \\
21.11 .13 & 1371.9 & Minimally overcast & 0 \\
22.11 .13 & 713.4 & Overcast & 0 \\
23.11 .13 & 1199.3 & Partially overcast & 0 \\
24.11 .13 & 642.7 & Overcast & 0 \\
25.11 .13 & 1108.4 & Partially overcast & 0 \\
26.11 .13 & NA & Clear & 0 \\
27.11 .13 & 915.2 & Partially overcast & 0 \\
28.11 .13 & 818.5 & Overcast & 0 \\
29.11 .13 & 1666.0 & Clear & $<5$ \\
30.11 .13 & 1304.9 & Minimally overcast & $<5$ \\
01.12 .13 & 1465.9 & Clear & 0 \\
02.12 .13 & 1182.6 & Partially overcast & 0 \\
03.12 .13 & 1151.5 & Partially overcast & 0 \\
\hline
\end{tabular}


Sup. Table 8: Statistical interactions of negative controls used in A. 2012 in situ incubation, B. 2013 in situ incubation, C. laboratory-based incubation experiments, as determined by a linear regression runs test.

\begin{tabular}{|c|c|c|c|c|c|c|}
\hline \multicolumn{2}{|c|}{ Treatment } & $M\left(a b s \mathrm{~cm}^{-1}\right)$ & $S E$ & df & $F$ & $p$ \\
\hline \multirow{4}{*}{$0.3 \mathrm{~m}$} & $\mathbf{M}_{0}$ & 0.019 & 0.002 & 1,6 & 3.709 & 0.102 \\
\hline & $\mathbf{M}_{1}$ & 0.020 & 0.003 & 1,6 & 0.021 & 0.889 \\
\hline & $\mathbf{M}_{2}$ & 0.019 & 0.003 & 1,6 & 0.582 & 0.475 \\
\hline & $\mathbf{M}_{3}$ & 0.018 & 0.004 & 1,6 & 1.629 & 0.249 \\
\hline \multirow{4}{*}{$0.7 \mathrm{~m}$} & $\mathbf{M}_{0}$ & 0.020 & 0.003 & 1,6 & 0.018 & 0.897 \\
\hline & $\mathbf{M}_{1}$ & 0.020 & 0.003 & 1,6 & 0.004 & 0.951 \\
\hline & $\mathbf{M}_{2}$ & 0.021 & 0.003 & 1,6 & 0.745 & 0.421 \\
\hline & $\mathbf{M}_{3}$ & 0.018 & 0.003 & 1,6 & 1.814 & 0.227 \\
\hline \multirow{4}{*}{$1 \mathrm{~m}$} & $\mathbf{M}_{0}$ & 0.018 & 0.003 & 1,6 & 0.044 & 0.841 \\
\hline & $\mathbf{M}_{1}$ & 0.020 & 0.003 & 1,6 & 0.848 & 0.393 \\
\hline & $\mathbf{M}_{2}$ & 0.018 & 0.003 & 1,4 & 0.096 & 0.772 \\
\hline & $\mathbf{M}_{3}$ & 0.020 & 0.003 & 1,5 & 3.187 & 0.134 \\
\hline
\end{tabular}

\begin{tabular}{|c|c|c|c|c|c|c|c|}
\hline & & MB & 0.010 & 0.004 & 1,9 & 4.288 & 0.068 \\
\hline & & $10 \% \mathrm{MB}$ & 0.015 & 0.007 & 1,9 & 0.621 & 0.451 \\
\hline \multicolumn{8}{|l|}{ C } \\
\hline \multirow{4}{*}{$12^{\circ} \mathrm{C}$} & \multirow{2}{*}{ Light } & MB & 0.001 & 0.001 & 1,26 & 1.119 & 0.300 \\
\hline & & $10 \% \mathrm{MB}$ & -0.002 & 0.001 & 1,26 & 0.390 & 0.538 \\
\hline & \multirow{2}{*}{ Dark } & MB & 0.001 & 0.001 & 1,26 & 2.797 & 0.107 \\
\hline & & $10 \% \mathrm{MB}$ & 0.002 & 0.001 & 1,26 & 0.728 & 0.401 \\
\hline \multirow{4}{*}{$4^{\circ} \mathrm{C}$} & \multirow{2}{*}{ Light } & MB & 0.000 & 0.001 & 1,50 & 3.198 & 0.080 \\
\hline & & $10 \% \mathrm{MB}$ & 0.002 & 0.001 & 1,50 & 0.309 & 0.581 \\
\hline & \multirow{2}{*}{ Dark } & MB & 0.001 & $<0.001$ & 1,50 & 0.619 & 0.435 \\
\hline & & $10 \% \mathrm{MB}$ & 0.003 & $<0.001$ & 1,50 & 0.369 & 0.546 \\
\hline \multirow{4}{*}{$-1^{\circ} \mathrm{C}$} & \multirow{2}{*}{ Light } & MB & -0.001 & 0.001 & 1,50 & 0.658 & 0.421 \\
\hline & & $10 \% \mathrm{MB}$ & 0.004 & 0.001 & 1,50 & 0.748 & 0.391 \\
\hline & \multirow{2}{*}{ Dark } & MB & 0.002 & 0.001 & 1,50 & 1.272 & 0.265 \\
\hline & & $10 \% \mathrm{MB}$ & 0.002 & 0.001 & 1,50 & 2.572 & 0.115 \\
\hline
\end{tabular}




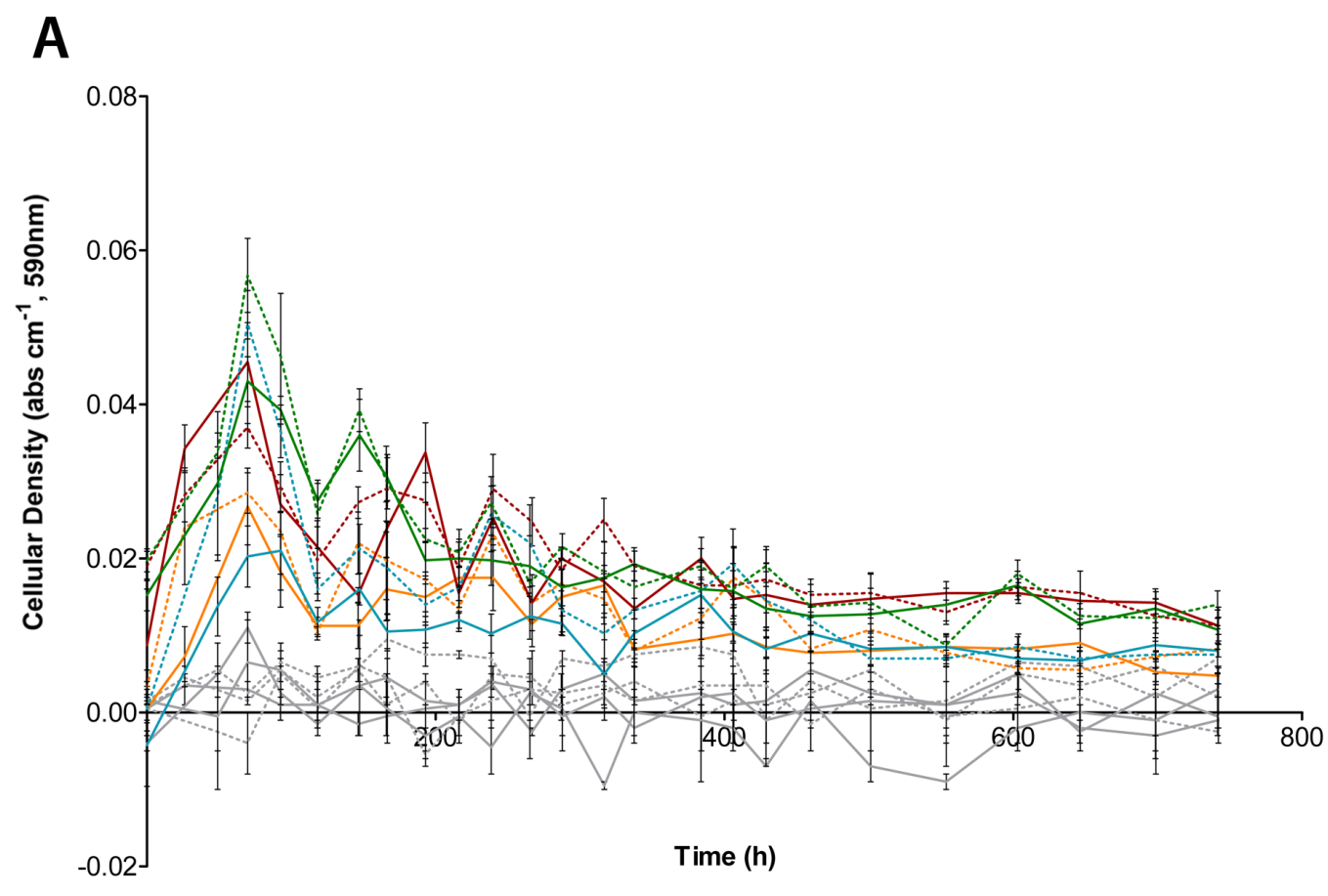

B

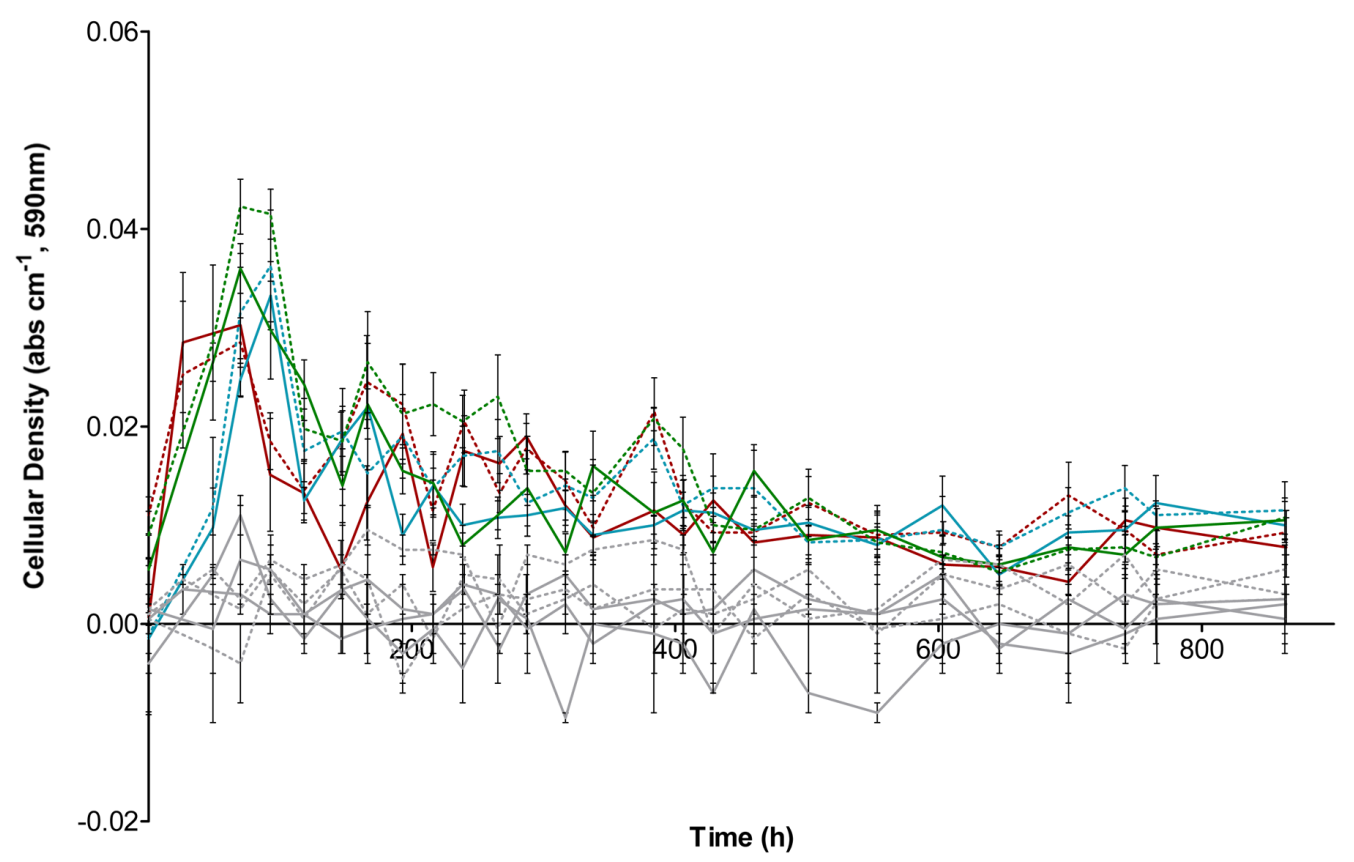

Sup. Figure 4: Mean absorbance measurements of A. Ps. nivimaris and B. P. torquis cultures lacking growth, incubated under varying light, media and temperature treatments. Solid line: light (5-20 $\mu \mathrm{mol}$ photons $\mathrm{m}^{-2} \mathrm{~s}^{-1}$ ); dashed line: complete darkness. Oranage: $4^{\circ} \mathrm{C}, \mathrm{MB}$; red: $4^{\circ} \mathrm{C}, 10 \% \mathrm{MB}$; blue: $-1^{\circ} \mathrm{C}, \mathrm{MB}$; green: $-1^{\circ} \mathrm{C}, 10 \% \mathrm{MB}$; grey: negative controls. Error bars represent standard errors. 
Sup. Table 9: Statistical interactions of treatments used in the laboratory-based incubation experiment, as determined by a one-way, factorial ANOVA.

\begin{tabular}{l|ccc}
\hline \hline & df & $\boldsymbol{F}$ & $\boldsymbol{p}$ \\
\hline Temperature & 2 & 168.139 & 0.000 \\
Species & 2 & 99.734 & 0.000 \\
Media & 1 & 38.909 & 0.000 \\
Light & 2 & 88.493 & 0.000 \\
Temperature ${ }^{*}$ Species & 1 & 1.493 & 0.226 \\
Temperature ${ }^{*}$ Media & 2 & 7.915 & 0.001 \\
Temperature ${ }^{*}$ Light & 2 & 3.637 & 0.032 \\
Species ${ }^{*}$ Media & 2 & 40.068 & 0.000 \\
Species ${ }^{*}$ Light & 2 & 0.809 & 0.449 \\
Media ${ }^{*}$ Light & 1 & 0.610 & 0.438 \\
Temperature ${ }^{*}$ Species ${ }^{*}$ Light & 1 & 7.238 & 0.009 \\
Temperature ${ }^{*}$ Media ${ }^{*}$ Light & 2 & 1.423 & 0.248 \\
Species ${ }^{*}$ Media ${ }^{*}$ Light & 2 & 2.265 & 0.111 \\
Error & 69 & & \\
\hline
\end{tabular}

